\title{
Cumulative HaRm and Resilient Liability Rules for Product Markets
}

\author{
by
}

Andrew F. Daughety and Jennifer F. Reinganum

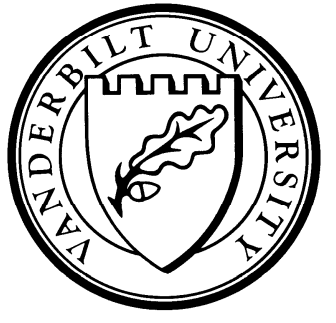

Working Paper No. 11-W25

December 2011

DEPARTMENT OF ECONOMICS AND LAW SCHOOL

VANDERBILT UNIVERSITY

NASHVILLE, TN 37235

www.vanderbilt.edu/econ 


\title{
Cumulative Harm and Resilient Liability Rules for Product Markets*
}

\author{
Andrew F. Daughety \\ Jennifer F. Reinganum \\ Department of Economics \\ and Law School \\ Vanderbilt University \\ andrew.f.daughety@vanderbilt.edu \\ jennifer.f.reinganum@vanderbilt.edu
}

September 2011

This version: December 2011

\begin{abstract}
* We thank seminar audiences at the Center for the Study of Democratic Institutions, Vanderbilt University, and at the Law and Economics/Applied Microeconomics Seminar Series, Vanderbilt University for helpful comments and suggestions on an earlier draft.
\end{abstract}




\title{
Cumulative Harm and Resilient Liability Rules for Product Markets
}

\author{
Andrew F. Daughety \\ Jennifer F. Reinganum
}

\begin{abstract}
In the traditional model of the law and economics of torts, harm accrues proportional to use. This has the remarkable implication for products-generated torts that product performance concerns (e.g., issues of care and of liability for harm) can be considered independently of market performance concerns (e.g., market structure and competition). Moreover, the classical analysis finds that all liability regimes (strict liability, no liability, and negligence based on the socially-efficient due care standard) yield the same choice of care by the firm in the unilateral care tort model.

We modify the standard model to allow for cumulative harm (that is, the per-unit expected harm is increasing in the level of use); examples from pharmaceuticals, environmental risks, privacy, food products, and mechanical systems are provided. We show that, when expected harm is cumulative, the separation between the level of care and the level of output does not occur. We further show that the different possible liability regimes now produce different outcomes and yield different implications for social efficiency.

This implies an interaction between law concerned with liability and law concerned with market performance. Since these generally governmental (and private law) responsibilities are divided among relevant agencies and institutions, and are the subjects of different bodies of law, this presents a challenge to the correct design of rules for agents in the economy. We argue for selection among alternative liability regimes based upon what we refer to as "resilience:" a resilient policy is robust to the incentives for agents to undermine it and flexible with respect to outside influences (e.g., from antitrust authorities or regulators). Strict liability is a resilient policy; no liability and negligence are not resilient. Thus, we provide a new argument for strict liability with respect to product-generated harms.
\end{abstract}

JEL Codes: K13, L13, L15

Keywords: Products liability, strict liability, negligence, cumulative harm, product quality 


\section{Introduction}

Large size necessitates specialization, and this is no less true for a government than for a corporation. Specialization, however, may breed either direct conflicts or coordination failure between one sub-unit and another, as each sub-unit pursues their appointed tasks. ${ }^{1}$ For example, antitrust goals can readily conflict with the goal of enhancing growth via granting intellectual property (IP) rights.

Antitrust is generally aimed at improving market performance, while IP rights bestow monopoly power on inventors (via patents) or creative artists (via copyright) in order to encourage innovation; especially since the recipients of IP rights may be corporations, market performance may be affected. ${ }^{2}$

One might expect this conflict to arise in all sorts of policy settings but, interestingly, the traditional unilateral-care model used in the economic analysis of products liability generally predicts otherwise. The general result is that market performance considerations (e.g., the conditions of supply, the degree of monopoly power, the level of prices for products, and the amount of output) do not interfere with product performance considerations (in particular, the provision of safety or care and liability for compensation). ${ }^{3}$ This is because, in the traditional model, firms choose precaution/care to minimize the sum of per-unit production costs and per-unit expected harm-related costs, and all of these are assumed to be independent of the level of output.

In the rest of this paper we will show that when we re-formulate the model of harm to account for cumulative effects, ${ }^{4}$ this basic result derived from the traditional model changes in a fundamental way:

1 The observation that decentralization may lead to lack of coordination and the presence of conflict, and the ways that this can be resolved in an efficient manner, are basic ones in economics, from the question of a decentralized economy to that of an organization with some centralized resources and separate sub-unit managers who make decisions. Our purpose in this paper is considerably more modest.

${ }^{2}$ For example, this conflict has emerged in cases involving "negative settlements," which negotiate IP rights between an original patent-holder (e.g., a drug manufacturer) and a potential entrant (such as a producer of a generic substitute for the original drug), possibly leading to delayed entry and high prices; for details and a discussion of an antitrust rule for settlement disputes, see Shapiro, 2003.

${ }^{3}$ We review the traditional unilateral-care model in Section 2 and discuss some models that depart from it and exhibit more complexity in the relationship between market performance and product performance objectives.

${ }^{4}$ Cumulative damage effects were introduced by Marino (1988); we discuss this paper further in Section 1.2. 
alternative liability regimes provide different outcomes, in terms of the choice of level of care, and those outcomes depend upon the structure of the market (the degree of pricing power by firms). That is, market performance and product performance are now inextricably linked.

The economist's classical response is to try to prescribe some modification of incentives (e.g., perhaps via taxes and/or subsidies) to coordinate market performance considerations and product performance considerations but, as we remarked above, this potentially flies in the face of the institutional realities of a complex governmental organization pursuing multiple social-efficiency objectives, usually via different fields of law. Market performance is the subject of antitrust law (or regulation) while product performance (at least in terms of safety) falls under tort law (as well as the purview of administrative agencies, such as the Consumer Products Safety Commission), and these areas of the law and of administrative control are subject to different statutory (and court-based precedent) influences, sometimes originating from different levels of the federal/state system. To assume that some overarching scheme could be successfully implemented and administered in such a setting strains credulity.

Instead we propose a more decentralized, process-oriented approach by examining alternative liability regimes ${ }^{5}$ as to their resilience with respect to outside (of liability) choices, in particular market-

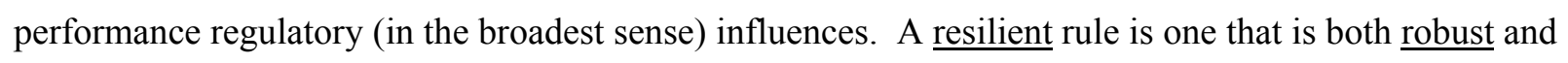
flexible; we find that strict liability is the only resilient liability rule. Strict liability is robust in that: 1) negligence is unstable: if subjected to negligence, firms will choose to violate the due care standard and pay compensation, thus assuming strict liability for harm; and 2) no liability is undermined when consumers lack observable safety information whereas strict liability is not. Strict liability is flexible in response to outside influences since equilibrium output-care choices by the firm move towards the overall socially-efficient outcome as market-performance-enhancing actions by other actors (regulators or

\footnotetext{
${ }^{5}$ There has been a continuing, and long-running, debate in law and economics (and more generally among legal scholars) over what liability regime is appropriate for dealing with harms from products. The most recent extensive discussion arguing for no liability for firms in the case of mass-marketed products is Polinsky and Shavell (2010).
} 
antitrust agencies) occur, while this is not true for either the regime of no liability or a negligence regime (presumably enforced with punitive damages, due to its instability noted above). In particular, no liability (in the presence of outside influences that work to improve market performance) leads to reduced overall social efficiency. Furthermore, under strict liability a court need not be concerned with market performance considerations; while strict liability alone does not achieve both optimal market and product performance, it achieves optimal product performance for any given market performance and it responds appropriately as market performance improves. In this sense resilience of regime provides us with a selection criterion which allows for the naturally occurring divided responsibilities of the government to be implemented so as to lead to greater product and market performance efficiency. Thus, another contribution of this paper is a new argument supporting the use of strict liability in the context of productrelated torts.

\subsection{Examples of Processes and Products that Give Rise to Cumulative Harm}

The Exelon Patch, produced by Novartis Pharmaceutical Corporation, is a daily treatment for mild to moderate Alzheimer's disease and memory problems associated with Parkinson's disease. ${ }^{6}$ As the name suggests, it is a patch applied to the skin, and is generally placed on the patient's upper or lower back or on the upper arm or chest. The website lists a number possible adverse effects. The full prescribing information circular indicates the following test results: ${ }^{7}$ a less-than doubling of the dosage was accompanied by an approximate tripling (in percentage terms) of test subjects reporting nausea, vomiting, anorexia/decreased appetite, weight decrease, and/or dizziness. In this example, more individuals in the test group were harmed at a greater than proportional rate as the dosage went up, which suggests an increasing likelihood of any individual being harmed as a function of the level of dosage. More precisely, the probability of harm was increasing in the level of usage, and that rate of increase was

\footnotetext{
${ }^{6}$ http://www.exelonpatch.com/home.jsp, accessed 7/23/2011.

7 See http://www.pharma.us.novartis.com/product/pi/pdf/exelonpatch.pdf, accessed 7/23/2011.
} 
itself greater than proportional to the usage rate in the range measured.

Similarly, some products or activities can result in realized harms that increase in the level of usage. One example of this is the use of radiation in medical procedures. Bogdanich (2010) reported on a series of incidents involving over-dosing from CT brain perfusion exams (used to examine for possible strokes), wherein individuals received significant overdoses (up to 13 times the generally accepted dose, depending upon the administering facility), resulting in hair loss, headaches, memory loss, and confusion and possibly leading to cancer and brain damage. ${ }^{8}$ The effects of overdoses are quite non-linear, with small overdoses resulting in nausea, fatigue, and vomiting, while larger overdoses can lead to internal bleeding, central nervous system damage, and death. Even without significant overdoses, repeated scans potentially contribute to cumulative dosage levels which are associated with harms greater than those associated with each exposure. ${ }^{9}$ For example, the practice of double-scanning chest patients $(80 \%$ of whom are medicare patients) has expanded (see Bogdanich and McGinty, 2011); the utility and safety of doing this has been questioned.

Notice that in both examples the level of expected harm is not proportional to the level of use; this is inconsistent with the traditional model. We will say that a process or product gives rise to

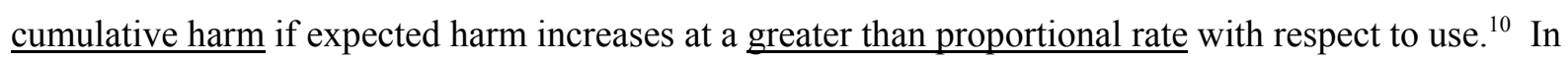
this paper we specifically focus on cumulative expected harm at the level of an individual, which can occur via the probability of harm or via the level of harm suffered, or through both avenues. Here are

${ }^{8}$ Blame appears to be attributed to both equipment malfunction (a software problem) as well as human error both in terms of operation and in terms of manufacturer's suggested machine settings. The FDA, in a followup, indicated that 385 patients across six facilities had been over-exposed during CT brain perfusion exams, and found problems with equipment and user information and training; see FDA Alerts and Notices (Medical Device) 11/9/2010, available at: http://www.fda.gov/MedicalDevices/Safety/AlertsandNotices/ucm185898.htm (accessed 7/25/2011).

9 Some organs recover from one-time irradiation while others (e.g., hearts, bladders, kidneys, and possibly brains - there is less information on the latter) are more sensitive and do not recover as readily; see Nieder, Milas, and Ang (2000).

10 This is not to say that the direct utility gain does not exceed the level of expected harm; in fact we will assume that the direct utility from the product does exceed the harm (at least at some level of safety investment by the firm). Overall expected utility reflects the direct utility of the product-in-use minus the expected harm. 
some further potential examples.

1) Analgesics: a) increases in the usage of acetaminophen can raise both the probability and extent of liver damage; b) increases in the usage of aspirin, aspirin-based products, and other over-the-counter non-steroidal anti-inflammatory drugs can raise both the probability and extent of internal bleeding (gastrointestinal and renal); and c) increases in the use of opiods (e.g., Percocet, Vicodin) can raise both the probability and extent of addiction, confusion, restlessness, nausea, seizures, and dosage-related respiratory depression.

2) Food safety: potential sources and types of food poisoning include: a) chicken with bacteria such as salmonella or campylobacter; b) fish with mercury; c) pork with listeria; d) peanut butter with aflatoxin or salmonella; and e) vegetables with shigella. The degree and likelihood of food poisoning (or worse) upon exposure to the above sources is often a function of the amount consumed. For example, the EPA recommends not having shark, swordfish, king mackerel, or tilefish more than twice per month (EPA publications recommend never eating these fish if pregnant) because of mercury contamination of the waters that are usually fished.

3) Environmental Safety: Bioaccumulation is the "biological sequestering of a substance at a higher concentration than that at which it occurs in the surrounding environment or medium."11 Environmental concerns focus around exposure to toxins, usually in the air or water. Mercury, PCBs, and some pesticides accumulate in tissues and can lead to devastating harm to the individual. Some other exposure examples with potentially cumulative effect include: a) radon in homes; b) smoke from tobacco products, either as the consumer or as a third party; and c) leadlaced products, such as paint in older homes, children's jewelry and toys, drinking water, imported food in cans, and cosmetics, among others. ${ }^{12}$

\footnotetext{
${ }^{11}$ See the United States Geological Survey, Toxic Substance Hydrology Program for a selection of definitions: http://toxics.usgs.gov/definitions/bioaccumulation.html accessed 7/23/2011.

${ }^{12}$ See http://www.health.state.ny.us/environmental/lead/sources.htm (Accessed 7/25/2011).
} 
4) Privacy vs. predictability: More frequent use of computers and "smart" phones appears to increase the likelihood of outside observers being able to track and predict a subject's behavior and location. Online, "cookies" can be used to acquire information on search and buying habits, thereby leading to individually-tailored price discrimination by sellers; frequent users of internet services are encouraged to more frequently change passwords and to delete cookies, as longer exposure online allows better tracking and more chances for "malware" to be surreptiouslyinstalled, allowing discovery of passwords for personal financial activities.

5) Mechanical failure: Mechanical devices with high-speed moving parts frequently deteriorate with use. When the bearings in a motor wear unevenly, bearing failure and uneven axial loading can result, leading to overheating and possible motor failure. If this happens in an air conditioning unit, the result is inconvenience; if this happens in a jet engine, the results can be catastrophic. In particular, the likelihood of failure of such mechanical systems depends upon the amount of use, as it is use that creates further deterioration of the bearings, making the overall effect more than proportional to use.

\subsection{Literature Review}

A number of previous articles have compared various liability rules in terms of their induced product performance. In the law and economics literature, expected harm has typically been modeled as being proportional to the use of the product. Shavell (1980) and Landes and Posner (1985) compare no liability, strict liability, and negligence in a model with well-informed and risk-neutral consumers. They find that these liability regimes are all equally-well-suited to achieving the socially-optimal level of care. ${ }^{13}$ Since cost is written as a per-unit term (that is independent of output) times the number of units produced, the resulting choice of level of care is independent of output level (this model will be reviewed

${ }^{13}$ Spence (1977), using a proportional harm model with unit demand, showed that strict liability achieved the socially-optimal level of care when consumers were fully-informed and risk-neutral, but he did not consider a regime of no liability or negligence since his focus was on relaxing the assumptions about consumers. 
briefly in Section 2). In the industrial organization literature, Spence (1975) and Sheshinski (1976) compared a monopolist's choice of product quality and output to the socially-optimal levels for demand functions that exhibit more complicated dependence on quality than is permitted by the proportional-harm model. Since they do not consider products liability, these papers can be interpreted as comparing the outcomes under a regime of no liability to the socially-optimal outcomes. They obtain some of the results to be established below, such as the fact that (for the functional forms we consider) quality is oversupplied for a given level of output, while output is under-supplied for a given level of quality. Both Spence and Sheshinski focus more on how one might engage in joint regulation of output and quality, rather than considering divided responsibilities wherein products liability law governs the choice of care while another agency (the antitrust division, or a regulator) assumes primary responsibility for output determination. Marino (1988) specifically compares monopoly outcomes under no liability and strict liability with the socially-optimal outcome, for quite general specifications of expected harm. In particular, he considers cases in which: (1) the marginal expected harm is increasing in consumption (this is the pattern we consider below); and (2) the marginal expected harm is decreasing in consumption (which he refers to as "tolerance"). Marino also obtains some of the results to be established below, such as that under strict liability(for any given level of output) the firm provides the socially-optimal level of care, and that (for any given level of care) output is lowest under no liability and highest under welfaremaximization, with output under strict liability in between. These rankings allow him to conclude (as we do) that the equilibrium levels of output and care under strict liability are lower than the socially-optimal levels. ${ }^{14}$ Spulber (1989) also considers a relatively general model of the expected harm as a function of care and output, and finds similar conclusions to Marino in terms of the outcomes under strict liability versus welfare-maximization. He refers the reader to Spence and Sheshinski for the case of no liability

\footnotetext{
${ }^{14}$ Marino (1988) goes on to consider safety regulation as a substitute or complement for liability. A similar question is addressed in Shavell $(1984 \mathrm{a}, \mathrm{b})$ in a proportional harm model. Both of these authors also consider various forms of consumer and/or regulator misperceptions.
} 
and, although he briefly mentions the negligence regime, he treats it as if the firm automatically complies with the due care standard (we will see below that this is not true for the case of cumulative harm).

As compared to this strand of the literature, we make more progress (using a specific functional form for expected harm) in evaluating welfare at the prevailing outcomes under no liability versus strict liability (we provide a plausible sufficient condition for welfare to be higher under strict liability than under no liability). We also model negligence more carefully and show that (when expected harm is cumulative) the firm always prefers strict liability so it would simply violate the due care standard and pay compensation as a (lower) cost of doing business. We extend the analysis to consider an arbitrary number of firms, which necessitates further consideration of how harm is generated. Two polar cases of harm-generation are considered; in the first model, the consumer chooses a "portfolio" of products that generate uncorrelated harms, while in the second model the consumer's expected harm depends on the aggregate consumption of all of the products. Finally, we discuss the desirability of using a resilient liability rule that is both robust and flexible, when the products liability system is largely focused on the level of care, while the level of output in the market is viewed as being primarily the responsibility of another decision-maker (e.g., the antitrust authorities or a regulatory agency).

There are three other papers that involve substantial interactions between market performance and product performance, although this interaction does not arise from cumulative harm (as it does in our model). Polinsky (1980) departs from the proportional harm model but incorporates a strong separability in the profit function between output and care. In particular, price-taking firms each have an average cost function that is U-shaped in output and independent of the level of care. Each firm also makes a lumpsum investment in care which reduces the expected harm created by the product, where the expected harm is independent of the level of output. Thus, the profit-maximizing output level is independent of the level of care and the level of care that minimizes the combined costs of care and expected liability (the efficient level of care) is independent of the level of output. For a fixed number of firms, strict liability and negligence (with the due-care standard equal to the efficient level of care) both achieve the social 
optimum; however, there is excessive entry under negligence because a firm that meets the due care standard faces no liability and thus has lower costs than under strict liability.

Polinsky and Rogerson (1983) compare strict liability, negligence, and no liability in a proportional harm model with imperfect competition. If consumers could observe the firms' level of care, then all three liability rules would achieve the socially-optimal level of care, independent of output; to the extent the firms have market power, their output will be socially insufficient. However, Polinsky and Rogerson assume that consumers under-estimate the expected harm associated with the product (and thus over-estimate their marginal willingness to pay for the product) under a negligence rule or under no liability, which tends to counteract the firms' tendency to reduce output when they have market power. Polinsky and Rogerson vary the extent of market power and consumer misperceptions to determine when each liability regime is best.

Daughety and Reinganum (2006) provide a model in which expected harm is proportional to output but the cost of care affects both the marginal production cost and a firm's fixed cost. That is, care involves an endogenous fixed cost such as safety-related R\&D. ${ }^{15}$ Multiple firms first choose safety levels and subsequently choose output levels. Because a firm's investment in care (endogenous fixed cost) depends on how much output it expects to produce, firms' equilibrium care levels decrease as the number of firms increases; this can lead to under-provision of care. However, when the products are sufficiently good substitutes, then firms can over-provide care as a consequence of "business-stealing" incentives. This effect works through demand shifting under a regime of no liability (since consumers shift demand to safer products), or through cost-reduction under a regime of strict liability (since more care reduces marginal expected liability costs, thus making the firm a stronger competitor in the market).

\footnotetext{
15 Examples of industries that produce products for which care entails both higher marginal production costs and endogenous safety-related fixed costs are pharmaceuticals, automobiles, and airframes, wherein there are substantial costs of design, development, and testing to verify and improve safety, even before any production for sale.
} 


\subsection{Plan of the Paper}

Section 2 provides the basic setup for analyzing the monopoly case. We use this to review the traditional model and its results, present the cumulative-harm formulation, and characterize welfareoptimal and equilibrium care and output levels under strict and no liability. Section 3 compares the alternative liability regimes (and incorporates negligence as well), in terms of social and firm preferences over the regimes. We use these results to develop the notion of a resilient liability rule as a basis for selecting among regimes. Section 4 extends the cumulative harm model to allow for multiple firms; this is done in two ways: 1) when harms are independent in the sense that different products produce different risks and the expected harm is the sum of these independent elements (e.g., various sources of alternative bacterial infections from food); and 2) when harms are interdependent (or joint) and increasing in the aggregate consumption of a specific product produced by multiple firms (e.g., mercury poisoning from consumption of fish). Section 5 provides a summary of our results for the cumulative harm model and the choice of liability regime, and conclusions. Appendix A provides details of the analysis in Sections 2 and 3 while Appendix B provides details of generalizations of the analysis in Sections 2 and 3; Appendix C provides supporting detail for Section 4.

\section{Model Setup and Results in the Monopoly Case}

We first describe the basic unilateral-care model for the case of a monopolist, since that will be our primary focus; later we will discuss how the model can be modified to incorporate multiple firms. The model will also assume a single representative consumer. The consumer allocates her income, denoted I, between two goods, the good of interest and a numeraire good to which she devotes the rest of her income. To simplify this discussion, we assume the utility for the good of interest is quadratic in the amount consumed (in Appendix B we consider a more general utility model); this formulation captures the idea that the consumer has diminishing marginal utility for the good of interest. Thus, the consumer's utility gross of any harm, denoted $u(q)$, can be written as $u(q)=\alpha q-(\beta / 2) q^{2}+I-p q$, where $\alpha$ and $\beta$ are 
positive constants, $\mathrm{q}$ is the number of units of the good purchased and consumed by this individual, $\mathrm{p}$ is the price per unit of the good, and I - pq is the value of the amount consumed of the numeraire good. The consumer's overall utility function may also involve expected costs of harm (e.g., when the firm is not liable), and these will be incorporated below when appropriate. Finally, when the consumer maximizes her utility, taking the price per unit as given, this results in an inverse demand curve that represents her marginal willingness to pay for the good.

The firm faces the consumer's inverse demand curve in the market for the good. The firm will have two choice variables: care, denoted x; and output, denoted q. The firm's choice of q implies a corresponding price via the consumer's demand function. ${ }^{16}$ Production costs are assumed to be proportional to output, but increasing and convex in care. That is, the cost of producing q units of output when care is $\mathrm{x}$ is given by $\mathrm{c}(\mathrm{x}) \mathrm{q}$, with $\mathrm{c}(\mathrm{x})$ increasing and convex in $\mathrm{x} .{ }^{17}$ The assumption of constant returns-to-scale in production (which is standard in much of the traditional literature) means that we can think of the firm as producing to order for a representative price-taking consumer.

\subsection{Results for the Proportional Harm Model}

The canonical model of expected harm used in most law and economics analyses of products liability assumes that expected harm is proportional to the quantity consumed (we will refer to this as the "proportional harm" model) and that care is unilateral in nature. That is, expected harm is given by h(x)q, where $\mathrm{h}(\mathrm{x})$ is a positive, decreasing and convex function of $\mathrm{x}$, so that care reduces expected harm, but

${ }^{16}$ In the case of a monopolist, it does not matter whether the firm chooses price or output, since the other variable is given by the consumer's demand curve. Thus, the firm picks q, which implies a maximum willingness-to-pay of $p$. At this price $p$ the representative consumer acquires $q$ units. In the case of multiple firms, it does matter whether the firms choose price or output levels; in Section 4 we consider multiple firms choosing output strategies with alternative constructions of cumulative harm.

${ }^{17}$ In Section 3 we briefly consider quadratic production costs $\mathrm{c}(\mathrm{x}) \mathrm{q}^{2}$. For the entire paper we assume that $\mathrm{c}(\mathrm{x})$ has the following technical properties: a) $c(x)>0$ for all $x ; 2) c^{\prime}(0)=0$ and $c^{\prime}(x)>0$ for all $x>0$; and 3$) c^{\prime \prime}(x)>0$ for all $\mathrm{x}$. Furthermore, for the material in the main text and in Appendices $\mathrm{A}$ and $\mathrm{C}$, in order to assure that there is an interior optimum for all optimization problems, we assume that there exists $\overline{\mathrm{x}}$ positive and finite such that $\mathrm{c}(\overline{\mathrm{x}})=\alpha$. In the sequel we will always consider $\mathrm{x}$ as occurring in the interval $[0, \overline{\mathrm{x}})$. 
further investments in care are less effective at reducing expected harm. ${ }^{18}$ This model has an appealing simplicity and yields correspondingly simple results but, we will argue, it is a very special functional form that results in overly-optimistic conclusions about the role of the products liability system in ensuring product safety.

The primary result obtained in the model using proportional harm is that all of the major liability regimes (no liability, strict liability, and negligence with a due care standard equal to the welfaremaximizing care level) result in the socially-optimal level of care. ${ }^{19}$ Moreover, this level of care is independent of how many units are produced. Thus, if the allocation of liability is the responsibility of the tort law, while other agencies (e.g., the Antitrust Division of the Department of Justice) are tasked with optimizing the performance of markets through influencing price and/or output, then tort law can go about its business of influencing product performance without reference to the behavior of agencies and/or agents focused on market performance. On the other hand, under monopoly, the socially-optimal or profit-maximizing output level will depend on the level of care, so there is still some linkage between the activities of tort law and those of other agencies.

To see how these results arise, we construct the following payoff functions: social welfare, denoted $\mathrm{W}(\mathrm{x}, \mathrm{q})$; the firm's profits under strict liability, denoted $\Pi^{\mathrm{SL}}(\mathrm{x}, \mathrm{q})$; the firm's profits under no liability, denoted $\Pi^{\mathrm{NL}}(\mathrm{x}, \mathrm{q})$; and the firm's profits under negligence, denoted $\Pi^{\mathrm{NEG}}(\mathrm{x}, \mathrm{q})$.

Social welfare is the sum of the payoffs of the consumer and the firm (suppressing the consumer's income):

$$
W(x, q)=\alpha q-(\beta / 2) q^{2}-h(x) q-c(x) q
$$

Under strict liability, the consumer need not worry about expected harm, so she simply chooses q to maximize $u(q)=\alpha q-(\beta / 2) q^{2}+I-p q$. This results in the inverse demand curve $p(q)=\alpha-\beta q$. Under strict

${ }^{18}$ Formally, assume that $\mathrm{h}(0)$ is positive and finite, $\mathrm{h}^{\prime}(\mathrm{x})<0$, and $\mathrm{h}^{\prime \prime}(\mathrm{x})>0$ for all $\mathrm{x}$.

19 Results to this effect for models of unilateral care can be found in early contributions such as Spence (1977), Shavell (1980), and Landes and Posner (1985). 
liability, the firm anticipates compensating the consumer in the amount of the expected harm, and thus the firm's profits under strict liability are given by:

$$
\Pi^{\mathrm{SL}}(\mathrm{x}, \mathrm{q})=(\alpha-\beta \mathrm{q}) \mathrm{q}-\mathrm{h}(\mathrm{x}) \mathrm{q}-\mathrm{c}(\mathrm{x}) \mathrm{q} .
$$

Under no liability, the consumer anticipates bearing the expected harm associated with her consumption of the good. Unless specifically stated otherwise, we assume that the consumer can observe the firm's level of care prior to purchase. Thus her overall utility is given by $U(q ; x)=\alpha q-(\beta / 2) q^{2}-h(x) q+I-$ pq. ${ }^{20}$ Choosing q to maximize this expression results in the inverse demand curve $\mathrm{p}(\mathrm{q} ; \mathrm{x})=\alpha-\beta \mathrm{q}-\mathrm{h}(\mathrm{x})$; that is, the consumer simply deducts the expected harm per unit from her marginal willingness to pay for the good. The firm's profits under no liability are given by:

$$
\Pi^{N L}(x, q)=(\alpha-\beta q-h(x)) q-c(x) q .
$$

That is, for all $(x, q), \Pi^{\mathrm{NL}}(x, q)=\Pi^{\mathrm{SL}}(\mathrm{x}, \mathrm{q})$.

Finally, the firm's profits under negligence are given by $\Pi^{\mathrm{SL}}(\mathrm{x}, \mathrm{q})$ if $\mathrm{x}<\mathrm{x}^{\mathrm{NEG}}$ and $\Pi^{\mathrm{NL}}(\mathrm{x}, \mathrm{q})$ if $\mathrm{x} \geq$ $\mathrm{x}^{\mathrm{NEG}}$, where $\mathrm{x}^{\mathrm{NEG}}$ is the due care standard. That is, the firm will be strictly liable if it takes less care than $\mathrm{x}^{\mathrm{NEG}}$ and it will bear no liability if its care meets or exceeds this level. The firm's profit function under negligence is exactly the same as under strict liability or no liability: if the firm does not bear the expected harm directly (because it complies with the due care standard), then it bears it indirectly as the consumer shifts it to the firm by deducting the expected harm per unit from her marginal willingness to pay.

Inspection of the welfare function and the two profit functions displayed above reveals that in all three cases the choice of care will minimize $h(x)+c(x)$; denote this level of care by $x^{*}$. If the due care standard in a negligence regime is set equal to $\mathrm{x}^{*}$, then the firm will exactly meet the due care standard, since $\mathrm{x}^{*}$ also minimizes the firm's expected costs under a negligence regime. Thus, tort law may allocate liability in whatever way it finds most convenient based on other considerations; in particular, it need not as given.

${ }^{20}$ The semicolon in $\mathrm{U}(\mathrm{q} ; \mathrm{x})$ is there to capture the fact that the consumer takes $\mathrm{x}$ (which is chosen by the firm) 
be concerned with how much output will be produced in the market. Given that we are modeling a monopoly, the firm will produce less output than would be welfare-maximizing. But tort law need not concern itself with how another government agency might adjust market performance through, for instance, price regulation or the use of subsidies.

Figure 1 below, which graphs the level of care, $x$, on the horizontal axis versus the level of output, q, on the vertical axis displays the basic results for the proportional-harm model. The vertical line labeled $x^{*}$ is the socially efficient level of care, and this occurs under any liability regime; moreover, it is independent of the output level. On the other hand, the socially-optimal and profit-maximizing output levels (as functions of the level of care and under strict liability and no liability) are illustrated by the curves labeled (respectively) $\mathrm{q}^{\mathrm{W}}(\mathrm{x}), \mathrm{q}^{\mathrm{SL}}(\mathrm{x})$, and $\mathrm{q}^{\mathrm{NL}}(\mathrm{x})$. It can be shown that $\mathrm{q}^{\mathrm{SL}}(\mathrm{x})=\mathrm{q}^{\mathrm{NL}}(\mathrm{x})=(1 / 2) \mathrm{q}^{\mathrm{W}}(\mathrm{x})$ for each possible value of $\mathrm{x}$. The dots in the picture, where the relevant curves cross the vertical line, indicate the socially efficient outcome (at $\mathrm{x}^{*}$ and $\left.\mathrm{q}^{*}\right)$ and the market equilibrium outcome (at $\mathrm{x}^{*}$ and $\mathrm{q}^{\mathrm{SL}}=$ $\left.\mathrm{q}^{\mathrm{NL}}\right)$.

Figure 1 about here

\subsection{Results for the Cumulative Harm Model}

We now modify the foregoing model to incorporate cumulative, rather than proportional, harm. In general we denote expected harm as $\mathrm{H}(\mathrm{x}, \mathrm{q})$; this is meant to reflect both the way that care and usage affect the likelihood of harm as well as the way they affect the level of harm. Cumulative harm means that $\mathrm{H}(\mathrm{x}, \mathrm{q})$ should be increasing and convex in both $\mathrm{x}$ and $\mathrm{q}$ (see Appendix B for technical details on the general form). For the purposes of the discussion and analysis presented in the main text, we will choose a specific functional form to use: $H(x, q)=h(x) q^{2}$, again assumed to be convex in $x$ and $q$. We use this specific form because it is the simplest and most tractable modification of the traditional formulation that incorporates cumulative harm. Cumulative harm will result in "entangled" choices of care and output; 
that is, for every level of output there will be a different best level of care, and for every level of care there will be a different best level of output. The welfare-maximizing, or profit-maximizing, choices of care and output will be those levels that satisfy both of these properties simultaneously.

Before proceeding to the detailed analysis, it is worth pre-viewing the results and providing some intuition. However, the intuition will be most clear if we take a moment to consider the consumer's behavior under a regime of no liability. The consumer chooses $q$ to maximize $U(q ; x)=\alpha q-(\beta / 2) q^{2}-$ $h(x) q^{2}+I-p q$, resulting in the inverse demand curve $p=\alpha-\beta q-2 h(x) q$. Notice that the consumer's marginal willingness to pay is reduced by the marginal expected harm, $2 \mathrm{~h}(\mathrm{x}) \mathrm{q}$. We will use this result repeatedly in explaining why the following results obtain.

The results described in this paragraph do not depend on the quadratic specification of cumulative expected harm; see Appendix B for an analysis using a more general functional form for expected harm. First, for any given level of care, welfare-maximizing output exceeds the firm's output under strict liability, which in turn exceeds the firm's output under no liability. One should expect that welfaremaximizing output would exceed profit-maximizing output, since a monopoly restricts output in order to charge a higher price. The difference between output under strict and no liability is due to the fact that under strict liability the firm expects to pay the average expected harm, h(x)q, per unit of output (resulting in a total expected liability cost of $\left.\mathrm{h}(\mathrm{x}) \mathrm{q}^{2}\right)$ while under no liability the consumer "charges" the firm the marginal expected harm, $2 h(x) q$, per unit (resulting in an amount $2 h(x) q^{2}$ in foregone profits). Since the marginal expected harm exceeds the average expected harm under this quadratic specification, it is "as if" the firm has higher marginal expected liability costs in the no liability regime and, consequently, it provides less output. Second, for any given level of output, welfare-maximizing care and the firm's choice of care under strict liability are the same, while the firm's choice of care under no liability is higher (because its perceived marginal benefit of harm-reducing care is higher). Third, comparing the equilibrium choices (which solve both equations that characterize the firm's profit maximization simultaneously), we find that welfare-maximizing output and care are higher than the firm's profit- 
maximizing output and care under strict liability. Fourth, the firm always prefers a regime of strict liability to one of no liability (again, because it is "as if" the firm has higher expected liability costs, for any $\mathrm{x}$ and $\mathrm{q}$, under no liability). Finally, consider a negligence regime with a due care standard equal to the socially-optimal level of care (recall that this level exceeds the chosen level of care under strict liability). If the firm complies with the due care standard, then it receives its maximized profits under no liability. On the other hand, if it violates the due care standard (by choosing less care), then it will obtain its maximized profits under strict liability. As indicated above, a result that holds quite generally is that the firm prefers its maximized profits under strict liability to those under no liability. Thus, the negligence regime is "unstable" in the sense that it does not induce the firm to comply with the due care standard; rather, a negligence regime devolves into strict liability.

The following results hold for our quadratic (and convex) specification of expected harm, but need not hold for more general expected harm functions (again, see Appendix B for detailed discussion and analysis). Employing our quadratic specification of expected harm, we find that the firm's choice of care under no liability is equal to the welfare-maximizing level, ${ }^{21}$ and therefore the firm exerts more care under no liability than under strict liability. The joint convexity of expected harm is sufficient to imply that the firm's output level under strict liability exceeds that under no liability, which suggests a potential welfare tradeoff: strict liability provides more output of lower safety as compared to no liability. In fact, we find that welfare is higher under strict liability than under no liability.

\subsubsection{Care and Output under Welfare-Maximization}

We begin the formal analysis by considering the social planner's problem; the details of the analysis are given in Appendix A. Welfare (again, suppressing the consumer's income) is given by: ${ }^{22}$

${ }^{21}$ The fact that the care level under no liability equals the welfare-maximizing care level is an artifact of the quadratic form of expected harm, and it will not hold true in general. However, we retain the quadratic form for expected harm since this facilitates solving the model due to there only being linear and quadratic terms in the model.

22 To economize on notation, we re-use the function names $\mathrm{W}, \Pi^{\mathrm{SL}}, \Pi^{\mathrm{NL}}$ and $\Pi^{\mathrm{NEG}}$ to describe the same expressions, modulo inserting cumulative harm $\mathrm{h}(\mathrm{x}) \mathrm{q}^{2}$ in place of proportional harm $\mathrm{h}(\mathrm{x}) \mathrm{q}$. 


$$
W(x, q)=\alpha q-(\beta / 2) q^{2}-h(x) q^{2}-c(x) q .
$$

The first-order conditions are (where the subscript indicates the relevant partial derivative):

$$
\begin{aligned}
& \mathrm{W}_{\mathrm{x}}=-\mathrm{h}^{\prime}(\mathrm{x}) \mathrm{q}^{2}-\mathrm{c}^{\prime}(\mathrm{x}) \mathrm{q}=0 ; \\
& \mathrm{W}_{\mathrm{q}}=\alpha-\beta \mathrm{q}-2 \mathrm{~h}(\mathrm{x}) \mathrm{q}-\mathrm{c}(\mathrm{x})=0 .
\end{aligned}
$$

Simultaneous solution of equations (1) and (2) yields the socially-optimal combination of care and output, denoted $\hat{\mathrm{x}}^{\mathrm{W}}$ and $\hat{\mathrm{q}}^{\mathrm{W}}$, respectively. However, it is useful to consider each first-order condition separately. While equation (1) cannot be solved explicitly for the socially-optimal care level as a function of any given level of output, denoted $\mathrm{x}^{\mathrm{W}}(\mathrm{q})$, this function is defined implicitly by equation (1). We can use second-order conditions to prove that $\mathrm{x}^{\mathrm{W}}(\mathrm{q})$ is a strictly increasing function. Equation (2) can be solved for the socially-optimal output level for any given level of care, denoted $\mathrm{q}^{\mathrm{W}}(\mathrm{x})$, with the result that $\mathrm{q}^{\mathrm{W}}(\mathrm{x})$ $=(\alpha-\mathrm{c}(\mathrm{x})) /(\beta+2 \mathrm{~h}(\mathrm{x}))$. Although this function is not increasing everywhere, we can use second-order conditions to prove that it must be strictly increasing in the neighborhood of $\left(\hat{\mathrm{x}}^{\mathrm{W}}, \hat{\mathrm{q}}^{\mathrm{W}}\right)$ and that, when graphed in $(\mathrm{x}, \mathrm{q})$ space, the function that represents $\mathrm{x}^{\mathrm{W}}(\mathrm{q})$ crosses the function $\mathrm{q}^{\mathrm{W}}(\mathrm{x})$ "from below." That is, the curves are (roughly) as depicted below in Figure $2 .{ }^{23}$

\subsubsection{Care and Output under Strict Liability}

Under strict liability, the consumer expects to be fully-compensated for any harm she incurs.

Consequently, she simply chooses her consumption $q$ to maximize $u(q)=\alpha q-(\beta / 2) q^{2}+I-p q$, resulting in the inverse demand curve $\mathrm{p}(\mathrm{q})=\alpha-\beta \mathrm{q}$. The firm's profit function reflects the expected harm; it is given by:

$$
\Pi^{\mathrm{SL}}(\mathrm{x}, \mathrm{q})=(\alpha-\beta \mathrm{q}) \mathrm{q}-\mathrm{h}(\mathrm{x}) \mathrm{q}^{2}-\mathrm{c}(\mathrm{x}) \mathrm{q} .
$$

As in the case of welfare-maximization, the details of the analysis are given in Appendix A. The first-

\footnotetext{
${ }^{23}$ As indicated above, the function $\mathrm{q}^{\mathrm{W}}(\mathrm{x})$ is not increasing everywhere. In addition, we cannot tell whether the curves $\mathrm{q}^{\mathrm{W}}(\mathrm{x})$ and $\mathrm{x}^{\mathrm{W}}(\mathrm{q})$ are convex or concave and this does not matter to the results claimed; to make it easier to tell them apart, we have drawn the $\mathrm{q}^{\mathrm{W}}(\mathrm{x})$ function as concave and the $\mathrm{x}^{\mathrm{W}}(\mathrm{q})$ function as convex. We will follow the same conventions with functions resulting from profit maximization.
} 
order conditions are:

$$
\begin{aligned}
& \Pi_{\mathrm{x}}^{\mathrm{SL}}=-\mathrm{h}^{\prime}(\mathrm{x}) \mathrm{q}^{2}-\mathrm{c}^{\prime}(\mathrm{x}) \mathrm{q}=0 \\
& \Pi_{\mathrm{q}}^{\mathrm{SL}}=\alpha-2 \beta \mathrm{q}-2 \mathrm{~h}(\mathrm{x}) \mathrm{q}-\mathrm{c}(\mathrm{x})=0 .
\end{aligned}
$$

Simultaneous solution of equations (3) and (4) yield the firm's choice of care and output under strict liability, denoted $\hat{\mathrm{x}}^{\mathrm{SL}}$ and $\hat{\mathrm{q}}^{\mathrm{SL}}$, respectively. However, again it is useful to consider each first-order condition separately. Equation (3) defines implicitly the firm's profit-maximizing care level for any given level of output, denoted $\mathrm{x}^{\mathrm{SL}}(\mathrm{q})$. Note that equations (1) and (3) are the same, so the firm provides the socially-optimal level of care for any given output level $\mathrm{q}$ : that is, $\mathrm{x}^{\mathrm{SL}}(\mathrm{q})=\mathrm{x}^{\mathrm{W}}(\mathrm{q})$ for all $\mathrm{q}$. Equation (4) can be solved for the firm's profit-maximizing output level under strict liability for any given level of care, denoted $\mathrm{q}^{\mathrm{SL}}(\mathrm{x})$, with the result that $\mathrm{q}^{\mathrm{SL}}(\mathrm{x})=(\alpha-\mathrm{c}(\mathrm{x})) / 2(\beta+\mathrm{h}(\mathrm{x}))$. Comparison of equations (2) and (4) implies that, for any given care level $\mathrm{x}$, the firm provides less than the socially-optimal output level (that is, $\mathrm{q}^{\mathrm{SL}}(\mathrm{x})<\mathrm{q}^{\mathrm{W}}(\mathrm{x})$ for all $\left.\mathrm{x}\right)$. Although the function $\mathrm{q}^{\mathrm{SL}}(\mathrm{x})$ is not increasing everywhere, we can again we use second-order conditions to prove that it must be strictly increasing in the neighborhood of $\left(\hat{\mathrm{x}}^{\mathrm{SL}}\right.$, $\left.\hat{\mathrm{q}}^{\mathrm{SL}}\right)$ and that, when graphed in $(\mathrm{x}, \mathrm{q})$ space, the function that represents $\mathrm{x}^{\mathrm{SL}}(\mathrm{q})$ crosses the function $\mathrm{q}^{\mathrm{SL}}(\mathrm{x})$ "from below." The positions of these functions in relation to the corresponding functions for the social planner are illustrated in Figure 2 below. It is straightforward to show (and to see from the Figure) that $\hat{\mathrm{x}}^{\mathrm{SL}}<\hat{\mathrm{x}}^{\mathrm{W}}$ and $\hat{\mathrm{q}}^{\mathrm{SL}}<\hat{\mathrm{q}}^{\mathrm{W}}$; that is, the firm provides both too little care and too little output under strict liability as compared to the social optimum.

\subsubsection{Care and Output under No Liability}

Under no liability, the consumer anticipates bearing the expected harm associated with her consumption of the good. Thus, she chooses her consumption $q$ to maximize $U(q ; x)=\alpha q-(\beta / 2) q^{2}-$ $h(x) q^{2}+I-p q$, resulting in the inverse demand curve $p(q)=\alpha-\beta q-2 h(x) q$. The firm's profits under no liability are given by:

$$
\Pi^{N L}(x, q)=(\alpha-\beta q-2 h(x) q) q-c(x) q .
$$

Notice that, in comparison with $\Pi^{\mathrm{SL}}(\mathrm{x}, \mathrm{q})$, the firm's expected harm-related costs per unit sold are now 


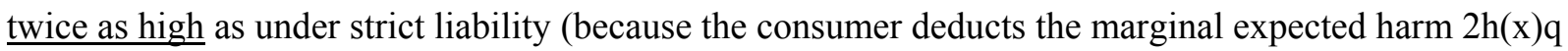
from her marginal willingness to pay for the good, and the marginal expected harm is twice the average expected harm). The details of the analysis are given in Appendix A.

The first-order conditions are:

$$
\begin{aligned}
& \Pi_{\mathrm{x}}^{\mathrm{NL}}=-2 \mathrm{~h}^{\prime}(\mathrm{x}) \mathrm{q}^{2}-\mathrm{c}^{\prime}(\mathrm{x}) \mathrm{q}=0 ; \\
& \Pi_{\mathrm{q}}^{\mathrm{NL}}=\alpha-2 \beta \mathrm{q}-4 \mathrm{~h}(\mathrm{x}) \mathrm{q}-\mathrm{c}(\mathrm{x})=0 .
\end{aligned}
$$

Simultaneous solution of equations (5) and (6) yield the firm's choice of care and output under no liability, denoted $\hat{\mathrm{x}}^{\mathrm{NL}}$ and $\hat{\mathrm{q}}^{\mathrm{NL}}$, respectively. Equation (5) defines implicitly the firm's profit-maximizing care level for any given level of output, denoted $\mathrm{x}^{\mathrm{NL}}(\mathrm{q})$. Second-order conditions can be used to prove that $\mathrm{x}^{\mathrm{NL}}(\mathrm{q})$ is a strictly increasing function of $\mathrm{q}$. Comparison of equations (1) and (5) implies that $\mathrm{x}^{\mathrm{NL}}(\mathrm{q})=$ $\mathrm{x}^{\mathrm{W}}(2 \mathrm{q})$ for all $\mathrm{q}$. Alternatively put, for any given output level, a firm facing no liability would provide more care than is socially optimal. Equation (6) can be solved for the firm's profit-maximizing output level under no liability for any given level of care, denoted $q^{\mathrm{NL}}(\mathrm{x})$, with the result that $\mathrm{q}^{\mathrm{NL}}(\mathrm{x})=(\alpha-$ $\mathrm{c}(\mathrm{x})) / 2(\beta+2 \mathrm{~h}(\mathrm{x}))$. Comparison of equations (2) and (6) imply that, for any given care level $\mathrm{x}$, the firm provides less than the socially-optimal output level; in fact, $\mathrm{q}^{\mathrm{NL}}(\mathrm{x})=(1 / 2) \mathrm{q}^{\mathrm{W}}(\mathrm{x})$ for all $\mathrm{x}$. Moreover, comparison of equations (4) and (6) imply that, for any given care level x, the firm provides less output under no liability than under strict liability; that is, $\mathrm{q}^{\mathrm{NL}}(\mathrm{x})<\mathrm{q}^{\mathrm{SL}}(\mathrm{x})$ for all $\mathrm{x}$. The function $\mathrm{q}^{\mathrm{NL}}(\mathrm{x})$ is not increasing everywhere, but we can use second-order conditions to prove that it must be strictly increasing in the neighborhood of $\left(\hat{\mathrm{x}}^{\mathrm{NL}}, \hat{\mathrm{q}}^{\mathrm{NL}}\right)$ and that, when graphed in $(\mathrm{x}, \mathrm{q})$ space, the function that represents $\mathrm{x}^{\mathrm{NL}}(\mathrm{q})$ crosses the function $\mathrm{q}^{\mathrm{NL}}(\mathrm{x})$ "from below." The positions of these functions in relation to the corresponding functions for the social planner, and for the firm facing strict liability, are illustrated in Figure 2 below. Finally, we note that the facts that $\mathrm{q}^{\mathrm{NL}}(\mathrm{x})=(1 / 2) \mathrm{q}^{\mathrm{W}}(\mathrm{x})$ for all $\mathrm{x}$, and $\mathrm{x}^{\mathrm{NL}}(\mathrm{q})=\mathrm{x}^{\mathrm{W}}(2 \mathrm{q})$ for all $\mathrm{q}$, imply that $\hat{\mathrm{x}}^{\mathrm{NL}}=\hat{\mathrm{x}}^{\mathrm{W}}$ and $\hat{\mathrm{q}}^{\mathrm{NL}}=(1 / 2) \hat{\mathrm{q}}^{\mathrm{W}}$. That is, under no liability the firm provides only half of the 
socially-optimal level of output, but it provides exactly the socially-optimal level of care. ${ }^{24}$

Figure 2 about here

\subsubsection{Summary of Results for the Cumulative Harm Model under Monopoly Product Provision}

The previous analysis has allowed us to construct several rankings. Ultimately, welfare and profit will depend on the solutions, which are denoted with a “^”. However, since we envision a situation with divided responsibilities wherein different agencies may be tasked with monitoring market versus product performance, we are also interested in the functions that represent the best care level for a given output level, and the best output level for a given care level. Although this is not formally a game, we can usefully think of these as "best response" functions. The following proposition summarizes what we have learned thus far.

Proposition 1. (a) Comparison of "best response" functions:

$$
\mathrm{x}^{\mathrm{W}}(\mathrm{q})=\mathrm{x}^{\mathrm{SL}}(\mathrm{q})<\mathrm{x}^{\mathrm{NL}}(\mathrm{q}) \text {; and } \mathrm{q}^{\mathrm{W}}(\mathrm{x})>\mathrm{q}^{\mathrm{SL}}(\mathrm{x})>\mathrm{q}^{\mathrm{NL}}(\mathrm{x})
$$

(b) Comparison of solutions:

$$
\hat{\mathrm{x}}^{\mathrm{SL}}<\hat{\mathrm{x}}^{\mathrm{NL}}=\hat{\mathrm{x}}^{\mathrm{W}} ; \text { and } \hat{\mathrm{q}}^{\mathrm{SL}}<\hat{\mathrm{q}}^{\mathrm{W}} \text { and } \hat{\mathrm{q}}^{\mathrm{NL}}=(1 / 2) \hat{\mathrm{q}}^{\mathrm{W}} .
$$

Part (a) indicates that, for any given output level, a firm facing strict liability would take the sociallyoptimal amount of care, while a firm facing no liability would take excessive care. For any given level of care, a firm facing strict liability would provide too little output, while a firm facing no liability would provide even less output. The results on no liability stem from the same effect wherein the consumer shifts the marginal expected harm through the market mechanism of demand-reduction: this raises the

24 Recall from footnote 21 that this latter result is an artifact of the functional form $\mathrm{h}(\mathrm{x}) \mathrm{q}^{2}$. Further evidence that this result is not robust is that, if production costs were also quadratic (i.e., $\left.c(x) q^{2}\right)$, then the optimal care choices are again output-independent (as they were in the case of proportional harm), but now the welfare-maximizing and strict liability care levels are the same (since they both minimize $\mathrm{h}(\mathrm{x})+\mathrm{c}(\mathrm{x})$ ) while the no liability care level is larger (since it minimizes $2 \mathrm{~h}(\mathrm{x})+\mathrm{c}(\mathrm{x}))$. 
firm's expected marginal cost (which induces it to reduce its output for a given care level) and its marginal return to expected harm reduction (which induces it to increase its care for a given output level).

Part (b) indicates that care is insufficient under strict liability, but socially-optimal under no liability. Although the firm always provides too little output, at this point we have not ranked $\hat{\mathrm{q}}^{\mathrm{SL}}$ and $\hat{\mathrm{q}}^{\mathrm{NL}}$. In the next subsection, we will use a parametrization of the firm's profit function to generate results on this output ranking and on the private and social preference ordering of liability regimes.

\section{Preferences over Liability Regimes and Regime Selection Criteria}

Inspection of the profit functions under strict and no liability reveals that we can employ a parametric specification that encompasses both regimes. In particular, define $\Pi(\mathrm{x}, \mathrm{q} ; \gamma)$ as follows:

$$
\Pi(x, q ; \gamma)=(\alpha-\beta q) q-\gamma h(x) q^{2}-c(x) q .
$$

Then $\Pi^{\mathrm{SL}}(\mathrm{x}, \mathrm{q})=\Pi(\mathrm{x}, \mathrm{q} ; \gamma=1)$ while $\Pi^{\mathrm{NL}}(\mathrm{x}, \mathrm{q})=\Pi(\mathrm{x}, \mathrm{q} ; \gamma=2)$. Using the same methodology as above (see Appendix A for the details), we can compute the profit-maximizing solution, denoted $(\hat{\mathrm{x}}(\gamma), \hat{\mathrm{q}}(\gamma)$ ); evaluating at $\gamma=1$ provides the profit-maximizing solution under strict liability and evaluating at $\gamma=2$ provides the profit-maximizing solution under no liability. For our quadratic formulation of expected harm (which is convex in $\mathrm{x}$ and $\mathrm{q}$ ) we find that $\mathrm{d} \hat{\mathrm{x}}(\gamma) / \mathrm{d} \gamma>0$ (which is consistent with our finding that $\hat{\mathrm{x}}^{\mathrm{SL}}$ $\left.<\hat{\mathrm{x}}^{\mathrm{NL}}\right)$ and $\mathrm{d} \hat{\mathrm{q}}(\gamma) / \mathrm{d} \gamma<0$. That is, under strict liability the firm provides more output but less care than under no liability; this explains the illustration of the relationships in Figure 2. Thus, we now have a ranking of the equilibrium output levels and the socially-optimal output level: $\hat{\mathrm{q}}^{\mathrm{NL}}<\hat{\mathrm{q}}^{\mathrm{SL}}<\hat{\mathrm{q}}^{\mathrm{W}}$.

\subsection{Preferences over Liability Regimes}

We can further employ this parametrization to obtain results about the preferences of the firm and of society over various liability regimes. First, consider the maximized parametrized profit function, $\Pi(\hat{x}(\gamma), \hat{\mathrm{q}}(\gamma) ; \gamma)$. Since the pair $(\hat{\mathrm{x}}(\gamma), \hat{\mathrm{q}}(\gamma))$ provides an interior maximum for the function $\Pi(\mathrm{x}, \mathrm{q} ; \gamma)$, the envelope theorem implies that we need only consider the direct impact of the parameter $\gamma$. Since $\Pi_{\gamma}=$ $\mathrm{h}(\hat{\mathrm{x}}(\gamma))(\hat{\mathrm{q}}(\gamma))^{2}<0$, the firm's profits are lower for higher $\gamma$; that is, the firm prefers a regime of strict 
liability to a regime of no liability. ${ }^{25}$

Finally, we evaluate the welfare function at the parametrized solution, $\mathrm{W}(\hat{\mathrm{x}}(\gamma), \hat{\mathrm{q}}(\gamma))$. This function does not depend directly on $\gamma$; it only depends on $\gamma$ indirectly through the solution $(\hat{\mathrm{x}}(\gamma), \hat{\mathrm{q}}(\gamma))$. We show in Appendix A that welfare is decreasing in $\gamma$. This is because, at the profit-maximizing solution $(\hat{\mathrm{x}}(\gamma), \hat{\mathrm{q}}(\gamma))$, overall welfare would be higher if there were more output and less care at the margin. An increase in $\gamma$ (a movement away from strict liability and toward no liability) causes care to $\underline{\text { increase }}$ (decreasing welfare) and causes output to decrease (decreasing welfare). Thus, $\underline{\text { social welfare is }}$ also higher under strict liability than under no liability. We summarize our findings on firm and social preferences in the following proposition.

Proposition 2. When harm is cumulative, the firm always prefers strict liability to no liability. When cumulative expected harm is given by $h(x) q^{2}$ and is convex in $x$ and $q$, welfare is also higher under strict liability.

\subsection{The Instability of the Negligence Regime}

An interesting implication of the firm's preference for strict over no liability is that a negligence regime is ineffective at increasing care. To see this, suppose that a negligence regime is in place and that the due care standard is the welfare-maximizing level of care $\hat{\mathrm{x}}^{\mathrm{W}}$ (which happens to coincides with $\hat{\mathrm{x}}^{\mathrm{NL}}$ for our quadratic expected harm function). To construct the firm's payoff under negligence, consider the functions $\Pi^{\mathrm{SL}}\left(\mathrm{x}, \mathrm{q}^{\mathrm{SL}}(\mathrm{x})\right)$ and $\Pi^{\mathrm{NL}}\left(\mathrm{x}, \mathrm{q}^{\mathrm{NL}}(\mathrm{x})\right)$; they attain their maximum values at $\hat{\mathrm{x}}^{\mathrm{SL}}$ and $\hat{\mathrm{x}}^{\mathrm{NL}}$, respectively, with $\hat{\mathrm{x}}^{\mathrm{SL}}<\hat{\mathrm{x}}^{\mathrm{NL}}=\hat{\mathrm{x}}^{\mathrm{W}}$. Moreover, inspection of the profit functions reveals that $\Pi^{\mathrm{SL}}(\mathrm{x}, \mathrm{q})>\Pi^{\mathrm{NL}}(\mathrm{x}, \mathrm{q})$ for each $(x, q)$. Then $\Pi^{\mathrm{SL}}\left(\mathrm{x}, \mathrm{q}^{\mathrm{SL}}(\mathrm{x})\right)>\Pi^{\mathrm{SL}}\left(\mathrm{x}, \mathrm{q}^{\mathrm{NL}}(\mathrm{x})\right)>\Pi^{\mathrm{NL}}\left(\mathrm{x}, \mathrm{q}^{\mathrm{NL}}(\mathrm{x})\right)$ for each $\mathrm{x}$; the first inequality follows from the fact that $\mathrm{q}^{\mathrm{SL}}(\mathrm{x})$ maximizes $\Pi^{\mathrm{SL}}(\mathrm{x}, \mathrm{q})$ for given $\mathrm{x}$, while the second inequality follows from the fact that $\Pi^{\mathrm{SL}}(\mathrm{x}, \mathrm{q})>\Pi^{\mathrm{NL}}(\mathrm{x}, \mathrm{q})$ for all $(\mathrm{x}, \mathrm{q})$.

If the firm complies with the negligence standard, then it bears no liability. Assuming that the

\footnotetext{
${ }^{25}$ This argument does not rely on the specific assumed quadratic form for expected harm; see Appendix B for a general statement and proof of this result.
} 
consumer observes the firm's compliance and properly adjusts her marginal willingness to pay (since she knows she will not be compensated), then if the firm complies, it optimally chooses $x=\hat{x}^{\mathrm{NL}}=\hat{\mathrm{x}}^{\mathrm{W}}$, because this is its profit-maximizing care level under no liability. It also chooses $\mathrm{q}=\hat{\mathrm{q}}^{\mathrm{NL}}$ and obtains profits of $\Pi^{\mathrm{NL}}\left(\hat{\mathrm{x}}^{\mathrm{NL}}, \hat{\mathrm{q}}^{\mathrm{NL}}\right)$. On the other hand, if the firm violates the due care standard by choosing $\mathrm{x}<\hat{\mathrm{x}}^{\mathrm{W}}$, then the firm will face strict liability for the harm caused. Assuming that the consumer observes the firm's noncompliance and properly adjusts her marginal willingness to pay (since she knows she will be fully compensated), then the firm optimally chooses $\hat{\mathrm{x}}^{\mathrm{SL}}$ (which is less than $\hat{\mathrm{x}}^{\mathrm{W}}$ ) and the associated output level and profits are $\hat{\mathrm{q}}^{\mathrm{SL}}$ and $\Pi^{\mathrm{SL}}\left(\hat{\mathrm{x}}^{\mathrm{SL}}, \hat{\mathrm{q}}^{\mathrm{SL}}\right)$. Since the negligence rule basically allows the firm to choose between strict liability and no liability, and since we have found that the firm's maximized profits under strict liability are higher than those under no liability, the firm will simply violate the due care standard and compensate the consumer as a cost of doing business.

This stark construction of the negligence rule induces a downward jump in the profit function at the due care standard ${ }^{26}$ by assuming that the consumer can perfectly observe the firm's choice of care and adjust her willingness to pay accordingly. One might think that the consumer would not be sufficiently sensitive to small amounts of over- or under-compliance. But notice that the firm's incentive is not to violate the due care standard by just a small amount; rather, it wants to violate the due care standard by a relatively substantial amount. Indeed, the firm wants to make it clear to the consumer that it has violated the due care standard, so as to persuade the consumer not to discount her marginal willingness to pay. In order to actually ensure that the firm would meet the due care standard, the negligence rule would have to specify a penalty in addition to making the firm liable for the consumer's harm. ${ }^{27}$

\subsection{Divided Responsibilities and Resilient Liability Rules}

${ }^{26}$ Recall that in the proportional harm model of Section 2.1 there is no difference in the profit functions under strict liability versus no liability and no jump at the due care standard.

${ }^{27}$ In order to make the firm meet the standard, $\hat{\mathrm{x}}^{\mathrm{W}}$, and not defect to the SL-solution, society would need to add an additional penalty of at least $\Pi^{\mathrm{SL}}\left(\hat{\mathrm{x}}^{\mathrm{SL}}, \hat{\mathrm{q}}^{\mathrm{SL}}\right)-\Pi^{\mathrm{NL}}\left(\hat{\mathrm{x}}^{\mathrm{W}}, \mathrm{q}^{\mathrm{NL}}\left(\hat{\mathrm{x}}^{\mathrm{W}}\right)\right)$. Note we assume that this penalty is paid to society and not to the consumer. As was shown above, forcing this change is socially inefficient under our assumptions on $h(x) q^{2}$. 
The foregoing analysis tends to lean heavily toward strict liability as the socially-optimal products liability regime when harm is cumulative. The firm always prefers strict liability to no liability; indeed, the firm would find it optimal to violate the due care standard in a negligence regime in order to "provoke" strict liability. When expected harm is of the form $\mathrm{h}(\mathrm{x}) \mathrm{q}^{2}$ and is convex, then welfare is higher under strict liability; under our more general formulation discussed in Appendix B, this statement is not guaranteed to be globally true, but it does hold for a (not necessarily small) neighborhood of the social optimum. But in this subsection, we argue that there is an even stronger motivation for the use of strict liability, which arises from the presence of divided responsibilities.

A common feature of the profit-maximizing solutions is that a firm with market power produces less than the socially-optimal level of output. Yet the role of products liability law seems to be to allocate the responsibility for harms due to product failures; it does not seem to include the evaluation of, and improvement in, market performance (as measured by, typically, total surplus). This task is the responsibility of other entities such as antitrust law or regulatory agencies. When separate agencies both take actions or implement policies that affect the overall functioning of a market, it would be desirable to have rules or policies that do not require too much fine coordination.

Strict liability is a rule that is resilient in the sense that it is robust, yet flexible. In particular, as we saw above, strict liability yields the socially-optimal level of care for any given output level: $x^{\mathrm{SL}}(\mathrm{q})=$ $\mathrm{x}^{\mathrm{W}}(\mathrm{q})$ for all $\mathrm{q}$, though it does not - by itself - induce the socially-optimal level of either $\mathrm{x}$ or $\mathrm{q}$. However, to the extent that another agency tasked with optimizing market performance engages in policies that would increase output (e.g., price regulation, or output subsidies), the regime of strict liability would move the level of care along the socially-optimal path. In the limit as output converges to the socially-optimal level $\hat{\mathrm{q}}^{\mathrm{W}}$, care under strict liability converges to the socially-optimal level of care $\hat{\mathrm{x}}^{\mathrm{W}}$. By contrast, although the regime of no liability results in the socially-optimal level of care $\hat{\mathrm{x}}^{\mathrm{W}}$ at the firm's chosen output level $\hat{\mathrm{q}}^{\mathrm{NL}}=(1 / 2) \hat{\mathrm{q}}^{\mathrm{W}}$, as output is increased (e.g., through the activities of marketperformance-enhancing agencies and/or agents), the level of care becomes increasingly excessive since 
$\mathrm{x}^{\mathrm{NL}}(\mathrm{q})>\mathrm{x}^{\mathrm{W}}(\mathrm{q})$ for all $\mathrm{q}$ ( see the position of the curves $\mathrm{x}^{\mathrm{W}}(\mathrm{q}), \mathrm{x}^{\mathrm{SL}}(\mathrm{q})$, and $\mathrm{x}^{\mathrm{NL}}(\mathrm{q})$ in Figure 2). Even if no liability were an optimal regime at $\hat{\mathrm{q}}^{\mathrm{NL}}$ (and this could happen if $\hat{\mathrm{q}}^{\mathrm{NL}}$ was substantially larger than $\hat{\mathrm{q}}^{\mathrm{SL}}$, which appears to be technically possible for some cumulative expected harm functions), there would be a critical value of q closer to $\hat{\mathrm{q}}^{\mathrm{W}}$ beyond which strict liability would always yield higher welfare than no liability. In this sense, the no liability regime is not resilient; it is flexible, but not robust, as it would need to be changed to strict liability when output closer to the socially optimal level is induced (or else there will be significant over-provision of care).

\subsubsection{What if Care is Not Observable by the Consumer?}

Another sense in which strict liability is resilient is that it operates equally well when we assume that the consumer cannot observe the firm's choice of care prior to purchase (and the court cannot verify it ex post of harm). Under strict liability, the consumer expects to be compensated for her harm, so she need not discount her marginal willingness to pay for the good. It does not matter whether the firm's choice of care is observable ex ante or verifiable ex post; the firm will still choose the socially-optimal level of care for any given level of output and, as output converges to the socially-optimal level (e.g., as a consequence of actions taken by another agency), so does care. On the other hand, under a regime of no liability, the consumer must discount her marginal willingness to pay by the marginal expected harm based on her conjecture about the firm's choice of care. While this conjecture must be correct in equilibrium, it is insensitive to the firm's actual choice of care. Unfortunately, this insensitivity implies that the firm's optimal choice of care, given the consumer's conjecture, is that which minimizes the production $\operatorname{cost} \mathrm{c}(\mathrm{x}) \mathrm{q}$; that is, $\mathrm{x}=0$, which is assuredly not socially optimal.

\subsection{Robustness of the Results to Inclusion of Litigation Costs}

One aspect of strict liability that we have not addressed is the fact that it engenders litigation costs. Indeed, for the case of proportional harm, wherein no liability, negligence, and strict liability all work equally well (assuming that care is observable by consumers prior to purchase), litigation costs are sometimes invoked to argue against strict liability and in favor of no liability. After all, why use a costly 
court system when the market can perform the same function "for free." In that context, the litigation costs associated with strict liability would have the effect of inducing excessive care and reducing equilibrium output. However, we have just shown that these are precisely the same effects that are associated with a regime of no liability when harm is cumulative. Even though there are no litigation costs, the firm faces harm-related costs (through reduced consumer willingness-to-pay) that reflect the marginal expected harm, which exceeds the average expected harm that it would face under strict liability. As shown earlier, quadratic expected cumulative harm implies that strict liability is strictly sociallypreferred to no liability, so if litigation costs are low, this ordering will continue to hold. While one could argue (likely without satisfactory resolution) about whether litigation costs under strict liability, or marginal expected harm under no liability, is more distortionary of care and output, we believe that strict liability still possesses two other benefits over no liability. First, no liability performs very poorly if care is unobservable to consumers ex ante; unobservable care seems to be a real possibility in the production and sale of products. Second, one can imagine providing streamlined procedures that will further lower the costs of litigation under strict liability (e.g., class actions, consolidation, or alternative dispute resolution procedures such as mediation and arbitration), whereas the distortions due to a regime of no liability are (by definition) not subject to improvement.

\section{Oligopoly Models with Cumulative Harm}

In this section, we extend the basic model of cumulative harm to the case of multiple firms. Subsection 4.1 considers products that are substitutes in consumption, but whose consumption generates independent and identifiable risks. An example of this, which we refer to as the "Diner's Dilemma," is the problem of composing one's diet using various foods, any one of which may be contaminated by bacteria or toxins. For instance, beef may involve exposure to e coli, chicken may involve exposure to salmonella or campylobacter, pork products may involve exposure to listeria, peanut butter may involve exposure to aflatoxin or salmonella, vegetables may involve exposure to shigella, and fish or seafood 
may involve exposure to ciguatera. If we assume that the expected harm associated with consuming each type of food is cumulative, but that there is essentially no interaction between the foods in terms of generating harm, then we will say that the consumer's problem involves "independent cumulative harms." If the goods are all purchased from the same store, or if the offending agents are sufficiently unique (e.g., it is often possible to trace bacterial contamination to the original source using DNA), then a firm that provides a contaminated food item can be identified for potential legal responsibility.

On the other hand, in some cases the goods that are substitutes in consumption generate harm through bioaccumulation; for instance, there may be a variety of fish that contain mercury, and they may be acquired from a variety of sellers. The mercury from all sources is retained in the body until, in some cases, the person becomes ill with mercury poisoning. Lead and radiation poisoning can also be acquired through chronic (in addition to acute) exposure. This requires both a somewhat different model of harm, which we will call "joint cumulative harm," and a somewhat different liability rule (which is related to market share liability). Subsection 4.2 extends the basic model of cumulative harm to the case wherein all products contribute to the production of harm, but the extent of each product's contribution is (potentially) identifiable.

\subsection{Independent Cumulative Harms}

In this subsection, we assume that the consumer views the n products as perfect substitutes in consumption if we abstract from any harm-related disutility. ${ }^{28}$ That is, $\mathrm{u}\left(\mathrm{q}_{1}, \mathrm{q}_{2}, \ldots, \mathrm{q}_{\mathrm{n}}\right)=\alpha \Sigma_{\mathrm{i}} \mathrm{q}_{\mathrm{i}}-(\beta / 2)\left(\Sigma_{\mathrm{i}} \mathrm{q}_{\mathrm{i}}\right)^{2}$ $+\mathrm{I}-\Sigma_{\mathrm{i}} \mathrm{p}_{\mathrm{i}} \mathrm{q}_{\mathrm{i}}$, where $\alpha$ and $\beta$ are positive constants, $\mathrm{q}_{\mathrm{i}}$ is the number of units of good i purchased and consumed by the individual, $\mathrm{p}_{\mathrm{i}}$ is the price per unit of good $\mathrm{i}$, the summation $\Sigma_{\mathrm{i}}$ goes from $\mathrm{i}=1$ to $\mathrm{i}=\mathrm{n}$, and $\mathrm{I}-\Sigma_{\mathrm{i}} \mathrm{p}_{\mathrm{i}} \mathrm{q}_{\mathrm{i}}$ is the value of the amount consumed of the numeraire good. We characterize output and care under welfare-maximization and under symmetric Nash equilibrium play by reference to a pair of first-order conditions. In all cases, joint convexity of expected harm in $\mathrm{x}$ and $\mathrm{q}$ implies that the matrix of

\footnotetext{
${ }^{28}$ This is a simplification for expositional purposes. One can readily extend the model to allow for horizontal differentiation of goods (i.e., goods with other attributes that make them imperfect substitutes).
} 
second partial derivatives associated with these first-order conditions is negative definite, so we will not discuss second-order conditions further.

\subsubsection{Care and Output under Welfare-Maximization}

For simplicity, we assume that all $\mathrm{n}$ products have the same form of expected harm function, $\mathrm{h}\left(\mathrm{x}_{\mathrm{i}}\right)\left(\mathrm{q}_{\mathrm{i}}\right)^{2}$, and the same cost function, $\mathrm{c}\left(\mathrm{x}_{\mathrm{i}}\right) \mathrm{q}_{\mathrm{i}}$, where $\mathrm{x}_{\mathrm{i}}$ is the level of care applied to product $\mathrm{i}$. Since the consumer views the goods as perfect substitutes in consumption, the social planner will choose the same levels of care and output for all $\mathrm{n}$ products; denote these un-subscripted values for the planner by $\mathrm{x}$ and $\mathrm{q}$. Then welfare (suppressing the consumer's income) is given by:

$$
W(q, x ; n)=\alpha n q-(\beta / 2)(n q)^{2}-n h(x) q^{2}-c(x) n q .
$$

Notice that the independence of the cumulative harms is reflected in the term $n h(x) q^{2}$, whereas all of the other terms are expressible in terms of aggregate industry output (nq). The first-order conditions are:

$$
\begin{aligned}
& \mathrm{W}_{\mathrm{x}}=-n h^{\prime}(\mathrm{x}) \mathrm{q}^{2}-\mathrm{nc}^{\prime}(\mathrm{x}) \mathrm{q}=0 ; \\
& \mathrm{W}_{\mathrm{q}}=\mathrm{n} \alpha-\beta \mathrm{n}^{2} \mathrm{q}-2 \mathrm{nh}(\mathrm{x}) \mathrm{q}-\mathrm{nc}(\mathrm{x})=0 .
\end{aligned}
$$

Simultaneous solution of equations (7) and (8) yields the socially-optimal combination of care and output, denoted $\hat{\mathrm{x}}^{\mathrm{W}}(\mathrm{n})$ and $\hat{\mathrm{q}}^{\mathrm{W}}(\mathrm{n})$, respectively. However, again it is useful to consider each first-order condition separately. Equation (7) is identical to equation (1) except for the pre-multiplication by n, and therefore the socially-optimal care level as a function of any given level of output, denoted $\mathrm{x}^{\mathrm{W}}(\mathrm{q} ; \mathrm{n})$ is exactly the same (strictly increasing function) as before; $\mathrm{x}^{\mathrm{W}}(\mathrm{q} ; \mathrm{n})=\mathrm{x}^{\mathrm{W}}(\mathrm{q})$ for all $\mathrm{n}$. Equation (8) can be solved for the socially-optimal output level for any given level of care, denoted $\mathrm{q}^{\mathrm{W}}(\mathrm{x} ; \mathrm{n})$, with the result that $\mathrm{q}^{\mathrm{W}}(\mathrm{x} ; \mathrm{n})=$ $(\alpha-c(x)) /(n \beta+2 h(x))$. For any given level of care, less output is produced per firm as the number of firms increases; however, the total (aggregate) amount of output, $\mathrm{nq}^{\mathrm{W}}(\mathrm{x} ; \mathrm{n})$, increases as the number of firms increases.

The facts that the function representing $\mathrm{x}^{\mathrm{W}}(\mathrm{q} ; \mathrm{n})=\mathrm{x}^{\mathrm{W}}(\mathrm{q})$ is independent of $\mathrm{n}$, while the function $\mathrm{q}^{\mathrm{W}}(\mathrm{x} ; \mathrm{n})=(\alpha-\mathrm{c}(\mathrm{x})) /(\mathrm{n} \beta+2 \mathrm{~h}(\mathrm{x}))$ shifts downward as $\mathrm{n}$ increases, jointly imply that the per-firm welfaremaximizing levels of both care and output decrease as $\mathrm{n}$ increases. It is straightforward to show that 
$\mathrm{W}\left(\hat{\mathrm{q}}^{\mathrm{W}}(\mathrm{n}), \hat{\mathrm{x}}^{\mathrm{W}}(\mathrm{n}) ; \mathrm{n}\right)$ is increasing in $\mathrm{n}$; if there were no fixed costs associated with entering the market and producing the good, then it would be socially-optimal to have an infinite number of goods, each produced in a vanishingly small amount (with the aggregate industry output converging to $(\alpha-c(x)) / \beta)$, and with a vanishingly small level of care. ${ }^{29}$ Since there are likely to be significant fixed costs in most markets, and since the "independent risks" assumption also seems less likely to hold as more and more products enter the market (e.g., different strains of salmonella may cooperate to cause illness, more like the situation to be described in the Section 4.2 below), we think that examining small changes in the number of firms, for $\mathrm{n}$ finite, is of greater interest than the limiting result.

\subsubsection{Care and Output under Strict Liability}

Under strict liability, the consumer expects to be fully-compensated for any harm she incurs. Consequently, she simply chooses her consumption of good $\mathrm{i}, \mathrm{q}_{\mathrm{i}}$, so as to maximize her utility $\mathrm{u}\left(\mathrm{q}_{1}, \mathrm{q}_{2}, \ldots\right.$, $\left.\mathrm{q}_{\mathrm{n}}\right)=\alpha \Sigma_{\mathrm{i}} \mathrm{q}_{\mathrm{i}}-(\beta / 2)\left(\Sigma_{\mathrm{i}} \mathrm{q}_{\mathrm{i}}\right)^{2}+\mathrm{I}-\Sigma_{\mathrm{i}} \mathrm{p}_{\mathrm{i}} \mathrm{q}_{\mathrm{i}}$. This results in the inverse demand curve for good $\mathrm{i}: \mathrm{p}_{\mathrm{i}}\left(\mathrm{q}_{1}, \mathrm{q}_{2}, \ldots, \mathrm{q}_{\mathrm{n}}\right)=$ $\alpha-\beta Q$, where $\mathrm{Q}=\Sigma_{\mathrm{i}} \mathrm{q}_{\mathrm{i}}$, where the summation is taken over $\mathrm{i}=1$ to $\mathrm{i}=\mathrm{n}$.

Profits for firm i now depend on the output and care levels of all firms, and reflect the expected harm to the consumer as a result of her consumption of $q_{i}$ units of good i. For notational convenience, however, we suppress the vector of other firms' output and care levels, and denote firm i's profits simply by $\Pi_{\mathrm{i}}^{\mathrm{SL}}\left(\mathrm{x}_{\mathrm{i}}, \mathrm{q}_{\mathrm{i}} ; \mathrm{n}\right)$. Then:

$$
\Pi_{\mathrm{i}}^{\mathrm{SL}}\left(\mathrm{x}_{\mathrm{i}}, \mathrm{q}_{\mathrm{i}} ; \mathrm{n}\right)=(\alpha-\beta Q) \mathrm{q}_{\mathrm{i}}-\mathrm{h}\left(\mathrm{x}_{\mathrm{i}}\right)\left(\mathrm{q}_{\mathrm{i}}\right)^{2}-\mathrm{c}\left(\mathrm{x}_{\mathrm{i}}\right) \mathrm{q}_{\mathrm{i}} .
$$

To solve for the symmetric oligopoly equilibrium, we first differentiate this expression with respect to $\mathrm{x}_{\mathrm{i}}$ and $\mathrm{q}_{\mathrm{i}}$ (see the Appendix for the details). We then invoke symmetry to reduce the firm-specific first-order conditions to two equations that characterize the symmetric equilibrium values of $\mathrm{x}$ and $\mathrm{q}$ :

$$
-h^{\prime}(x) q^{2}-c^{\prime}(x) q=0 ;
$$

29 If $\mathrm{h}(0)$ was not finite, then care might not go to zero in the limit. This is like having a perfectly-diversified portfolio; the investor owns a tiny amount of each of a collection of uncorrelated assets and bears essentially no risk. 


$$
\alpha-(n+1) \beta q-2 h(x) q-c(x)=0 .
$$

Simultaneous solution of equations (9) and (10) yields the symmetric Nash equilibrium combination of care and output, denoted $\hat{\mathrm{x}}^{\mathrm{SL}}(\mathrm{n})$ and $\hat{\mathrm{q}}^{\mathrm{SL}}(\mathrm{n})$, respectively. Again, we consider each equation separately. Equation (9) is identical to equation (3) from the single-firm case, so $x^{\mathrm{SL}}(\mathrm{q} ; n)=x^{\mathrm{SL}}(q)$, independent of $n$. Moreover, equations (7) and (9) have the same solution, so $x^{\mathrm{SL}}(\mathrm{q} ; \mathrm{n})=\mathrm{x}^{\mathrm{W}}(\mathrm{q} ; \mathrm{n})\left(=\mathrm{x}^{\mathrm{SL}}(\mathrm{q})=\mathrm{x}^{\mathrm{W}}(\mathrm{q})\right)$. The symmetric Nash equilibrium level of care, for any given symmetric output level, is the same as the socially-optimal level. On the other hand, solving equation (10) for the symmetric Nash equilibrium output level, for any given level of care, yields $\mathrm{q}^{\mathrm{SL}}(\mathrm{x} ; \mathrm{n})=(\alpha-\mathrm{c}(\mathrm{x})) /((\mathrm{n}+1) \beta+2 \mathrm{~h}(\mathrm{x}))<\mathrm{q}^{\mathrm{W}}(\mathrm{x} ; \mathrm{n})$; firms produce too little output (for a given level of care) in the symmetric Nash equilibrium. Taken together, these imply that $\hat{\mathrm{x}}^{\mathrm{SL}}(\mathrm{n})<\hat{\mathrm{x}}^{\mathrm{W}}(\mathrm{n})$ and $\hat{\mathrm{q}}^{\mathrm{SL}}(\mathrm{n})<\hat{\mathrm{q}}^{\mathrm{W}}(\mathrm{n})$ for all $\mathrm{n}$; that is, in the symmetric Nash equilibrium under strict liability, firms produce too little output and take too little care. Moreover, since the function representing $\mathrm{x}^{\mathrm{SL}}(\mathrm{q} ; \mathrm{n})$ remains fixed as $\mathrm{n}$ increases, while the function $\mathrm{q}^{\mathrm{SL}}(\mathrm{x} ; \mathrm{n})$ decreases as $\mathrm{n}$ increases, it follows that $\hat{\mathrm{x}}^{\mathrm{SL}}(\mathrm{n})$ and $\hat{\mathrm{q}}^{\mathrm{SL}}(\mathrm{n})$ both decrease as $n$ increases. ${ }^{30}$

\subsubsection{Care and Output under No Liability}

Under no liability, the consumer anticipates bearing the expected harm associated with her consumption of the good. Thus, she chooses her consumption $\mathrm{q}$ to maximize $\mathrm{U}\left(\mathrm{q}_{1}, \mathrm{q}_{2}, \ldots, \mathrm{q}_{\mathrm{n}} ; \mathrm{x}_{1}, \mathrm{x}_{2}, \ldots, \mathrm{x}_{\mathrm{n}}\right)$ $=\alpha \Sigma_{\mathrm{i}} \mathrm{q}_{\mathrm{i}}-(\beta / 2)\left(\Sigma_{\mathrm{i}} \mathrm{q}_{\mathrm{i}}\right)^{2}-\Sigma_{\mathrm{i}} \mathrm{h}\left(\mathrm{x}_{\mathrm{i}}\right)\left(\mathrm{q}_{\mathrm{i}}\right)^{2}+\mathrm{I}-\Sigma_{\mathrm{i}} \mathrm{p}_{\mathrm{i}} \mathrm{q}_{\mathrm{i}}$. Although the consumer continues to view the goods as perfect substitutes for consumption purposes, they are differentiated products in terms of their respective expected harms. This results in the inverse demand curve for good $\mathrm{i}: \mathrm{p}_{\mathrm{i}}\left(\mathrm{q}_{1}, \mathrm{q}_{2}, \ldots, \mathrm{q}_{\mathrm{n}} ; \mathrm{x}_{\mathrm{i}}\right)=\alpha-\beta \mathrm{Q}-$ $2 h\left(x_{i}\right) q_{i}$.

Firm i’s profits under no liability are given by:

${ }^{30}$ As the number of firms gets arbitrarily large, each firm produces a vanishingly small amount and takes essentially no care, while the aggregate industry output converges to the socially-optimal amount; thus the Nash equilibrium approaches the welfare optimum as n goes to infinity. The same is true of the Nash equilibrium under no liability (see below), but in both the SL and NL cases we expect that fixed costs or other entry barriers (e.g., patents) will limit entry to a finite number of firms. 


$$
\Pi_{i}^{N L}\left(x_{i}, q_{i} ; n\right)=\left(\alpha-\beta Q-2 h\left(x_{i}\right) q_{i}\right) q_{i}-c\left(x_{i}\right) q_{i} .
$$

Notice that, as in the monopoly case, firm i's expected harm-related costs per unit sold are now twice as

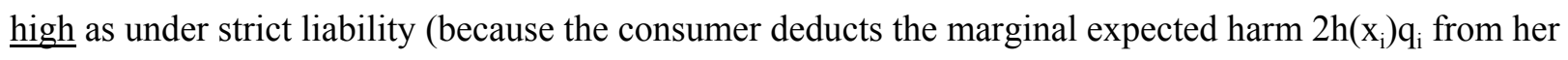
marginal willingness to pay for good $\mathrm{i}$, and the marginal expected harm is twice the average expected harm). Again, we differentiate firm i's profit function with respect to $x_{i}$ and $q_{i}$ (see the Appendix for the details) and then invoke symmetry to obtain a system of equations that characterizes the symmetric equilibrium levels of care and output:

$$
\begin{aligned}
& -2 h^{\prime}(x) q^{2}-c^{\prime}(x) q=0 ; \\
& \alpha-(n+1) \beta q-4 h(x) q-c(x)=0 .
\end{aligned}
$$

Simultaneous solution of equations (11) and (12) yields the symmetric Nash equilibrium combination of care and output, denoted $\hat{\mathrm{x}}^{\mathrm{NL}}(\mathrm{n})$ and $\hat{\mathrm{q}}^{\mathrm{NL}}(\mathrm{n})$, respectively. Again, we consider each equation separately. Equation (11) is identical to equation (5) from the single-firm case, so $x^{\mathrm{NL}}(q ; n)=x^{\mathrm{NL}}(q)$, independent of n. Since $x^{\mathrm{W}}(\mathrm{q} ; \mathrm{n})$ is also independent of $\mathrm{n}$, the result we found for the monopoly case carries over to the case of multiple firms: $x^{\mathrm{NL}}(\mathrm{q} ; \mathrm{n})=\mathrm{x}^{\mathrm{W}}(2 \mathrm{q} ; \mathrm{n})$, for all $\mathrm{q}$ and $\mathrm{n}$. This implies that, for any given output level, a firm facing no liability would provide more care than is socially optimal. Solving equation (12) for the symmetric Nash equilibrium output level, for any given level of care, yields $q^{\mathrm{NL}}(\mathrm{x} ; \mathrm{n})=(\alpha-\mathrm{c}(\mathrm{x})) /((\mathrm{n}+$ 1) $\beta+4 h(x))$, resulting in the output ordering: $\mathrm{q}^{\mathrm{NL}}(\mathrm{x} ; \mathrm{n})<\mathrm{q}^{\mathrm{SL}}(\mathrm{x} ; \mathrm{n})<\mathrm{q}^{\mathrm{W}}(\mathrm{x} ; \mathrm{n})$; firms produce too little output (for a given level of care) in the symmetric Nash equilibrium, and they produce less output under no liability than under strict liability. Moreover, since the function representing $x^{\mathrm{NL}}(\mathrm{q} ; \mathrm{n})$ remains fixed as $n$ increases, while the function $\mathrm{q}^{\mathrm{NL}}(\mathrm{x} ; \mathrm{n})$ decreases as $\mathrm{n}$ increases, it follows that $\hat{\mathrm{x}}^{\mathrm{NL}}(\mathrm{n})$ and $\hat{\mathrm{q}}^{\mathrm{NL}}(\mathrm{n})$ both decrease as $n$ increases.

The following relationships can be used to order the welfare-maximizing level of care and the levels of care under no liability and strict liability, respectively. First, recall that $x^{\mathrm{NL}}(\mathrm{q} ; \mathrm{n})=\mathrm{x}^{\mathrm{W}}(2 \mathrm{q} ; \mathrm{n})$; second, note that $\mathrm{q}^{\mathrm{NL}}(\mathrm{x} ; \mathrm{n})>.5 \mathrm{q}^{\mathrm{W}}(\mathrm{x} ; \mathrm{n})$ for $\mathrm{n} \geq 2$. Taken together, these imply that $\hat{\mathrm{x}}^{\mathrm{NL}}(\mathrm{n})>\hat{\mathrm{x}}^{\mathrm{W}}(\mathrm{n})$, which we already know is larger than $\hat{\mathrm{x}}^{\mathrm{SL}}(\mathrm{n})$. It is interesting to note that, for $\mathrm{n} \geq 2$, noncooperative firms take 
excessive care in equilibrium, while for $n=1$ they took exactly the socially-optimal level of care (albeit this coincidence is an artifact of the quadratic specification). The reason the noncooperative firms now take excessive care is that they use care to facilitate "business-stealing": if two goods have the same price but one embodies relatively greater care, then the consumer will demand more of the higher-care, and less of the lower-care, product.

\subsubsection{Stability of the Negligence Regime}

We now reconsider the effectiveness of a negligence regime in inducing socially-optimal care. If the negligence standard is set at $\hat{\mathrm{x}}^{\mathrm{W}}(\mathrm{n})$, then from the discussion above we know that if it is an equilibrium for the firms to comply with the negligence standard, then they will actually over-provide care, since $\hat{\mathrm{X}}^{\mathrm{NL}}(\mathrm{n})>\hat{\mathrm{x}}^{\mathrm{W}}(\mathrm{n})$. It may (or may not) be an equilibrium for the firms to comply since unilateral defection ${ }^{31}$ may not (or may) lead to higher profits. On the other hand, if the firms' over-provision were eliminated (e.g., they could be induced to provide no more than the socially-optimal care level $\hat{x}^{\mathrm{W}}(\mathrm{n})$ through, for instance, taxes or penalties for over-provision), then it will be optimal for any individual firm to defect to $\mathrm{x}_{\mathrm{i}}<\hat{\mathrm{x}}^{\mathrm{W}}(\mathrm{n})$ and thereby reallocate liability to itself. The only way that firms could be induced to provide the care level $\hat{\mathrm{x}}^{\mathrm{W}}(\mathrm{n})$ would be to penalize (substantially) both over- and under-provision of care. This seems especially problematical when the threshold $\hat{x}^{\mathrm{W}}(\mathrm{n})$ is so complicated, depending as it does on all of the demand- and cost-related parameters in addition to the number of firms.

In contrast, a policy of strict liability continues to be resilient in the sense that, for every $q$ and $n$, it generates the socially-optimal level of care. Thus, as antitrust or regulatory authorities implement policies to adjust $\mathrm{q}$ and/or $\mathrm{n}$ in a welfare-improving direction, under strict liability firms adjust their levels

31 If firm $i$ were going to defect, it would choose $x_{i}<\hat{x}^{w}(n)$ and $q_{i}$ to maximize $\Pi_{i}^{S L}\left(x_{i}, q_{i} ; n\right)=\left(\alpha-\beta q_{i}\right.$ $\left.(\mathrm{n}-1) \hat{\mathrm{q}}^{\mathrm{NL}}(\mathrm{n})\right) \mathrm{q}_{\mathrm{i}}-\mathrm{h}\left(\mathrm{x}_{\mathrm{i}}\right)\left(\mathrm{q}_{\mathrm{i}}\right)^{2}-\mathrm{c}\left(\mathrm{x}_{\mathrm{i}}\right) \mathrm{q}_{\mathrm{i}}$. The question is whether this provides higher profits than compliance, which yields profits of $\Pi_{i}^{\mathrm{NL}}\left(\hat{\mathrm{x}}^{\mathrm{NL}}(\mathrm{n}), \hat{\mathrm{q}}^{\mathrm{NL}}(\mathrm{n}) ; \mathrm{n}\right)=\left(\alpha-\beta \mathrm{n} \hat{\mathrm{q}}^{\mathrm{NL}}(\mathrm{n})-2 \mathrm{~h}\left(\hat{\mathrm{x}}^{\mathrm{NL}}(\mathrm{n})\right) \hat{\mathrm{q}}^{\mathrm{NL}}(\mathrm{n})\right) \hat{\mathrm{q}}^{\mathrm{NL}}(\mathrm{n})-\mathrm{c}\left(\hat{\mathrm{x}}^{\mathrm{NL}}(\mathrm{n}) \hat{\mathrm{q}}^{\mathrm{NL}}(\mathrm{n})\right.$. When $\mathrm{n}=1$, unilateral defection is easily shown to be optimal since the defecting firm need only undercut $\hat{\mathrm{x}}^{\mathrm{NL}}(1)=\hat{\mathrm{x}}^{\mathrm{W}}(1)$ marginally in order to re-allocate liability to itself (of course, it turns out that the firm will undercut it substantially). For larger n, the firm would have to cut its care level from $\hat{\mathrm{x}}^{\mathrm{NL}}(\mathrm{n})$ to less than $\hat{\mathrm{x}}^{\mathrm{W}}(\mathrm{n})$, and now this is not a marginal change. 
of care in the socially-optimal direction. On the other hand, under no liability, firms provide excessive care for any given $\mathrm{q}$ and $\mathrm{n}$, but too little output for any given $\mathrm{x}$ and $\mathrm{n}$; an antitrust or regulatory policy that promotes greater output (say, for a given n) would only drive care up further beyond the socially-optimal level.

\subsection{Joint Cumulative Harm}

In this subsection, we continue to assume that the consumer views the $\mathrm{n}$ products as perfect substitutes in consumption if we abstract from any harm-related disutility, so that $u\left(\mathrm{q}_{1}, \mathrm{q}_{2}, \ldots, \mathrm{q}_{\mathrm{n}}\right)=\alpha \Sigma_{\mathrm{i}} \mathrm{q}_{\mathrm{i}}$ $(\beta / 2)\left(\Sigma_{\mathrm{i}} \mathrm{q}_{\mathrm{i}}\right)^{2}+\mathrm{I}-\Sigma_{\mathrm{i}} \mathrm{p}_{\mathrm{i}} \mathrm{q}_{\mathrm{i}}$. However, we now modify the specification of expected harm to reflect the assumption that each product is a source of some exposure that contributes to harm, and the expected harm depends on the aggregate amount of the exposure from all sources. For instance, different varieties (or providers) of fish may contain mercury, and the expected harm to a human consumer is a function of the aggregate amount of mercury that accumulates in the body. Similarly, a consumer may be exposed to radiation through a variety of medical and dental procedures, as well as through environmental exposures, and it is the aggregate amount of radiation exposure that determines expected harm. We assume that the extent of each firm's contribution depends on the firm's level of care. For instance, let $\mu\left(x_{i}\right)$ denote the amount of exposure per unit of good i consumed, where $\mu\left(\mathrm{x}_{\mathrm{i}}\right)$ has the same properties as $\mathrm{h}\left(\mathrm{x}_{\mathrm{i}}\right){ }^{32}$ Then $\mu\left(x_{i}\right) q_{i}$ denotes the amount of exposure contributed by good $\mathrm{i}$, while $\mathrm{M} \equiv \Sigma_{\mathrm{i}} \mu\left(\mathrm{x}_{\mathrm{i}}\right) \mathrm{q}_{\mathrm{i}}$, where the sum ranges from $\mathrm{i}=1$ to $\mathrm{i}=\mathrm{n}$, denotes the aggregate amount of exposure. ${ }^{33}$ Finally, suppose that the consumer's expected harm from consuming the vector of goods $\left(\mathrm{q}_{1}, \mathrm{q}_{2}, \ldots, \mathrm{q}_{\mathrm{n}}\right)$ with associated care levels $\left(\mathrm{x}_{1}, \mathrm{x}_{2}, \ldots, \mathrm{x}_{\mathrm{n}}\right)$ is given by $\lambda \mathrm{M}^{2}$, where $\lambda$ is a positive constant. We will characterize output and care under welfaremaximization and under symmetric Nash equilibrium play by reference to a pair of first-order conditions. In all cases, the matrix of second partial derivatives associated with these first-order conditions is negative

\footnotetext{
${ }^{32}$ To be more specific, we assume that $\mu(0)$ is positive and finite, $\mu^{\prime}(\mathrm{x})<0$, and $\mu^{\prime \prime}(\mathrm{x})>0$ for all $\mathrm{x}$.

33 Formally, $\mathrm{M}$ is a function of the vector of output level and the vector of care levels. We suppress this dependence in the interests of improving readability.
} 
definite, so we will not discuss second-order conditions further.

\subsubsection{Care and Output under Welfare-Maximization}

We assume that the firms continue to have the same production cost functions, $c\left(x_{i}\right) q_{i}$, where $x_{i}$ is the level of care applied to product i. Since the consumer views the goods as perfect substitutes in consumption, the social planner will choose the same levels of care and output for all $\mathrm{n}$ products. Then aggregate exposure is given by $\mathrm{M}=\mathrm{n} \mu(\mathrm{x}) \mathrm{q}$, and welfare (suppressing the consumer's income) is given by:

$$
W^{\mathrm{J}}(\mathrm{q}, \mathrm{x} ; \mathrm{n})=\alpha \mathrm{nq}-(\beta / 2)(\mathrm{nq})^{2}-\lambda(\mathrm{n} \mu(\mathrm{x}) \mathrm{q})^{2}-\mathrm{c}(\mathrm{x}) \mathrm{nq}
$$

where we have used the superscript $\mathrm{J}$ to distinguish the case of joint cumulative harm. In this case, all of the components of the welfare function can be expressed in terms of aggregate industry output (nq). The first-order conditions are (where the subscript indicates the relevant partial derivative):

$$
\begin{aligned}
& \mathrm{W}_{\mathrm{x}}^{\mathrm{J}}=-\lambda(\mathrm{nq})^{2} 2 \mu(\mathrm{x}) \mu^{\prime}(\mathrm{x})-\mathrm{nc}^{\prime}(\mathrm{x}) \mathrm{q}=0 ; \\
& \mathrm{W}_{\mathrm{q}}^{\mathrm{J}}=\alpha \mathrm{n}-\beta \mathrm{n}^{2} \mathrm{q}-2 \lambda(\mathrm{n} \mu(\mathrm{x}))^{2} \mathrm{q}-\mathrm{nc}(\mathrm{x})=0 .
\end{aligned}
$$

Equations (13) and (14) can be solved simultaneously for the socially-optimal combination of care and output, denoted $\hat{\mathrm{x}}^{\mathrm{JW}}(\mathrm{n})$ and $\hat{\mathrm{q}}^{\mathrm{JW}}(\mathrm{n})$, respectively, where the JW superscript indicates that this is the joint cumulative harm version of welfare-maximization.

Treating $\mathrm{q}$ as a parameter, equation (13) defines implicitly the optimal level of care for a given level of output (and $n), x^{\mathrm{JW}}(\mathrm{q} ; \mathrm{n})$, which is an increasing function of $\mathrm{q}$. Treating $\mathrm{x}$ as a parameter and solving equation (14) implies that the optimal level of output for a given level of care (and $n)$ is $q^{\mathrm{JW}}(\mathrm{x} ; \mathrm{n})$ $=(\alpha-\mathrm{c}(\mathrm{x})) / \mathrm{n}\left[\beta+2 \lambda(\mu(\mathrm{x}))^{2}\right]$. When graphed in $(\mathrm{x}, \mathrm{q})$ space, the function representing $\mathrm{x}^{\mathrm{JW}}(\mathrm{q} ; \mathrm{n})$ crosses the function $\mathrm{q}^{\mathrm{JW}}(\mathrm{x} ; \mathrm{n})$ from below at $\left(\hat{\mathrm{x}}^{\mathrm{JW}}(\mathrm{n}), \hat{\mathrm{q}}^{\mathrm{JW}}(\mathrm{n})\right)$.

The optimal solution in the joint cumulative harm model has several interesting features. First, the optimal aggregate industry output, $\mathrm{Q}^{\mathrm{JW}}(\mathrm{x} ; \mathrm{n})=\mathrm{nq}^{\mathrm{JW}}(\mathrm{x} ; \mathrm{n})=(\alpha-\mathrm{c}(\mathrm{x})) /\left[\beta+2 \lambda(\mu(\mathrm{x}))^{2}\right]$, is independent of n. Moreover, although the function $\mathrm{q}^{\mathrm{JW}}(\mathrm{x} ; \mathrm{n})$ shifts down as $\mathrm{n}$ increases, now the function $\mathrm{x}^{\mathrm{JW}}(\mathrm{q} ; \mathrm{n})$ shifts 
to the right as $\mathrm{n}$ increases, so that the $\mathrm{x}$-value at which they cross is the same for all $\mathrm{n} ;{ }^{34}$ that is, $\hat{\mathrm{x}}^{\mathrm{JW}}(\mathrm{n})=$ $\hat{\mathrm{X}}^{\mathrm{JW}}(1)=\hat{\mathrm{x}}^{\mathrm{W}}$. This further implies that, at the welfare-maximizing solution, the expected harm is the same, regardless of the number of firms, since $M=Q^{J W}(x ; n) \mu\left(\hat{x}^{W}\right)$. Thus, if there is any fixed cost associated with entering the industry, the welfare-maximizing number of firms would be 1 ; it would be better to produce the optimal aggregate industry output at a single firm. Recall that with independent harms, as $n$ increased each firm took less care and produced less output, but welfare improved because total output increased and the risks were better-diversified. In the joint cumulative harm model, additional firms do not provide any benefit in terms of either increased output or the diversification of risks, since the level of care, the total output, and the expected harm are the same, regardless of $n$.

\subsubsection{Care and Output under Strict Liability}

Under strict liability, the consumer expects to be fully-compensated for any harm she incurs. Thus (as in the case of multiple independent risks), she simply chooses her consumption of good $\mathrm{i}$, $\mathrm{q}_{\mathrm{i}}$, so as to maximize her utility $\mathrm{u}\left(\mathrm{q}_{1}, \mathrm{q}_{2}, \ldots, \mathrm{q}_{\mathrm{n}}\right)$, resulting in the inverse demand curve for good $\mathrm{i}: \mathrm{p}_{\mathrm{i}}\left(\mathrm{q}_{1}, \mathrm{q}_{2}, \ldots, \mathrm{q}_{\mathrm{n}}\right)$ $=\alpha-\beta Q$. Profits for firm i now depend not only on the output and care levels of all firms, which generates the total expected harm of $\lambda \mathrm{M}^{2}$, but also on how the liability for this total expected harm is allocated across the $\mathrm{n}$ firms that contribute to it. A natural approach would be to allocate the liability across firms based on their "market share" of contribution to the harm. ${ }^{35}$ For instance, if each unit of good $i$ generates exposure in the amount $\mu\left(x_{i}\right)$, then the total exposure is $M=\Sigma_{i} \mu\left(x_{i}\right) q_{i}$. and firm i's contribution to the total exposure is $\mu\left(\mathrm{x}_{\mathrm{i}}\right) \mathrm{q}_{\mathrm{i}}$. Then firm i's share of the liability for the total expected harm of $\lambda \mathrm{M}^{2}$ would be the ratio $\mu\left(\mathrm{x}_{\mathrm{i}}\right) \mathrm{q}_{\mathrm{i}} / \mathrm{M}$.

However, it turns out that this will generate insufficient care (for a given output level and number of firms). This should not be surprising since now firm i's level of care is a public good that reduces the

${ }^{34}$ See Appendix $\mathrm{C}$ for the verification of this claim.

${ }^{35}$ While the sources of harms might be traceable to individual producers, we have adopted the market share approach since it is the joint action of the industry which produces harm in this portion of the analysis. 
expected liability payments for its rival firms, and firm i will not consider these positive externalities to the other firms when it chooses its level of care (details are provided in the Appendix). A simple adjustment to the strict liability regime can induce noncooperative firms to provide the socially-optimal level of care for a given output level. Rather than making firm i responsible for the share $\mu\left(x_{i}\right) q_{i} / M$ of the total harm, it is made liable for the share $[2 n /(n+1)] \mu\left(x_{i}\right) q_{i} / M$ of the total harm. Since this adjusted share is always greater than 1 but less than 2, the sum of all firms' expected liability payments will exceed the expected harm whenever $n \geq 2$. Provided the excess liability payments are collected by the state, consumer behavior will not be affected by this adjustment. As shown below, this adjustment still imposes less liability-related cost on the firm than the consumer would impose via the market under no liability.

In what follows, we will use the superscript JSL (not joint and several liability!) to indicate the case with joint cumulative harm and this modified version of strict liability, again suppressing the payoff function's dependence on other firms' output and care levels. Firm i's profits, denoted $\Pi_{i}^{\mathrm{JSL}}\left(\mathrm{x}_{\mathrm{i}}, \mathrm{q}_{\mathrm{i}} ; \mathrm{n}\right)$, are given by:

$$
\Pi_{i}^{\mathrm{JSL}}\left(\mathrm{x}_{\mathrm{i}}, \mathrm{q}_{\mathrm{i}} ; \mathrm{n}\right)=(\alpha-\beta Q) \mathrm{q}_{\mathrm{i}}-(2 \mathrm{n} /(\mathrm{n}+1)) \lambda \mu\left(\mathrm{x}_{\mathrm{i}}\right) \mathrm{q}_{\mathrm{i}} \mathrm{M}-\mathrm{c}\left(\mathrm{x}_{\mathrm{i}}\right) \mathrm{q}_{\mathrm{i}} .
$$

We differentiate this expression with respect to $x_{i}$ and $q_{i}$, and then use symmetry to derive the following set of equations that characterize the symmetric equilibrium care and output levels (see Appendix $\mathrm{C}$ for details).

$$
\begin{aligned}
& -\lambda 2 n \mu(x) \mu^{\prime}(x) q^{2}-c^{\prime}(x) q=0 \\
& \alpha-(n+1) \beta q-\lambda 2 n(\mu(x))^{2} q-c(x)=0 .
\end{aligned}
$$

Equation (15) now coincides with equation (13), so that $\mathrm{x}^{\mathrm{JSL}}(\mathrm{q} ; \mathrm{n})=\mathrm{x}^{\mathrm{JW}}(\mathrm{q} ; \mathrm{n})$ for all $\mathrm{q}$ and $\mathrm{n}$; equation (16) implies that $\mathrm{q}^{\mathrm{JSL}}(\mathrm{x} ; \mathrm{n})=(\alpha-\mathrm{c}(\mathrm{x})) /\left[(\mathrm{n}+1) \beta+2 \lambda \mathrm{n}(\mu(\mathrm{x}))^{2}\right]<\mathrm{q}^{\mathrm{JW}}(\mathrm{x} ; \mathrm{n})=(\alpha-\mathrm{c}(\mathrm{x})) / \mathrm{n}\left[\beta+2 \lambda(\mu(\mathrm{x}))^{2}\right]$. Adjusting the market share strict liability rule by the multiplier $2 n /(n+1)$ is, again, not sufficient to solve 
the entire problem of inducing socially-optimal care and output. ${ }^{36}$ Nevertheless, it restores the resiliency of the strict liability rule, since market interventions by an antitrust or regulatory authority that are designed to move output in a welfare-enhancing manner will be accompanied by the movement of the equilibrium care level along the adjusted strict liability/socially-optimal path.

\subsubsection{Care and Output under No Liability}

Under no liability, the consumer expects to bear any harm associated with consuming the $n$ goods; thus, she chooses her consumption $\mathrm{q}$ to maximize $\mathrm{U}\left(\mathrm{q}_{1}, \mathrm{q}_{2}, \ldots, \mathrm{q}_{\mathrm{n}} ; \mathrm{x}_{1}, \mathrm{x}_{2}, \ldots, \mathrm{x}_{\mathrm{n}}\right)=\alpha \Sigma_{\mathrm{i}} \mathrm{q}_{\mathrm{i}}-(\beta / 2)\left(\Sigma_{\mathrm{i}} \mathrm{q}_{\mathrm{i}}\right)^{2}$ $-\lambda \mathrm{M}^{2}+\mathrm{I}-\Sigma_{\mathrm{i}} \mathrm{p}_{\mathrm{i}} \mathrm{q}_{\mathrm{i}}$, where $\mathrm{M}=\Sigma_{\mathrm{i}} \mu\left(\mathrm{x}_{\mathrm{i}}\right) \mathrm{q}_{\mathrm{i}}$. This results in the inverse demand curve for good $\mathrm{i}: \mathrm{p}_{\mathrm{i}}\left(\mathrm{q}_{1}, \mathrm{q}_{2}, \ldots\right.$, $\left.\mathrm{q}_{\mathrm{n}} ; \mathrm{x}_{1}, \mathrm{x}_{2}, \ldots, \mathrm{x}_{\mathrm{n}}\right)=\alpha-\beta \mathrm{Q}-2 \lambda \mathrm{M} \mu\left(\mathrm{x}_{\mathrm{i}}\right)$. In what follows, we will use the superscript JNL to indicate the case with joint cumulative harm and no liability, again suppressing the payoff function's dependence on other firms' output and care levels. Firm i's profits under no liability are given by:

$$
\Pi_{\mathrm{i}}^{\mathrm{JNL}}\left(\mathrm{x}_{\mathrm{i}}, \mathrm{q}_{\mathrm{i}} ; \mathrm{n}\right)=\left(\alpha-\beta \mathrm{Q}-2 \lambda \mathrm{M} \mu\left(\mathrm{x}_{\mathrm{i}}\right)\right) \mathrm{q}_{\mathrm{i}}-\mathrm{c}\left(\mathrm{x}_{\mathrm{i}}\right) \mathrm{q}_{\mathrm{i}} .
$$

Again, we differentiate firm i's profit function with respect to $x_{i}$ and $q_{i}$ (see Appendix $C$ for the details) and then invoke symmetry to obtain a system of equations that characterizes the symmetric equilibrium levels of care and output:

$$
\begin{aligned}
& -2 \lambda(\mathrm{n}+1) \mu(\mathrm{x}) \mu^{\prime}(\mathrm{x}) \mathrm{q}^{2}-\mathrm{c}^{\prime}(\mathrm{x}) \mathrm{q}=0 \\
& \alpha-(\mathrm{n}+1) \beta \mathrm{q}-2 \lambda(\mathrm{n}+1)(\mu(\mathrm{x}))^{2} \mathrm{q}-\mathrm{c}(\mathrm{x})=0 .
\end{aligned}
$$

Simultaneous solution of equations (17) and (18) yields the symmetric Nash equilibrium combination of care and output, denoted $\hat{\mathrm{x}}^{\mathrm{JNL}}(\mathrm{n})$ and $\hat{\mathrm{q}}^{\mathrm{JNL}}(\mathrm{n})$, respectively.

Again, we consider each equation separately. Equation (17) defines implicitly the equilibrium care level for any given $\mathrm{q}$ and $\mathrm{n}$, which is denoted $\mathrm{x}^{\mathrm{JNL}}(\mathrm{q} ; \mathrm{n})$, while equation $(18)$ can be solved for the equilibrium output level for any given $x$ and $n, q^{\mathrm{JNL}}(\mathrm{x} ; \mathrm{n})=(\alpha-\mathrm{c}(\mathrm{x})) /(\mathrm{n}+1)\left[\beta+2 \lambda(\mu(\mathrm{x}))^{2}\right]$. Equations

${ }^{36}$ Since $\mathrm{x}^{\mathrm{JSL}}(\mathrm{q} ; \mathrm{n})=\mathrm{x}^{\mathrm{JW}}(\mathrm{q} ; \mathrm{n})$ and $\mathrm{q}^{\mathrm{JSL}}(\mathrm{x} ; \mathrm{n})<\mathrm{q}^{\mathrm{JW}}(\mathrm{x} ; \mathrm{n})$, the equilibrium values of aggregate industry output and care are both too low; that is, $\hat{\mathrm{x}}^{\mathrm{JSL}}(\mathrm{n})<\hat{\mathrm{x}}^{\mathrm{JW}}(\mathrm{n})$ and $\mathrm{n} \hat{\mathrm{q}}^{\mathrm{JSL}}(\mathrm{n})<\mathrm{n} \hat{\mathrm{q}}^{\mathrm{JW}}(\mathrm{n})$ ), although these values converge in the limit as $n$ goes to infinity. 
(13), (15), and (17) can be compared to yield the following ordering: $x^{\mathrm{JNL}}(\mathrm{q} ; n)>x^{\mathrm{JSL}}(\mathrm{q} ; n)=x^{\mathrm{JW}}(\mathrm{q} ; n)$; that is, for any given values of $\mathrm{q}$ and $\mathrm{n}$, no liability results in excessive care, while adjusted strict liability results in socially-optimal care. Direct comparison of the equilibrium output levels provides the following ordering: $\mathrm{q}^{\mathrm{JNL}}(\mathrm{x} ; \mathrm{n})<\mathrm{q}^{\mathrm{JSL}}(\mathrm{x} ; \mathrm{n})<\mathrm{q}^{\mathrm{JW}}(\mathrm{x} ; \mathrm{n})$; that is, no liability results in less output than does strict liability, but both are insufficient as compared to the socially-optimal output level.

Finally, we note that, although the function $\mathrm{q}^{\mathrm{JNL}}(\mathrm{x} ; \mathrm{n})$ shifts down as $\mathrm{n}$ increases, while the function $\mathrm{x}^{\mathrm{JNL}}(\mathrm{q} ; \mathrm{n})$ shifts to the right in Figure 2 as $\mathrm{n}$ increases, the $\mathrm{x}$-value at which they cross is the same for all ${ }^{37}$ that is, $\hat{\mathrm{x}}^{\mathrm{JNL}}(\mathrm{n})=\hat{\mathrm{x}}^{\mathrm{JNL}}(1)$; moreover this crossing is at the socially-optimal level of care, $\hat{\mathrm{x}}^{\mathrm{JW}}$. This further allows us to conclude that $\hat{\mathrm{q}}^{\mathrm{JNL}}(\mathrm{n})=(\mathrm{n} /(\mathrm{n}+1)) \hat{\mathrm{q}}^{\mathrm{JW}}(\mathrm{n})$. As in the monopoly case, the regime of no liability induces the socially-optimal level of care for a given n, but too little output. ${ }^{38}$ Although the fact that the socially-optimal level of care is achieved would appear to be a desirable attribute of the no liability regime, if intervention by the antitrust authorities or a regulatory agency were to increase output toward the socially-optimal level, this would result in the equilibrium care level becoming increasingly excessive.

\subsubsection{Stability of the Negligence Regime}

We can also reconsider the stability of the negligence regime under joint cumulative harm. A plausible negligence regime in the case of joint cumulative harm would set the due care standard at $\hat{\mathrm{x}}^{\mathrm{W}}$ (which is the same as $\hat{\mathrm{x}}^{\mathrm{JW}}(\mathrm{n})$ for all $\mathrm{n}$ ) and would relieve the firm of liability if it met or exceeded this standard. In what follows, we will assume that the firm's liability, should it fail to comply with the standard, is given by the adjusted strict liability regime. Suppose that all other firms comply with the due care standard (which is the symmetric equilibrium care level under no liability, $\hat{\mathrm{x}}^{\mathrm{JN}}(\mathrm{n})$ ), and that they produce the associated symmetric equilibrium output level, $\hat{\mathrm{q}}^{\mathrm{JNL}}(\mathrm{n})$. The question we pose is whether firm i would prefer to deviate to a lower level of care (and thus face the adjusted strict liability regime)

${ }^{37}$ See Appendix $\mathrm{C}$ for the verification of this claim.

38 Again, as $\mathrm{n}$ goes to infinity, aggregate industry output $\mathrm{nq}{ }^{\mathrm{NL}}(\mathrm{n})$ converges to the socially-optimal level $\left.n \hat{q}^{\mathrm{JW}}(\mathrm{n})\right)$, although fixed costs would tend to limit entry to a finite number of firms. 
and a correspondingly optimal deviation output. Thus, we are comparing the payoff functions $\Pi_{i}^{\mathrm{JSL}}\left(\mathrm{x}_{\mathrm{i}}, \mathrm{q}_{\mathrm{i}}\right.$; n) and $\Pi_{i}^{\mathrm{NL}}\left(\mathrm{x}_{\mathrm{i}}, \mathrm{q}_{\mathrm{i}} ; n\right)$, where all other firms' strategies are fixed at the symmetric equilibrium levels under no liability. Notice that these payoff functions differ only in terms of the expected liability payments, which are $(2 \mathrm{n} /(\mathrm{n}+1)) \lambda \mu\left(\mathrm{x}_{\mathrm{i}}\right) \mathrm{q}_{\mathrm{i}} \mathrm{M}$ under adjusted strict liability, and $2 \lambda \mathrm{M} \mu\left(\mathrm{x}_{\mathrm{i}}\right) \mathrm{q}_{\mathrm{i}}$ under no liability. Since $\mathrm{n} /(\mathrm{n}+1)<1$, the firm prefers the payoff function under adjusted strict liability to that under no liability for all $\left(\mathrm{x}_{\mathrm{i}}, \mathrm{q}_{\mathrm{i}}\right)$. Thus, firm $\mathrm{i}$ could cut its level of care marginally (making it clear to consumers that the firm will be liable so they can adjust their willingness-to-pay upwards), keep its output level the same, and enjoy a discrete upward jump in profits. Of course, the firm's best deviation will involve a substantial cut in care and a substantially different output level as well. Consequently, the negligence regime specified above is not stable in the sense that it is not a Nash equilibrium for all of the firms to comply with it; each will have a unilateral incentive to defect to noncompliance and face lower expected liability costs under adjusted strict liability. ${ }^{39}$

\section{Summary and Conclusions}

We began this paper by noting that, in a modern society, different institutions/agencies/actors are assigned and pursue different objectives by means of different instruments, and that these different objectives and instruments might interact or even come into conflict (such as our example of antitrust and market performance considerations versus encouraging and enhancing intellectual property rights). The interaction between market performance (in terms of output and price levels) and product performance (in terms of a firm's incentives to make appropriate investments in care) appears not to occur in the traditional law and economics analysis of torts. We showed that this is really a result of a particular assumption about how expected harm is related to the level of product use (i.e., that it is proportional). When we allow for a broader description of how harm accrues to a victim, due to the consumption of, or

39 This instability also prevails if noncompliance with the due care standard leads to the pure market-share liability rule rather than the adjusted one, since the nature of the adjustment was to raise the firm's expected liability payments. 
exposure to, a product, this separation no longer holds.

It is tempting (and fairly classical) to argue for a policy that jointly solves both the market performance and product performance problems at the same time. Implementing such a policy, however, is likely to significantly raise the cost of administering regulatory processes and to simultaneously significantly raise the costs of adjudicating legal cases that will arise under such a grand scheme. For example, judges considering a suit brought in tort would now also need to understand and apply law associated with antitrust concerns. Instead we proposed the promulgation of "resilient" policy rules when they can be found. In the context of allowing for both market performance and product performance considerations, we showed that under cumulative expected harm strict liability is strictly sociallypreferred $^{40}$ to no liability (and to negligence) as a liability regime; strict liability and market performance enhancements jointly move the market towards socially-efficient levels of price, output, and care. Moreover, negligence is unstable, and no liability can actually lead to conflict with market performance objectives, as enhancement of market performance will result in excessively high levels of care being induced. $^{41}$

Entry by firms into the market might be expected to help, and under some conditions, it can cause the adjustment paths for the alternative regimes (and for the socially efficient path) to become closer to each other (though their ordering is maintained). Specifically, using a standard (Cournot) n-firm oligopoly we explored two alternative ways that cumulative expected harm could arise when there are multiple firms in the product market. When harms arise independently (e.g., alternative sources of tainted food) we find that increases in competition may help reduce inefficiencies in the market equilibrium. However, when harms arise in a joint manner (for example, bioaccumulation of a specific toxin, such as mercury poisoning, arising from eating fish from a number of producers), then the socially efficient

\footnotetext{
${ }^{40}$ As observed earlier, this statement is globally true for the quadratic expected harm model and locally true for the more general model in Appendix B. level is minimal.

${ }^{41}$ When the level of care is unobservable and the regime is no liability, consumers should expect that the care
} 
number of firms is one, so entry reduces rather than raises efficiency.

Thus, one interpretation of these latter results is that the independent harms case may be best resolved via reliance on strict liability, in conjunction with whatever market performance measures are taken by those authorities. However, in the joint-harm case, stronger interference is called for, as entry is not a good solution. Hence, market performance may be best enhanced via entry restriction and price regulation, again in conjunction with strict liability with respect to harm.

Therefore, in general, whether expected harm arises in a cumulative or proportional manner, we argue for employing strict liability to address product-generated torts. This is because strict liability is the only resilient policy when harm is cumulative, and the traditional analysis has made it clear that strict liability induces the optimal choice of care when expected harm is proportional to use. 


\section{Appendix A: Monopoly Results for the Quadratic Harm Model}

In what follows we assume that $\mathrm{h}(\bullet)$ and $\mathrm{c}(\bullet)$ are twice continuously differentiable functions.

This implies that the welfare function and all profit functions are twice continuously differentiable. In the text we assumed that $h(x) q^{2}$ is convex in $(x, q)$; this implies that $h^{\prime \prime}(x) h(x)-2\left(h^{\prime}(x)\right)^{2} \geq 0$ for all $x$.

Welfare Maximization. The social welfare maximizing planner chooses $\mathrm{q}$ and $\mathrm{x}$ to maximize:

$$
W(x, q)=\alpha q-(\beta / 2) q^{2}-h(x) q^{2}-c(x) q .
$$

While $\mathrm{W}(\mathrm{x}, \mathrm{q})$ is not globally-concave, it is still very well-behaved. We first prove that any welfaremaximizing solution is interior; that is, it is socially optimal to exert some care and produce some output. To see this, first notice that $\mathrm{W}(\mathrm{x}, 0)=0$ for all $\mathrm{x}$. Moreover (see equation A. 2 below), $\mathrm{W}_{\mathrm{q}}(\mathrm{x}, \mathrm{q}) \leq 0$ for all $\mathrm{q} \geq 0$ if $\mathrm{x} \geq \overline{\mathrm{x}}$ such that $\alpha=\mathrm{c}(\overline{\mathrm{x}})$. Thus, $\mathrm{W}(\mathrm{x}, \mathrm{q}) \leq 0$ for all $(\mathrm{x}, \mathrm{q})$ such that $\mathrm{x} \geq \overline{\mathrm{x}}$ and $\mathrm{q} \geq 0$. However, since $\mathrm{W}_{\mathrm{q}}(\mathrm{x}, 0)>0$ for $\mathrm{x} \in[0, \overline{\mathrm{x}})$, there exist values of $(\mathrm{x}, \mathrm{q})$ such that $\mathrm{x} \in[0, \overline{\mathrm{x}})$ and $\mathrm{q}>0$ for which $\mathrm{W}(\mathrm{x}$, $q)>0$. Thus, any welfare-maximizing solution must be one of these $(x, q)$ combinations. To see that $x=$ 0 cannot be part of a welfare-maximizing solution, note that (see equation A.1 below) $\mathrm{W}_{\mathrm{x}}(0, \mathrm{q})>0$ for all $\mathrm{q}>0$ since $\mathrm{h}^{\prime}(0)<0$ and $\mathrm{c}^{\prime}(0)=0$. Thus, any welfare-maximizing solution must involve $(\mathrm{x}, \mathrm{q})$ such that $\mathrm{x} \in(0, \overline{\mathrm{x}})$ and $\mathrm{q}>0$. conditions:

Let $\left(\hat{\mathrm{x}}^{\mathrm{W}}, \hat{\mathrm{q}}^{\mathrm{W}}\right)$ denote a welfare-maximizing solution. Then $\left(\hat{\mathrm{x}}^{\mathrm{W}}, \hat{\mathrm{q}}^{\mathrm{W}}\right)$ must satisfy the first-order

$$
\begin{aligned}
& \mathrm{W}_{\mathrm{x}}=-\mathrm{h}^{\prime}(\mathrm{x}) \mathrm{q}^{2}-\mathrm{c}^{\prime}(\mathrm{x}) \mathrm{q}=0 ; \\
& \mathrm{W}_{\mathrm{q}}=\alpha-\beta \mathrm{q}-2 \mathrm{~h}(\mathrm{x}) \mathrm{q}-\mathrm{c}(\mathrm{x})=0 .
\end{aligned}
$$

We now argue that any interior solution to the first-order conditions (A.1)-(A.2) must be a strict local maximum. This follows from the fact that the matrix of second derivatives is negative definite at any interior solution to (A.1)-(A.2). To see this, we verify that $\mathrm{W}_{\mathrm{xx}}<0, \mathrm{~W}_{\mathrm{qq}}<0$, and $\mathrm{W}_{\mathrm{xx}} \mathrm{W}_{\mathrm{qq}}-\left(\mathrm{W}_{\mathrm{xq}}\right)^{2}>0$ at any interior solution to (A.1)-(A.2). The relevant second derivatives are:

$$
\begin{aligned}
& \mathrm{W}_{\mathrm{xx}}=-\mathrm{h}^{\prime \prime}(\mathrm{x}) \mathrm{q}^{2}-\mathrm{c}^{\prime \prime}(\mathrm{x}) \mathrm{q}<0 ; \\
& \mathrm{W}_{\mathrm{xq}}=-2 \mathrm{~h}^{\prime}(\mathrm{x}) \mathrm{q}-\mathrm{c}^{\prime}(\mathrm{x}) ; \\
& \mathrm{W}_{\mathrm{qq}}=-\beta-2 \mathrm{~h}(\mathrm{x})<0 .
\end{aligned}
$$

Notice that (for $\mathrm{q}>0$ ) equation (A.1) implies that $\mathrm{W}_{\mathrm{xq}}=-\mathrm{h}^{\prime}(\mathrm{x}) \mathrm{q}+(1 / \mathrm{q}) \mathrm{W}_{\mathrm{x}}=-\mathrm{h}^{\prime}(\mathrm{x}) \mathrm{q}>0$ everywhere along the solution to (A.1). Evaluating the expression $\mathrm{W}_{\mathrm{xx}} \mathrm{W}_{\mathrm{qq}}-\left(\mathrm{W}_{\mathrm{xq}}\right)^{2}$ yields:

$$
\left(h^{\prime \prime}(x) q^{2}+c^{\prime \prime}(x) q\right)(\beta+2 h(x))-\left(h^{\prime}(x) q\right)^{2}>\left[2 h^{\prime \prime}(x) h(x)-\left(h^{\prime}(x)\right)^{2}\right] q^{2}>0,
$$

where the first inequality follows from the fact that $\mathrm{h}^{\prime \prime}(\mathrm{x}), \mathrm{c}^{\prime \prime}(\mathrm{x}), \beta$, and $\mathrm{q}$ are positive, and the second inequality follows from the convexity of expected harm in $(x, q)$. Thus, any interior solution to (A.1)(A.2) is a strict local maximum.

Equation (A.1) defines implicitly the socially-optimal care level for any given level of output, denoted $\mathrm{x}^{\mathrm{W}}(\mathrm{q})$; it is clear that $\mathrm{x}^{\mathrm{W}}(\mathrm{q})>0$ for all $\mathrm{q}>0$, and $\lim _{\mathrm{q} \rightarrow 0} \mathrm{x}^{\mathrm{W}}(\mathrm{q})=0$. Differentiating equation (A.1) with respect to $\mathrm{x}$ and $\mathrm{q}$ and collecting terms yields $\mathrm{dx}(\mathrm{q}) / \mathrm{dq}=\mathrm{W}_{\mathrm{xq}} /\left(-\mathrm{W}_{\mathrm{xx}}\right)$. The denominator is positive, while the numerator is also positive along $\mathrm{x}^{\mathrm{W}}(\mathrm{q})$ because equation (A.1) implies that $\mathrm{W}_{\mathrm{xq}}=-\mathrm{h}^{\prime}(\mathrm{x}) \mathrm{q}+$ $(1 / q) W_{x}=-h^{\prime}(x) q>0$, since with $q$ being treated as a parameter, $W_{x}=0$ for each value of $q$. Thus, $x^{W}(q)$ is strictly increasing in $\mathrm{q}$. 
Equation (A.2) defines the socially-optimal output level for any given level of output, denoted $\mathrm{q}^{\mathrm{W}}(\mathrm{x})$, with $\mathrm{q}^{\mathrm{W}}(\mathrm{x})=(\alpha-\mathrm{c}(\mathrm{x})) /(\beta+2 \mathrm{~h}(\mathrm{x}))>0$ for $\mathrm{x}<\overline{\mathrm{x}}$ and $\mathrm{q}^{\mathrm{W}}(\overline{\mathrm{x}})=0$. Differentiating equation (A.2) with respect to $\mathrm{q}$ and $\mathrm{x}$ and collecting terms implies that $\mathrm{dq}^{\mathrm{W}}(\mathrm{x}) / \mathrm{dx}=\mathrm{W}_{\mathrm{qx}} /\left(-\mathrm{W}_{\mathrm{qq}}\right)$. While we don't know the sign of this in general, we know that $\mathrm{W}_{\mathrm{qx}}>0$ at $\left(\hat{\mathrm{x}}^{\mathrm{W}}, \hat{\mathrm{q}}^{\mathrm{W}}\right)$ (by the previous argument using equation (A.1)). Thus, $\mathrm{q}^{\mathrm{W}}(\mathrm{x})$ is strictly increasing in a neighborhood of $\left(\hat{\mathrm{x}}^{\mathrm{W}}, \hat{\mathrm{q}}^{\mathrm{W}}\right)$, where equations (A.1) and (A.2) are satisfied simultaneously.

In $(x, q)$ space, we are graphing the functions $q^{\mathrm{W}}(\mathrm{x})$ and the inverse of $\mathrm{x}^{\mathrm{W}}(\mathrm{q})$, denoted $\tilde{\mathrm{q}}^{\mathrm{W}}(\mathrm{x})$. Both of these are continuous functions. To see that $\tilde{q}^{\mathrm{W}}(\mathrm{x})$ crosses $\mathrm{q}^{\mathrm{W}}(\mathrm{x})$ "from below," first notice that $\tilde{\mathrm{q}}^{\mathrm{W}}(0)=0<\mathrm{q}^{\mathrm{W}}(0)$, but $\tilde{\mathrm{q}}^{\mathrm{W}}(\overline{\mathrm{x}})>0=\mathrm{q}^{\mathrm{W}}(\overline{\mathrm{x}})$; since both functions are continuous, they must cross at least once. To see that any crossing is "from below," note that $\mathrm{dq}^{\mathrm{w}}(\mathrm{x}) / \mathrm{dx}=1 / \mathrm{dx}{ }^{\mathrm{W}}(\mathrm{q}) / \mathrm{dq}=\left(-\mathrm{W}_{\mathrm{xx}}\right) / \mathrm{W}_{\mathrm{xq}}>\mathrm{W}_{\mathrm{xq}} /(-$ $\left.\mathrm{W}_{\mathrm{qq}}\right)=\mathrm{dq}^{\mathrm{W}}(\mathrm{x}) / \mathrm{dx}$, where the inequality follows from the fact that $\mathrm{W}_{\mathrm{qq}} \mathrm{W}_{\mathrm{xx}}-\left(\mathrm{W}_{\mathrm{xq}}\right)^{2}>0$ at $\left(\hat{\mathrm{x}}^{\mathrm{W}}, \hat{\mathrm{q}}^{\mathrm{W}}\right)$.

Finally, we can conclude that $\left(\hat{\mathrm{x}}^{\mathrm{W}}, \hat{\mathrm{q}}^{\mathrm{W}}\right)$ is the unique interior solution to (A.1)-(A.2). For if there were another interior solution, then it would also have to be a strict local maximum; that is, the function $\tilde{\mathrm{q}}^{\mathrm{W}}(\mathrm{x})$ would have to cross the function $\mathrm{q}^{\mathrm{W}}(\mathrm{x})$ again "from below" at, say, $\hat{\mathrm{x}}^{\prime}$. But then there would have to be yet another value of $x$ (between $\hat{x}^{\mathrm{W}}$ and $\hat{\mathrm{x}}^{\prime}$ ) at which the function $\tilde{\mathrm{q}}^{\mathrm{W}}(\mathrm{x})$ would have to cross the function $\mathrm{q}^{\mathrm{W}}(\mathrm{x})$ "from above." But such a location involves an (x, q)-pair that would also satisfy (A.1)(A.2) and yet it could not be a strict local maximum, which is a contradiction. Thus, the welfaremaximizing solution $\left(\hat{\mathrm{x}}^{\mathrm{W}}, \hat{\mathrm{q}}^{\mathrm{W}}\right)$ is the unique interior solution to the first-order conditions (A.1)-(A.2).

Profit-Maximization under Strict Liability. Under strict liability, the firm's profit is given by:

$$
\Pi^{\mathrm{SL}}(\mathrm{x}, \mathrm{q})=(\alpha-\beta \mathrm{q}) \mathrm{q}-\mathrm{h}(\mathrm{x}) \mathrm{q}^{2}-\mathrm{c}(\mathrm{x}) \mathrm{q} .
$$

While $\Pi^{\mathrm{SL}}(\mathrm{x}, \mathrm{q})$ is not globally-concave, it is still very well-behaved. It can be shown (using an argument analogous to that used in the case of welfare-maximization) that any profit-maximizing solution is interior; that is, it must involve $(x, q)$ such that $x \in(0, \bar{x})$ and $q>0$. Let $\left(\hat{x}^{\mathrm{SL}}, \hat{\mathrm{q}}^{\mathrm{SL}}\right)$ denote a profitmaximizing solution under strict liability. Then $\left(\hat{\mathrm{x}}^{\mathrm{SL}}, \hat{\mathrm{q}}^{\mathrm{SL}}\right)$ must satisfy the first-order conditions:

$$
\begin{aligned}
& \Pi_{\mathrm{x}}^{\mathrm{SL}}=-\mathrm{h}^{\prime}(\mathrm{x}) \mathrm{q}^{2}-\mathrm{c}^{\prime}(\mathrm{x}) \mathrm{q}=0 \\
& \Pi_{\mathrm{q}}^{\mathrm{SL}}=\alpha-2 \beta \mathrm{q}-2 \mathrm{~h}(\mathrm{x}) \mathrm{q}-\mathrm{c}(\mathrm{x})=0 .
\end{aligned}
$$

To see that any interior solution to the first-order conditions (A.3)-(A.4) must be a strict local maximum, we need only verify that the matrix of second derivatives is negative definite at any interior solution to (A.3)-(A.4). The relevant second derivatives are:

$$
\begin{aligned}
& \Pi_{\mathrm{xx}}^{\mathrm{SL}}=-\mathrm{h}^{\prime \prime}(\mathrm{x}) \mathrm{q}^{2}-\mathrm{c}^{\prime \prime}(\mathrm{x}) \mathrm{q}<0 ; \\
& \Pi_{\mathrm{xq}}^{\mathrm{SL}}=-2 \mathrm{~h}^{\prime}(\mathrm{x}) \mathrm{q}-\mathrm{c}^{\prime}(\mathrm{x}) ; \\
& \Pi_{\mathrm{qq}}^{\mathrm{SL}}=-2 \beta-2 \mathrm{~h}(\mathrm{x})<0 .
\end{aligned}
$$

Notice that (for $q>0$ ) equation (A.3) implies that $\Pi_{x q}^{S L}=-h^{\prime}(x) q+(1 / q) \Pi_{x}^{S L}=-h^{\prime}(x) q>0$ everywhere along the solution to (A.3). Evaluating the expression $\Pi_{\mathrm{xx}}^{\mathrm{SL}} \Pi_{\mathrm{qq}}^{\mathrm{SL}}-\left(\Pi_{\mathrm{xq}}^{\mathrm{SL}}\right)^{2}$ yields:

$$
\left(h^{\prime \prime}(x) q^{2}+c^{\prime \prime}(x) q\right)(2 \beta+2 h(x))-\left(h^{\prime}(x) q\right)^{2}>\left[2 h^{\prime \prime}(x) h(x)-\left(h^{\prime}(x)\right)^{2}\right] q^{2}>0,
$$

where the first inequality follows from the fact that $\mathrm{h}^{\prime \prime}(\mathrm{x}), \mathrm{c}^{\prime \prime}(\mathrm{x}), \beta$, and $\mathrm{q}$ are positive, and the second inequality follows from the convexity of expected harm in (x, q). Thus, any interior solution to (A.3)(A.4) is a strict local maximum. 
Equation (A.3) defines implicitly the profit-maximizing care level for any given level of output, denoted $x^{\mathrm{SL}}(\mathrm{q})$; it is clear that $\mathrm{x}^{\mathrm{SL}}(\mathrm{q})>0$ for all $\mathrm{q}>0$, and $\lim _{\mathrm{q} \rightarrow 0} \mathrm{x}^{\mathrm{SL}}(\mathrm{q})=0$. Comparing equations (A.1) and (A.3), it is clear that $\mathrm{x}^{\mathrm{SL}}(\mathrm{q})=\mathrm{x}^{\mathrm{w}}(\mathrm{q})$ for all $\mathrm{q}$. Differentiating equation (A.3) with respect to $\mathrm{x}$ and $\mathrm{q}$ and collecting terms implies that, along $x^{\mathrm{SL}}(\mathrm{q}), \mathrm{dx}^{\mathrm{SL}}(\mathrm{q}) / \mathrm{dq}=\Pi_{\mathrm{xq}}^{\mathrm{SL}} /\left(-\Pi_{\mathrm{xx}}^{\mathrm{SL}}\right)$. The denominator is positive, while the numerator is also positive along $x^{\mathrm{SL}}(\mathrm{q})$, since equation $(\mathrm{A} .3)$ implies that $\Pi_{\mathrm{xq}}^{\mathrm{SL}}=-\mathrm{h}^{\prime}(\mathrm{x}) \mathrm{q}+$ $(1 / \mathrm{q}) \Pi_{\mathrm{x}}^{\mathrm{SL}}=-\mathrm{h}^{\prime}(\mathrm{x}) \mathrm{q}>0$, since with $\mathrm{q}$ being treated as a parameter, $\Pi_{\mathrm{x}}^{\mathrm{SL}}=0$ for each value of $\mathrm{q}$. Thus, $\mathrm{x}^{\mathrm{SL}}(\mathrm{q})$ is strictly increasing in $\mathrm{q}$.

Solving equation (A.4) for the profit-maximizing output level for any given level of care, denoted $\mathrm{q}^{\mathrm{SL}}(\mathrm{x})$, we find that $\mathrm{q}^{\mathrm{SL}}(\mathrm{x})=(\alpha-\mathrm{c}(\mathrm{x})) / 2(\beta+\mathrm{h}(\mathrm{x}))>0$ for $\mathrm{x}<\overline{\mathrm{x}}$ and $\mathrm{q}^{\mathrm{SL}}(\overline{\mathrm{x}})=0$; moreover, for $\mathrm{x}<\overline{\mathrm{x}}$, $\mathrm{q}^{\mathrm{SL}}(\mathrm{x})$ $<\mathrm{q}^{\mathrm{W}}(\mathrm{x})=(\alpha-\mathrm{c}(\mathrm{x})) /(\beta+2 \mathrm{~h}(\mathrm{x}))$. Differentiating equation (A.4) with respect to $\mathrm{q}$ and $\mathrm{x}$ and collecting terms implies that $\mathrm{dq}^{\mathrm{SL}}(\mathrm{x}) / \mathrm{dx}=\Pi_{\mathrm{qx}}^{\mathrm{SL}} /\left(-\Pi_{\mathrm{qq}}^{\mathrm{SL}}\right)$. While we don't know the sign of this in general, we know that $\Pi_{\mathrm{qx}}^{\mathrm{SL}}>0$ at $\left(\hat{\mathrm{x}}^{\mathrm{SL}}, \hat{\mathrm{q}}^{\mathrm{SL}}\right)$ (by the previous argument using equation (A.3)). Thus, $\mathrm{q}^{\mathrm{SL}}(\mathrm{x})$ is strictly increasing in a neighborhood of $\left(\hat{\mathrm{x}}^{\mathrm{SL}}, \hat{\mathrm{q}}^{\mathrm{SL}}\right)$, where equations (A.3) and (A.4) are satisfied simultaneously.

In $(x, q)$ space, we are graphing the functions $\mathrm{q}^{\mathrm{SL}}(\mathrm{x})$ and the inverse of $\mathrm{x}^{\mathrm{SL}}(\mathrm{q})$, denoted $\tilde{\mathrm{q}}^{\mathrm{SL}}(\mathrm{x})$. These are both continuous functions. To see that $\tilde{q}^{\mathrm{SL}}(\mathrm{x})$ crosses $\mathrm{q}^{\mathrm{SL}}(\mathrm{x})$ "from below," first notice that $\tilde{\mathrm{q}}^{\mathrm{SL}}(0)=0<\mathrm{q}^{\mathrm{SL}}(0)$, but $\tilde{\mathrm{q}}^{\mathrm{SL}}(\overline{\mathrm{x}})>0=\mathrm{q}^{\mathrm{SL}}(\overline{\mathrm{x}})$; since both functions are continuous, they must cross at least once. To see that any crossing is "from below," note that $\mathrm{dq} \tilde{q}^{\mathrm{SL}}(\mathrm{x}) / \mathrm{dx}=1 / \mathrm{dx}(\mathrm{qL}) / \mathrm{dq}=\left(-\Pi_{\mathrm{xx}}^{\mathrm{SL}}\right) / \Pi_{\mathrm{xq}}^{\mathrm{SL}}>\Pi_{\mathrm{xq}}^{\mathrm{SL}} /(-$ $\left.\Pi_{\mathrm{qq}}^{\mathrm{SL}}\right)=\mathrm{dq}^{\mathrm{SL}}(\mathrm{x}) / \mathrm{dx}$, where the inequality follows from the fact that $\Pi_{\mathrm{xx}}^{\mathrm{SL}} \Pi_{\mathrm{qq}}^{\mathrm{SL}}-\left(\Pi_{\mathrm{xq}}^{\mathrm{SL}}\right)^{2}>0$ at $\left(\hat{\mathrm{x}}^{\mathrm{SL}}, \hat{\mathrm{q}}^{\mathrm{SL}}\right)$.

We can conclude that $\left(\hat{\mathrm{x}}^{\mathrm{SL}}, \hat{\mathrm{q}}^{\mathrm{SL}}\right)$ is the unique interior solution to (A.3)-(A.4) using an argument similar to that used to establish the uniqueness of $\left(\hat{\mathrm{x}}^{\mathrm{W}}, \hat{\mathrm{q}}^{\mathrm{W}}\right)$. Finally, since $\mathrm{q}^{\mathrm{SL}}(\mathrm{x})>\mathrm{q}^{\mathrm{W}}(\mathrm{x})$ for all $\mathrm{x}$, while $\mathrm{x}^{\mathrm{SL}}(\mathrm{q})=\mathrm{x}^{\mathrm{W}}(\mathrm{q})$ for all $\mathrm{q}$, it is immediate that $\hat{\mathrm{x}}^{\mathrm{SL}}<\hat{\mathrm{x}}^{\mathrm{W}}$ and $\hat{\mathrm{q}}^{\mathrm{SL}}<\hat{\mathrm{q}}^{\mathrm{W}}$.

Profit-Maximization under No Liability. Finally, under no liability, the firm's profit is given by:

$$
\Pi^{N L}(x, q)=(\alpha-\beta q-2 h(x) q) q-c(x) q .
$$

While $\Pi^{\mathrm{NL}}(\mathrm{x}, \mathrm{q})$ is not globally-concave, it is still very well-behaved. It can be shown (using an argument analogous to that used in the case of welfare-maximization) that any profit-maximizing solution is interior; that is, it must involve $(x, q)$ such that $x \in(0, \bar{x})$ and $q>0$. Let $\left(\hat{x}^{N L}, \hat{q}^{N L}\right)$ denote a profitmaximizing solution under no liability. Then $\left(\hat{\mathrm{x}}^{\mathrm{NL}}, \hat{\mathrm{q}}^{\mathrm{NL}}\right)$ must satisfy the first-order conditions:

$$
\begin{aligned}
& \Pi_{\mathrm{x}}^{\mathrm{NL}}=-2 \mathrm{~h}^{\prime}(\mathrm{x}) \mathrm{q}^{2}-\mathrm{c}^{\prime}(\mathrm{x}) \mathrm{q}=0 \\
& \Pi_{\mathrm{q}}^{\mathrm{NL}}=\alpha-2 \beta \mathrm{q}-4 \mathrm{~h}(\mathrm{x}) \mathrm{q}-\mathrm{c}(\mathrm{x})=0
\end{aligned}
$$

To see that any interior solution to the first-order conditions (A.5)-(A.6) must be a strict local maximum, we need only verify that the matrix of second derivatives is negative definite at any interior solution to (A.5)-(A.6). The relevant second derivatives are:

$$
\begin{aligned}
& \Pi_{\mathrm{xx}}^{\mathrm{NL}}=-2 \mathrm{~h}^{\prime \prime}(\mathrm{x}) \mathrm{q}^{2}-\mathrm{c}^{\prime \prime}(\mathrm{x}) \mathrm{q}<0 ; \\
& \Pi_{\mathrm{xq}}^{\mathrm{NL}}=-4 \mathrm{~h}^{\prime}(\mathrm{x}) \mathrm{q}-\mathrm{c}^{\prime}(\mathrm{x}) ; \\
& \Pi_{\mathrm{qq}}^{\mathrm{NL}}=-2 \beta-4 \mathrm{~h}(\mathrm{x})<0 .
\end{aligned}
$$

Notice that (for $q>0$ ) equation (A.5) implies that $\Pi_{x q}^{N L}=-2 h^{\prime}(x) q+(1 / q) \Pi_{x}^{N L}=-2 h^{\prime}(x) q>0$ everywhere along the solution to (A.5). Evaluating the expression $\Pi_{\mathrm{qq}}^{\mathrm{NL}} \Pi_{\mathrm{xx}}^{\mathrm{NL}}-\left(\Pi_{\mathrm{xq}}^{\mathrm{NL}}\right)^{2}$ yields:

$$
\left(2 h^{\prime \prime}(x) q^{2}+c^{\prime \prime}(x) q\right)(2 \beta+4 h(x))-\left(2 h^{\prime}(x) q\right)^{2}>\left[8 h^{\prime \prime}(x) h(x)-4\left(h^{\prime}(x)\right)^{2}\right] q^{2}>0,
$$


where the first inequality follows from the fact that $\mathrm{h}^{\prime \prime}(\mathrm{x}), \mathrm{c}^{\prime \prime}(\mathrm{x}), \beta$, and $\mathrm{q}$ are positive, and the second inequality follows from the convexity of expected harm in (x, q). Thus, any interior solution to (A.5)(A.6) is a strict local maximum.

Equation (A.5) defines implicitly the profit-maximizing care level for any given level of output, denoted $x^{N L}(q)$; it is clear that $x^{N L}(q)>0$ for all $q>0$, and $\lim _{\mathrm{q} \rightarrow 0} x^{N L}(q)=0$. Differentiating equation (A.5) with respect to $x$ and $q$ and collecting terms implies that, along $x^{\mathrm{NL}}(\mathrm{q}), \mathrm{dx}{ }^{\mathrm{NL}}(\mathrm{q}) / \mathrm{dq}=\Pi_{\mathrm{xq}}^{\mathrm{NL}} /\left(-\Pi_{\mathrm{xx}}^{\mathrm{NL}}\right)$. The denominator is positive, while the numerator is also positive along $x^{\mathrm{NL}}(\mathrm{q})$ because equation (A5) implies that $\Pi_{\mathrm{xq}}^{\mathrm{NL}}=-2 \mathrm{~h}^{\prime}(\mathrm{x}) \mathrm{q}+(1 / \mathrm{q}) \Pi_{\mathrm{x}}^{\mathrm{NL}}=-2 \mathrm{~h}^{\prime}(\mathrm{x}) \mathrm{q}>0$, since with $\mathrm{q}$ being treated as a parameter, $\Pi_{\mathrm{x}}^{\mathrm{NL}}=0$ for each value of $q$. Thus, $x^{\mathrm{NL}}(\mathrm{q})$ is strictly increasing in $\mathrm{q}$. Comparing equations (A1) and (A5) implies that $x^{N L}(q)=x^{W}(2 q)$ for all $q$.

Solving equation (A.6) for the profit-maximizing output level for any given level of care, denoted $\mathrm{q}^{\mathrm{NL}}(\mathrm{x})$, we find that $\mathrm{q}^{\mathrm{NL}}(\mathrm{x})=(\alpha-\mathrm{c}(\mathrm{x})) / 2(\beta+2 \mathrm{~h}(\mathrm{x}))>0$ for $\mathrm{x}<\overline{\mathrm{x}}$ and $\mathrm{q}^{\mathrm{NL}}(\overline{\mathrm{x}})=0$; moreover, $\mathrm{q}^{\mathrm{NL}}(\mathrm{x})=$ $(1 / 2) q^{W}(x)<q^{S L}(x)$. Differentiating equation (A.6) with respect to $q$ and $x$ and collecting terms implies that $\mathrm{dq}^{\mathrm{NL}}(\mathrm{x}) / \mathrm{dx}=\Pi_{\mathrm{qx}}^{\mathrm{NL}} /\left(-\Pi_{\mathrm{qq}}^{\mathrm{NL}}\right)$. While we don't know the sign of this in general, we know that $\Pi_{\mathrm{qx}}^{\mathrm{NL}}>0$ at $\left(\hat{\mathrm{x}}^{\mathrm{SL}}, \hat{\mathrm{q}}^{\mathrm{SL}}\right)$ (by the previous argument using equation (A.5)). Thus, $\mathrm{q}^{\mathrm{NL}}(\mathrm{x})$ is strictly increasing in a neighborhood of $\left(\hat{\mathrm{x}}^{\mathrm{NL}}, \hat{\mathrm{q}}^{\mathrm{NL}}\right)$, where equations (A.5) and (A.6) are satisfied simultaneously.

In $(x, q)$ space, we are graphing the functions $q^{N L}(x)$ and the inverse of $x^{N L}(q)$, denoted $\tilde{q}^{N L}(x)$. Both of these are continuous functions. To see that $\tilde{q}^{\mathrm{NL}}(\mathrm{x})$ crosses $\mathrm{q}^{\mathrm{NL}}(\mathrm{x})$ "from below," first notice that $\tilde{\mathrm{q}}^{\mathrm{NL}}(0)=0<\mathrm{q}^{\mathrm{NL}}(0)$, but $\tilde{\mathrm{q}}^{\mathrm{NL}}(\overline{\mathrm{x}})>0=\mathrm{q}^{\mathrm{NL}}(\overline{\mathrm{x}})$; since both functions are continuous, they must cross at least once. To see that any crossing is "from below," note that $\mathrm{d} \tilde{q}^{\mathrm{NL}}(\mathrm{x}) / \mathrm{dx}=1 / \mathrm{dx} \mathrm{NL}^{\mathrm{NL}}(\mathrm{q}) / \mathrm{dq}=\left(-\Pi_{\mathrm{xx}}^{\mathrm{NL}}\right) / \Pi_{\mathrm{xq}}^{\mathrm{NL}}>\Pi_{\mathrm{xq}}^{\mathrm{NL}} /(-$ $\left.\Pi_{\mathrm{qq}}^{\mathrm{NL}}\right)=\mathrm{dq}^{\mathrm{NL}}(\mathrm{x}) / \mathrm{dx}$, where the inequality follows from the fact that $\Pi_{\mathrm{qq}}^{\mathrm{NL}} \Pi_{\mathrm{xx}}^{\mathrm{NL}}-\left(\Pi_{\mathrm{xq}}^{\mathrm{NL}}\right)^{2}>0$ at $\left(\hat{\mathrm{x}}^{\mathrm{NL}}, \hat{\mathrm{q}}^{\mathrm{NL}}\right)$.

We can conclude that $\left(\hat{\mathrm{x}}^{\mathrm{NL}}, \hat{\mathrm{q}}^{\mathrm{NL}}\right)$ is the unique interior solution to (A.5)-(A.6) using an argument similar to that used to establish the uniqueness of $\left(\hat{x}^{\mathrm{W}}, \hat{\mathrm{q}}^{\mathrm{W}}\right)$. Finally, the facts that $\mathrm{q}^{\mathrm{NL}}(\mathrm{x})=(1 / 2) \mathrm{q}^{\mathrm{W}}(\mathrm{x})$ and $x^{N L}(q)=x^{W}(2 q)$ for all $q$ imply that $\hat{x}^{N L}=\hat{x}^{W}$ and $\hat{q}^{N L}=(1 / 2) \hat{q}^{W}$.

Profit Maximization under Parametrized Liablity. The parametrized profit function is given by:

$$
\Pi(x, q ; \gamma)=(\alpha-\beta q) q-\gamma h(x) q^{2}-c(x) q
$$

where $\gamma=1$ corresponds to strict liability and $\gamma=2$ corresponds to no liability. While $\Pi(\mathrm{x}, \mathrm{q} ; \gamma)$ is not globally-concave, it is still very well-behaved. It can be shown (using an argument analogous to that used in the case of welfare-maximization) that any profit-maximizing solution is interior; that is, it must involve $(x, q)$ such that $x \in(0, \bar{x})$ and $q>0$. Let $(\hat{x}(\gamma), \hat{q}(\gamma))$ denote a profit-maximizing solution. Then $(\hat{x}(\gamma), \hat{\mathrm{q}}(\gamma))$ must satisfy the first-order conditions:

$$
\begin{aligned}
& \Pi_{x}=-\gamma h^{\prime}(x) q^{2}-c^{\prime}(x) q=0 \\
& \Pi_{q}=\alpha-2 \beta q-2 \gamma h(x) q-c(x)=0 .
\end{aligned}
$$

To see that any interior solution to the first-order conditions (A.7)-(A.8) must be a strict local maximum, we need only verify that the matrix of second derivatives is negative definite at any interior solution to (A.7)-(A.8). The relevant second derivatives are:

$$
\begin{aligned}
& \Pi_{\mathrm{xx}}=-\gamma \mathrm{h}^{\prime \prime}(\mathrm{x}) \mathrm{q}^{2}-\mathrm{c}^{\prime \prime}(\mathrm{x}) \mathrm{q}<0 \\
& \Pi_{\mathrm{xq}}=-2 \gamma \mathrm{h}^{\prime}(\mathrm{x}) \mathrm{q}-\mathrm{c}^{\prime}(\mathrm{x}) \\
& \Pi_{\mathrm{qq}}=-2 \beta-2 \gamma \mathrm{h}(\mathrm{x})<0
\end{aligned}
$$


Notice that (for $q>0$ ) equation (A.7) implies that $\Pi_{x q}=-\gamma h^{\prime}(x) q+(1 / q) \Pi_{x}=-\gamma h^{\prime}(x) q>0$ everywhere along the solution to (A.7). Evaluating the expression $\Pi_{\mathrm{qq}} \Pi_{\mathrm{xx}}-\left(\Pi_{\mathrm{xq}}\right)^{2}$ yields:

$$
\left(\gamma h^{\prime \prime}(x) q^{2}+c^{\prime \prime}(x) q\right)(2 \beta+2 \gamma h(x))-\left(\gamma h^{\prime}(x) q\right)^{2}>\gamma^{2}\left[2 h^{\prime \prime}(x) h(x)-\left(h^{\prime}(x)\right)^{2}\right] q^{2}>0
$$

where the first inequality follows from the fact that $\mathrm{h}^{\prime \prime}(\mathrm{x}), \mathrm{c}^{\prime \prime}(\mathrm{x}), \beta$, and $\mathrm{q}$ are positive, and the second inequality follows from the convexity of expected harm in (x, q). Thus, any interior solution to (A.7)(A.8) is a strict local maximum. We can conclude that there is a unique interior solution $(\hat{\mathrm{x}}(\gamma), \hat{\mathrm{q}}(\gamma))$ to (A.7)-(A.8) using arguments similar to those used to establish the existence and uniqueness of $\left(\hat{\mathrm{x}}^{\mathrm{W}}, \hat{\mathrm{q}}^{\mathrm{W}}\right)$.

Differentiating the system (A.7)-(A.8) in terms of $\mathrm{x}, \mathrm{q}$, and $\gamma$, and solving for $\mathrm{d} \hat{\mathrm{x}}(\gamma) / \mathrm{d} \gamma$ and $\mathrm{d} \hat{\mathrm{q}}(\gamma) / \mathrm{d} \gamma$ yields:

and

$$
\mathrm{d} \hat{\mathrm{x}}(\gamma) / \mathrm{d} \gamma=\left\{\Pi_{\mathrm{qq}} \mathrm{h}^{\prime}(\mathrm{x}) \mathrm{q}^{2}-\Pi_{\mathrm{xq}} 2 \mathrm{~h}(\mathrm{x}) \mathrm{q}\right\} /\left\{\Pi_{\mathrm{xx}} \Pi_{\mathrm{qq}}-\left(\Pi_{\mathrm{xq}}\right)^{2}\right\}
$$

$$
\mathrm{d} \hat{\mathrm{q}}(\gamma) / \mathrm{d} \gamma=\left\{-\Pi_{\mathrm{xq}} \mathrm{h}^{\prime}(\mathrm{x}) \mathrm{q}^{2}+\Pi_{\mathrm{xx}} 2 \mathrm{~h}(\mathrm{x}) \mathrm{q}\right\} /\left\{\Pi_{\mathrm{xx}} \Pi_{\mathrm{qq}}-\left(\Pi_{\mathrm{xq}}\right)^{2}\right\},
$$

where all expressions are evaluated at the solution $(\hat{\mathrm{x}}(\gamma), \hat{\mathrm{q}}(\gamma))$. The denominator is positive in both cases. Consider the numerator in the expression for $\mathrm{d} \hat{\mathrm{x}}(\gamma) / \mathrm{d} \gamma$. Upon substituting for $\Pi_{\mathrm{qq}}$ and $\Pi_{\mathrm{xq}}$, and noting that (A.7) implies that $\Pi_{\mathrm{xq}}=-\gamma \mathrm{h}^{\prime}(\mathrm{x}) \mathrm{q}$, the numerator becomes $\left\{\gamma \mathrm{h}^{\prime}(\mathrm{x}) \mathrm{q} 2 \mathrm{~h}(\mathrm{x}) \mathrm{q}-2(\beta+\gamma \mathrm{h}(\mathrm{x})) \mathrm{h}^{\prime}(\mathrm{x}) \mathrm{q}^{2}\right\}=-$ $2 \beta h^{\prime}(x) q^{2}>0$. Thus, $d \hat{x}(\gamma) / d \gamma>0$, which implies that $\hat{x}^{N L}>\hat{x}^{S L}$. Now consider the numerator for the expression d $\hat{q}(\gamma) / d \gamma$. Upon substituting for $\Pi_{x x}$ and $\Pi_{x q}=-\gamma h^{\prime}(x) q$, the numerator becomes $q^{2}\left\{\gamma q\left[\left(h^{\prime}(x)\right)^{2}\right.\right.$ $\left.\left.-2 \mathrm{~h}(\mathrm{x}) \mathrm{h}^{\prime \prime}(\mathrm{x})\right]-2 \mathrm{~h}(\mathrm{x}) \mathrm{c}^{\prime \prime}(\mathrm{x})\right\}$. Since $\mathrm{c}^{\prime \prime}(\mathrm{x})>0$, a sufficient condition for this to be negative is that $\left[\left(\mathrm{h}^{\prime}(\mathrm{x})\right)^{2}-\right.$ $\left.2 \mathrm{~h}(\mathrm{x}) \mathrm{h}^{\prime \prime}(\mathrm{x})\right]<0$. But this inequality is implied by the convexity of expected harm in $(\mathrm{x}, \mathrm{q})$. Thus, $\mathrm{d} \hat{\mathrm{q}}(\gamma) / \mathrm{d} \gamma<0$, which implies that $\hat{\mathrm{q}}^{\mathrm{NL}}<\hat{\mathrm{q}}^{\mathrm{SL}}$.

Proof that welfare, evaluated at the profit-maximizing $(x, q)$, is decreasing in $\gamma$. Recall that $\mathrm{W}(\hat{\mathrm{x}}(\gamma), \hat{\mathrm{q}}(\gamma))$ $=\alpha \hat{\mathrm{q}}(\gamma)-(\beta / 2)(\hat{\mathrm{q}}(\gamma))^{2}-\mathrm{h}(\hat{\mathrm{x}}(\gamma))(\hat{\mathrm{q}}(\gamma))^{2}-\mathrm{c}(\hat{\mathrm{x}}(\gamma)) \hat{\mathrm{q}}(\gamma)$. Thus, $\mathrm{dW} / \mathrm{d} \gamma=\mathrm{W}_{\mathrm{x}}(\mathrm{d} \hat{\mathrm{x}}(\gamma) / \mathrm{d} \gamma)+\mathrm{W}_{\mathrm{q}}(\mathrm{d} \hat{\mathrm{q}}(\gamma) / \mathrm{d} \gamma)$, where $\mathrm{W}_{\mathrm{q}}$ and $\mathrm{W}_{\mathrm{x}}$ are evaluated at $(\hat{\mathrm{x}}(\gamma), \hat{\mathrm{q}}(\gamma))$. Evaluating equation (A.1) at the solution to equation (A.7) implies that $\mathrm{W}_{\mathrm{x}}(\hat{\mathrm{x}}(\gamma), \hat{\mathrm{q}}(\gamma))=(\gamma-1) \mathrm{h}^{\prime}(\hat{\mathrm{x}}(\gamma))(\hat{\mathrm{q}}(\gamma))^{2}<0(=0$ at $\gamma=1)$. Since $\mathrm{d} \hat{\mathrm{x}}(\gamma) / \mathrm{d} \gamma>0$, it is clear that $\mathrm{W}_{\mathrm{x}}(\mathrm{d} \hat{\mathrm{x}}(\gamma) / \mathrm{d} \gamma)<0(=0$ at $\gamma=1)$. Evaluating equation (A.2) at the solution to equation (A.8) implies that $\mathrm{W}_{\mathrm{q}}(\hat{\mathrm{x}}(\gamma), \hat{\mathrm{q}}(\gamma))=\beta \hat{\mathrm{q}}(\gamma)+2(\gamma-1) \mathrm{h}(\hat{\mathrm{x}}(\gamma)) \hat{\mathrm{q}}(\gamma)>0$. Since $\left.\mathrm{d} \hat{\mathrm{q}}(\gamma) / \mathrm{d} \gamma\right)<0$, it is clear that $\mathrm{W}_{\mathrm{q}}(\mathrm{d} \hat{\mathrm{q}}(\gamma) / \mathrm{d} \gamma)<0$. Combining the two terms implies that $\mathrm{dW} / \mathrm{d} \gamma<0$; that is, strict liability is socially-preferred to no liability. 
Appendix B: Results for the Generalized Expected Harm Formulation Under Monopoly ${ }^{42}$

\section{Initial considerations.}

In this Appendix we re-formulate the monopoly model considered in the main text by allowing for both a more general model of expected harm and a more general model of the representative consumer's utility (which leads to a more general model of demand for the product). We first make some assumptions on the elements of the model and then some further assumptions on the payoff functions so as to ensure that the first order conditions for each optimization problem properly characterize the respective optimal solutions, and that those solutions are in the interior (i.e., all relevant variables remain positive). We then employ the resulting models to show which results of the main text carry over to the more general environment and which may require further restrictions. As before, unless specified otherwise, $\mathrm{x}$ and $\mathrm{q}$ are assumed to be non-negative, and $\gamma=1$ if the liability regime is SL (strict liability) while $\gamma=2$ if the liability regime is NL (no liability); NEG (negligence) will be handled as a composite of the two regimes and will be more precisely defined when needed. For readability we will separately analyze the SL and NL settings, though we will return to the parametrized version for the discussion of firm and social preferences over regimes. In what follows, the expected harm is denoted as $\mathrm{H}(\mathrm{x}, \mathrm{q})$.

\section{Assumptions}

B1) The representative consumer's utility function, $\mathrm{U}(\mathrm{q}, \mathrm{z} ; \mathrm{x}, \gamma)$ is quasilinear in form:

$$
\mathrm{U}(\mathrm{q}, \mathrm{z} ; \mathrm{x}, \gamma)=\mathrm{u}(\mathrm{q})+\mathrm{z}-(\gamma-1) \mathrm{H}(\mathrm{x}, \mathrm{q})
$$

good

where $\mathrm{z}$ is the consumer's numeraire good and $\mathrm{u}(\mathrm{q})$ is the consumer's direct utility for the

of interest. The consumer faces the budget constraint $\mathrm{pq}+\mathrm{z} \leq \mathrm{I}$, where $\mathrm{I}>0$ is income and $\mathrm{p}$ is the (positive) price of the q-good; I is assumed sufficient to guarantee that the consumer always consumes positive amounts of the consumer's decision variable, $\mathrm{q}$ and $\mathrm{z}$, so that the demand for $q$ is independent of I. Assumptions on $u$ are that:

i) $\quad \mathrm{u}(\mathrm{q})$ is twice continuously differentiable for all $\mathrm{q} \geq 0$;

ii) $\quad \mathrm{u}(\mathrm{q}) \geq 0, \mathrm{u}^{\prime}(\mathrm{q})>0$, and $\mathrm{u}^{\prime \prime}(\mathrm{q})<0$ for all $\mathrm{q} \geq 0$.

B2) Expected Harm is modeled by the function $\mathrm{H}(\mathrm{x}, \mathrm{q})$ which is thrice continuously differentiable with the following properties:

i) $\quad \mathrm{H}(\mathrm{x}, 0)=0$ for all $\mathrm{x} \geq 0 ; \mathrm{H}(\mathrm{x}, \mathrm{q})>0$ for all $\mathrm{x} \geq 0$, and all $\mathrm{q}>0$;

ii) $\quad H_{x}(x, q)<0$ and $H_{q}(x, q)>0$ for all $(x, q)>0 ; H_{x}(x, 0)=0$ for all $x>0$;

iii) $\mathrm{H}(\mathrm{x}, \mathrm{q})$ is convex in $(\mathrm{x}, \mathrm{q})$ with strictly positive own-second partials: $\mathrm{H}_{\mathrm{xx}}(\mathrm{x}, \mathrm{q})>0 ; \mathrm{H}_{\mathrm{qq}}(\mathrm{x}, \mathrm{q})>0$ for all $(\mathrm{x}, \mathrm{q})>0$;

iv) $\quad \mathrm{H}_{\mathrm{xq}}(\mathrm{q}, \mathrm{x})<0$ for all $(\mathrm{x}, \mathrm{q})>0$;

v) $\quad \partial \mathrm{H}_{\mathrm{qq}}(\mathrm{x}, \mathrm{q}) / \partial \mathrm{x}<0$ for all $(\mathrm{x}, \mathrm{q})>0$.

B3) Production cost is modeled as in the main text: $\mathrm{C}(\mathrm{x}, \mathrm{q})=\mathrm{c}(\mathrm{x}) \mathrm{q}$, with $\mathrm{c}(\bullet)$ twice continuously differentiable, $c(x)>0, c^{\prime}(x)>0$, and $c^{\prime \prime}(x)>0$ for all $x \geq 0$.

B4) Optimization. All optimization problems have a unique interior maximum and all the respective payoff functions $\left(\mathrm{U}, \mathrm{W}, \Pi^{\mathrm{SL}}\right.$, and $\Pi^{\mathrm{NL}}$ ) have second-order matrices that are negative definite in

a sufficiently large neighborhood of these optima.

42 See Marino (1988) and Spulber (1989) for derivations overlapping some portions of this Appendix. 
Assumption B1 concerns the representative consumer's optimization problem. The utility function, $\mathrm{u}(\mathrm{q})$, is strictly increasing and concave, so the consumer's (inverse) demand function for the qgood can be written as:

$$
\mathrm{p}(\mathrm{q} ; \mathrm{x}, \gamma)=\max \left[\mathrm{u}^{\prime}(\mathrm{q})-(\gamma-1) \mathrm{H}_{\mathrm{q}}(\mathrm{x}, \mathrm{q}), 0\right],
$$

with derivative $\operatorname{dp}(\mathrm{q} ; \mathrm{x}, \gamma) / \mathrm{dq}=\min \left[\mathrm{u}^{\prime \prime}(\mathrm{q})-(\gamma-1) \mathrm{H}_{\mathrm{qq}}(\mathrm{x}, \mathrm{q}), 0\right]$. When $\gamma=1$ this simplifies to:

and

$$
\begin{aligned}
& \mathrm{p}^{\mathrm{SL}}(\mathrm{q})=\mathrm{u}^{\prime}(\mathrm{q})>0, \text { for all } \mathrm{q} \geq 0 \\
& \mathrm{dp}^{\mathrm{SL}}(\mathrm{q}) / \mathrm{dq}=\mathrm{u}^{\prime \prime}(\mathrm{q})<0 \text { for all } \mathrm{q} \geq 0
\end{aligned}
$$

Where both properties come from Assumption B1. When $\gamma=2$, under Assumption B1, the inverse demand function and derivative simplify to:

and

$$
\begin{aligned}
& \mathrm{p}^{\mathrm{NL}}(\mathrm{q} ; \mathrm{x})=\max \left[\mathrm{u}^{\prime}(\mathrm{q})-\mathrm{H}_{\mathrm{q}}(\mathrm{x}, \mathrm{q}), 0\right] \geq 0, \\
& \mathrm{dp}^{\mathrm{NL}}(\mathrm{q} ; \mathrm{x}) / \mathrm{dq}=\mathrm{u}^{\prime \prime}(\mathrm{q})-\mathrm{H}_{\mathrm{qq}}(\mathrm{x}, \mathrm{q})<0 \text { when } \mathrm{p}^{\mathrm{NL}}(\mathrm{q} ; \mathrm{x}) \text { is positive. }
\end{aligned}
$$

The derivative $\mathrm{dp}^{\mathrm{NL}}(\mathrm{q} ; \mathrm{x}) / \mathrm{dq}$ is negative when $\mathrm{p}^{\mathrm{NL}}(\mathrm{q} ; \mathrm{x})$ is positive because of Assumptions $\mathrm{B} 1(\mathrm{ii})$ and B2(iii). In order to avoid the kink in the NL case (in the inverse demand function), and assure that the willingness to pay is everywhere positive, we assume that $\mathrm{u}^{\prime}(\mathrm{q})-\mathrm{H}_{\mathrm{q}}(\mathrm{x}, \mathrm{q})>0$ over the relevant ranges of the $\mathrm{x}$ - and q-variables. This amounts to asserting that there are $(\mathrm{x}, \mathrm{q})$ combinations such that the product is socially valuable, and that all of the optima satisfy this requirement. Thus we take the inverse demand functions for the SL and NL cases to be the following:

and

$$
\mathrm{p}^{\mathrm{SL}}(\mathrm{q})=\mathrm{u}^{\prime}(\mathrm{q})>0 \text {, for all } \mathrm{q} \geq 0 \text {, }
$$

$$
\mathrm{p}^{\mathrm{NL}}(\mathrm{q} ; \mathrm{x})=\mathrm{u}^{\prime}(\mathrm{q})-\mathrm{H}_{\mathrm{q}}(\mathrm{x}, \mathrm{q})>0 \text { over the relevant range of }(\mathrm{x}, \mathrm{q}) \text {. }
$$

Assumption B2 provides basic properties of the expected harm function; we have assumed that third derivatives are continuous due to the need for property B2(v), which we discuss in more detail below. Note that this is an expected harm function, so it is reflects both the probability of harm taking on specific possible values as well as those possible values. Assumption B2(i) states that when the quantity consumed is zero then the expected harm is zero, independent of the level of care taken; positive levels of use generate a positive level of expected harm, for any given level of care. Assumption B2(ii) states that the level of expected harm is decreasing in the level of care taken but increasing in the amount consumed; it further asserts that when usage (q) is zero, then as with total expected harm, the marginal effect of increasing $x$ does not change the level of expected harm. Assumption B2(iii) states that expected harm is a convex function of $\mathrm{x}$ and $\mathrm{q}$, and that the own second partials are strictly positive. Thus, increases in care have diminishing returns with respect to care, but increases in usage increase marginal (with respect to usage) expected harm. Note that B2(iii) rules out expected harm models of the traditional form (h(x)q) but allows for the one considered in the main text $\left(\mathrm{h}(\mathrm{x}) \mathrm{q}^{2}\right)$ which focuses around cumulative expected harm. ${ }^{43}$ Assumption B2(iv) states that an increase in the level of use (q) raises the marginal benefit ($\mathrm{H}_{\mathrm{x}}(\mathrm{x}, \mathrm{q})$ ) of care; alternatively put, the cross derivative, $\mathrm{H}_{\mathrm{xq}}$, is negative; this, together with the fact that convexity implies that $\mathrm{H}_{\mathrm{xx}}(\mathrm{x}, \mathrm{q}) \mathrm{H}_{\mathrm{qq}}(\mathrm{x}, \mathrm{q}) \geq\left(\mathrm{H}_{\mathrm{xq}}(\mathrm{x}, \mathrm{q})\right)^{2}$ means that $\mathrm{H}_{\mathrm{xq}}$, while negative by assumption, is also restricted in magnitude. Lastly, Assumption B2(v) reflects an intuitive understanding that an increase in the level of care ameliorates the acceleration effect that usage has on expected harm (since $\mathrm{H}_{\mathrm{qq}}$ is positive).

The convexity of $\mathrm{H}$ (Assumption B2(iii)) also implies that, for positive levels of output, the

43 Assumption B2(iii), when applied to $H(x, q)=h(x) q^{2}$, means that $h(x)$ satisfies the side requirement that $h^{\prime \prime}(x) h(x) \geq 2\left(h^{\prime}(x)\right)^{2}$, which in turn implies the condition in the discussion of the sign of d $\hat{q} / d \gamma$ in the main text. 
marginal expected harm exceeds the average expected harm:

$$
H_{q}(x, q)>H(x, q) / q \text { for all }(x, q)>0 \text {. }
$$

To see this, observe that $\mathrm{H}(\mathrm{x}, \mathrm{q})=\int_{[0, \mathrm{q}]} \mathrm{H}_{\mathrm{q}}(\mathrm{x}, \mathrm{t}) \mathrm{dt}$, since by Assumption $\mathrm{B} 2(\mathrm{i}), \mathrm{H}_{\mathrm{x}}(\mathrm{x}, 0)=0$. Since $\mathrm{H}_{\mathrm{qq}}>$ $0, \mathrm{H}_{\mathrm{q}}(\mathrm{x}, \mathrm{t})$ is increasing in $\mathrm{t}$. Thus, the average of the area under the function $\mathrm{H}_{\mathrm{q}}(\mathrm{x}, \mathrm{t})$ as $\mathrm{t}$ ranges from 0 to $\mathrm{q},(1 / \mathrm{q}) \int_{[0, \mathrm{q}]} \mathrm{H}_{\mathrm{q}}(\mathrm{x}, \mathrm{t}) \mathrm{dt}$, must be less than the upper end of that curve, $\mathrm{H}_{\mathrm{q}}(\mathrm{x}, \mathrm{q})$, yielding the desired result. As will be seen below, this plays an important role in the discussion of the firm's preference for strict liability over no liability.

Finally, Assumption B2(v) implies that:

$$
H_{x q}(x, q)<H_{x}(x, q) / q \text { for all }(x, q)>0 .
$$

To see this (keep in mind that, by assumption, both sides of the above inequality are negative), observe that $\mathrm{H}_{\mathrm{x}}(\mathrm{x}, \mathrm{q})=\int_{[0, \mathrm{q}]} \mathrm{H}_{\mathrm{xq}}(\mathrm{x}, \mathrm{t}) \mathrm{dt}$, since by Assumption B2(ii), $\mathrm{H}_{\mathrm{x}}(\mathrm{x}, 0)=0$. Thus, $\mathrm{H}_{\mathrm{x}}(\mathrm{x}, \mathrm{q})-\mathrm{H}_{\mathrm{xq}}(\mathrm{x}, \mathrm{q}) \mathrm{q}_{<}^{>} 0$ as $\partial \mathrm{H}_{\mathrm{xq}}(\mathrm{x}, \mathrm{q}) / \partial \mathrm{q}>0$. While this last derivative is not particularly obvious, $\partial \mathrm{H}_{\mathrm{xq}}(\mathrm{x}, \mathrm{q}) / \partial \mathrm{q}=\partial \mathrm{H}_{\mathrm{qq}}(\mathrm{x}, \mathrm{q}) / \partial \mathrm{x}$, which (by Assumption B2(v)) is negative. Thus, we know that $\mathrm{H}_{\mathrm{x}}(\mathrm{q}, \mathrm{x})-\mathrm{H}_{\mathrm{xq}}(\mathrm{x}, \mathrm{q}) \mathrm{q}>0$, as claimed. We shall make use of this property later, too. ${ }^{44}$

Assumption B3 uses the same production cost function, $\mathrm{c}(\mathrm{x}) \mathrm{q}$, as in the main text. We maintain the same assumption here so as to highlight the effect of the expected harm function on social optimality and on firm optimal choices of $\mathrm{x}$ and $\mathrm{q}$.

Assumption B4 provides sufficient conditions that allow us to employ the first order conditions for all of our maximization models to characterize an (interior) optimum. Furthermore, the Assumption requires that at the respective (unique) optima, the sufficient conditions hold for a large enough portion of the space to allow for comparisons of the alternative equilibria and optimal outcomes.

\section{Comparison of SL and NL regimes with the Efficient Outcome.}

First, consider the $(\mathrm{x}, \mathrm{q})$ combination that maximizes social welfare. Denote social welfare as $\mathrm{W}(\mathrm{x}, \mathrm{q})$, so that:

$$
W(x, q)=u(q)-H(x, q)-c(x) q .
$$

Consider the result of solving the following single-variable problem, where we treat $\mathrm{q}$ as a parameter:

$$
\max _{\mathrm{x}} \mathrm{W}(\mathrm{x}, \mathrm{q})
$$

The optimal solution function for this problem, $x(q)$, satisfies the first order condition $-H_{x}(x, q)-c^{\prime}(x) q=$ 0 ; second order conditions are clearly satisfied, namely $\mathrm{W}_{\mathrm{xx}}(\mathrm{x}(\mathrm{q}), \mathrm{q})<0$. Totally differentiating the first order condition yields the derivative:

$$
\mathrm{dx}(\mathrm{q}) / \mathrm{dq}=\mathrm{W}_{\mathrm{xq}} /\left(-\mathrm{W}_{\mathrm{xx}}\right) \text {, where } \mathrm{W}_{\mathrm{xq}}(\mathrm{x}(\mathrm{q}), \mathrm{q})=-\mathrm{H}_{\mathrm{xq}}(\mathrm{x}(\mathrm{q}), \mathrm{q})-\mathrm{c}^{\prime}(\mathrm{x}(\mathrm{q})) \text {. }
$$

Using the first-order condition to re-express $\mathrm{W}_{\mathrm{xq}}(\mathrm{x}(\mathrm{q}), \mathrm{q})$, it is straightforward to find that:

44 Marino (1988) instead considers the case wherein $H_{x q}(x, q)>H_{x}(x, q) / q$ for all $(x, q)>0$. This is not consistent with our Assumption B2(v) which assumes that increasing care ameliorates the acceleration of harm arising from increased use. 


$$
W_{x q}(x(q), q)=-H_{x q}(x(q), q)+H_{x}(x(q), q) / q>0
$$

from the earlier discussion employing Assumption B2(v). Thus, $\mathrm{dx}(\mathrm{q}) / \mathrm{dq}>0$ for the single-variable problem.

Now let us turn to the full optimization problem, namely:

$$
\max _{(\mathrm{x}, \mathrm{q})} \mathrm{W}(\mathrm{x}, \mathrm{q}) \text {. }
$$

Under Assumption B4, the first-order-conditions characterize the social optimum in (x, q):

and

$$
\begin{array}{ll}
\mathrm{W}_{\mathrm{x}}= & -\mathrm{H}_{\mathrm{x}}(\mathrm{x}, \mathrm{q})-\mathrm{c}^{\prime}(\mathrm{x}) \mathrm{q}=0 \\
\mathrm{~W}_{\mathrm{q}}=\mathrm{u}^{\prime}(\mathrm{q})-\mathrm{H}_{\mathrm{q}}(\mathrm{x}, \mathrm{q})-\mathrm{c}(\mathrm{x})=0 .
\end{array}
$$

Solving the equation (B.1), $\mathrm{W}_{\mathrm{x}}=0$, yields (for arbitrary $\mathrm{q}$ ) the socially-optimal level of care as a function of the level of output, denoted again as $x^{\mathrm{W}}(\mathrm{q})$. However, this is exactly the same as that derived in the single-variable problem analysis above, so we immediately know that $\mathrm{x}^{\mathrm{W}}(\mathrm{q})$ is increasing in $\mathrm{q}$ : $\mathrm{dx}^{\mathrm{W}}(\mathrm{q}) / \mathrm{dq}=\mathrm{W}_{\mathrm{xq}}(\mathrm{x}, \mathrm{q}) /\left(-\mathrm{W}_{\mathrm{xx}}(\mathrm{x}, \mathrm{q})\right)>0$. This, in turn, means that $\mathrm{W}_{\mathrm{xq}}(\mathrm{x}, \mathrm{q})>0$ along the entire path $\mathrm{x}^{\mathrm{W}}(\mathrm{q})$. Notice also that $\mathrm{W}_{\mathrm{xq}}>0$ means that $\mathrm{q}$ and $\mathrm{x}$ are complements along the path $\mathrm{x}^{\mathrm{W}}(\mathrm{q})$ in the sense that increasing $\mathrm{q}$ raises the marginal contribution of $\mathrm{x}$ to welfare.

Solving the second first-order condition $\left(\mathrm{W}_{\mathrm{q}}=0\right)$ yields, for arbitrary $\mathrm{x}$, the level of sociallyoptimal output as a function of the level of care, denoted as $\mathrm{q}^{\mathrm{W}}(\mathrm{x})$, and in a similar manner one finds that $\mathrm{dq}^{\mathrm{W}}(\mathrm{x}) / \mathrm{dx}=\mathrm{W}_{\mathrm{xq}} /\left(-\mathrm{W}_{\mathrm{qq}}\right)$. Unfortunately, the same trick as used for the $\mathrm{x}$-variable cannot be used for the qvariable: in general, $\mathrm{W}_{\mathrm{xq}}(\mathrm{x}, \mathrm{q})$ can change sign along the path $\mathrm{q}^{\mathrm{W}}(\mathrm{x})$. However, since negative definiteness (and the assumption of interiority of the solution) means that the solution occurs where the $\mathrm{x}^{\mathrm{W}}$ - and $\mathrm{q}^{\mathrm{W}}$-functions cross, denoted as $\left(\hat{\mathrm{x}}^{\mathrm{W}}, \hat{\mathrm{q}}^{\mathrm{W}}\right), \mathrm{W}_{\mathrm{xq}}(\mathrm{x}, \mathrm{q})$ must be positive at least in a neighborhood of the optimum, so that the slope of $\mathrm{q}^{\mathrm{W}}(\mathrm{x}), \mathrm{dq}^{\mathrm{W}}(\mathrm{x}) / \mathrm{dx}=\mathrm{W}_{\mathrm{xq}}(\mathrm{x}, \mathrm{q}) /\left(-\mathrm{W}_{\mathrm{qq}}(\mathrm{x}, \mathrm{q})\right)$, is positive (at least in a neighborhood of the social optimum).

Thus, when graphed in $(x, q)$-space, the slope of the curve $x^{\mathrm{W}}(\mathrm{q})$ is given by $1 /\left(\mathrm{dx} \mathrm{x}^{\mathrm{W}}(\mathrm{q}) / \mathrm{dq}\right)$, so that the issue of the relative position of this curve and that of the curve $\mathrm{q}^{\mathrm{W}}(\mathrm{x})$ is given by whether $1 /\left(\mathrm{dx}^{\mathrm{W}}(\mathrm{q}) / \mathrm{dq}\right)^{>}<\mathrm{dq}^{\mathrm{W}}(\mathrm{x}) / \mathrm{dx}$; that is, by whether $\left(-\mathrm{W}_{\mathrm{xx}}\right) / \mathrm{W}_{\mathrm{xq}}<\mathrm{W}_{\mathrm{xq}} /\left(-\mathrm{W}_{\mathrm{qq}}\right)$. Since at the optimum the determinant of the second-order terms of $\mathrm{W}$ is positive, then $\mathrm{W}_{\mathrm{xx}} \mathrm{W}_{\mathrm{qq}}>\left(\mathrm{W}_{\mathrm{xq}}\right)^{2}$, independent of the sign of $\mathrm{W}_{\mathrm{xq}}$. However since (locally) $\mathrm{W}_{\mathrm{xq}}>0$ then both curves are upward-sloping and the curve $\mathrm{x}^{\mathrm{W}}(\mathrm{q})$ cuts the curve $\mathrm{q}^{\mathrm{W}}(\mathrm{x})$ from below, as was illustrated in the main text.

Next, consider the strict-liability regime. The firm's profit function under strict liability is:

$$
\Pi^{\mathrm{SL}}(\mathrm{x}, \mathrm{q})=\mathrm{p}^{\mathrm{SL}}(\mathrm{q}) \mathrm{q}-\mathrm{H}(\mathrm{x}, \mathrm{q})-\mathrm{c}(\mathrm{x}) \mathrm{q} .
$$

Assumption B4 guarantees a unique (interior) optimum for the firm's decision problem in (x, q) which is characterized by the first-order conditions for the firm:

and

$$
\begin{array}{ll}
\Pi_{\mathrm{x}}^{\mathrm{SL}}= & -\mathrm{H}_{\mathrm{x}}(\mathrm{x}, \mathrm{q})-\mathrm{c}^{\prime}(\mathrm{x}) \mathrm{q}=0 \\
\Pi_{\mathrm{q}}^{\mathrm{SL}}=\mathrm{u}^{\prime}(\mathrm{q})+\mathrm{u}^{\prime \prime}(\mathrm{q}) \mathrm{q}-\mathrm{H}_{\mathrm{q}}(\mathrm{x}, \mathrm{q})-\mathrm{c}(\mathrm{x}) & =0 .
\end{array}
$$

Note that the first-order condition for care, equation (B.3), is the same as that for maximizing welfare, equation (B.1), so that it is immediate that the optimal level-of-care function under strict liability (for an arbitrary level of $q), x^{S L}(q)$, equals that for maximizing welfare; that is, $x^{S L}(q)=x^{W}(q)$ for all $q$. 
Moreover, applying Assumption B2(v) again, equation (B.3) yields that $\Pi_{x q}^{\mathrm{SL}}(\mathrm{x}, \mathrm{q})>0$ along $\mathrm{x}^{\mathrm{SL}}(\mathrm{q})$. The optimal quantity function, $\mathrm{q}^{\mathrm{SL}}(\mathrm{x})$, however is not the same as $\mathrm{q}^{\mathrm{W}}(\mathrm{x})$, as becomes clear since the second term in the first-order condition for quantity, equation (B.4), does not appear in the first-order condition for quantity in the welfare conditions, equation (B.2). Evaluating $\Pi_{\mathrm{q}}^{\mathrm{SL}}(\mathrm{x}, \mathrm{q})$ at $\mathrm{q}^{\mathrm{W}}(\mathrm{x})$ shows that $\Pi_{\mathrm{q}}^{\mathrm{SL}}(\mathrm{x}$, $\left.\mathrm{q}^{\mathrm{W}}(\mathrm{x})\right)=\mathrm{u}^{\prime \prime}\left(\mathrm{q}^{\mathrm{W}}(\mathrm{x})\right) \mathrm{q}^{\mathrm{W}}(\mathrm{x})<0$ from Assumption B1(ii); that is, the SL-firm would want to reduce output at any given level of $x$. Thus, $\mathrm{q}^{\mathrm{SL}}(\mathrm{x})<\mathrm{q}^{\mathrm{W}}(\mathrm{x})$ for all $\mathrm{x}$ : in $(\mathrm{x}, \mathrm{q})$-space, the curve for $\mathrm{q}^{\mathrm{SL}}(\mathrm{x})$ is everywhere below that for $\mathrm{q}^{\mathrm{W}}(\mathrm{x})$. This immediately tells us that the solution to the first-order conditions for the firm under strict liability is "south-and-west" of that for welfare maximization: ( $\left(\hat{\mathrm{x}}^{\mathrm{SL}}, \hat{\mathrm{q}}^{\mathrm{SL}}\right)<\left(\hat{\mathrm{x}}^{\mathrm{W}}, \hat{\mathrm{q}}^{\mathrm{W}}\right)$, and (as illustrated in the main text) any policy that worked to increase the quantity provided by the firm would result (under strict liability) in a higher level of care provided. Moreover, if the quantity was increased to force $\hat{\mathrm{q}}^{\mathrm{SL}}$ to equal $\hat{\mathrm{q}}^{\mathrm{W}}$, then the firm would provide the associated socially-optimal level of care, $\hat{\mathrm{x}}^{\mathrm{W}}$, as movements will be along $\mathrm{x}^{\mathrm{W}}(\mathrm{q})$. As with $\mathrm{q}^{\mathrm{W}}(\mathrm{x})$, the slope of $\mathrm{q}^{\mathrm{SL}}(\mathrm{x})$ in a neighborhood of $\left(\hat{\mathrm{x}}^{\mathrm{SL}}, \hat{\mathrm{q}}^{\mathrm{SL}}\right)$ must be positive, but this need not hold over the entire space.

The slope of $x^{S L}(q), d x^{S L}(q) / d q$, is readily seen to be $\Pi_{x q}^{S L}(x, q) /\left(-\Pi_{x x}(x, q)\right)$; since $x^{S L}(q)=x^{W}(q)$ and $\Pi_{x x}^{S L}(x, q)<0$, then this means that $\Pi_{x q}^{S L}(x, q)>0$ everywhere along $x^{S L}(q)$. In $(x, q)$ space, the slope of the curve $\mathrm{x}^{\mathrm{SL}}(\mathrm{q})$ slope is given $1 / \mathrm{dx}^{\mathrm{SL}}(\mathrm{q}) / \mathrm{dq}=\left(-\Pi_{\mathrm{xx}}^{\mathrm{SL}}(\mathrm{x}, \mathrm{q})\right) / \Pi_{\mathrm{xq}}^{\mathrm{SL}}(\mathrm{x}, \mathrm{q})$. On the other hand, while the slope of the curve $\mathrm{q}^{\mathrm{SL}}(\mathrm{x}), \mathrm{dq}^{\mathrm{SL}}(\mathrm{x}) / \mathrm{dx}$, is readily found to be $\Pi_{\mathrm{xq}}^{\mathrm{SL}}(\mathrm{x}, \mathrm{q}) /\left(-\Pi_{\mathrm{qq}}^{\mathrm{SL}}(\mathrm{x}, \mathrm{q})\right)$, the sign of $\Pi_{\mathrm{xq}}^{\mathrm{SL}}(\mathrm{x}, \mathrm{q})$ is only guaranteed to be positive in a neighborhood of where the two curves cross. Again, employing Assumption B4 we know that $\Pi_{\mathrm{xx}}^{\mathrm{SL}} \Pi_{\mathrm{qq}}^{\mathrm{SL}}>\left(\Pi_{\mathrm{xq}}^{\mathrm{SL}}\right)^{2}$, so the curve $\mathrm{x}^{\mathrm{SL}}(\mathrm{q})$ cuts the curve $\mathrm{q}^{\mathrm{SL}}(\mathrm{x})$ from below.

Finally, we consider the no-liability regime. Here the consumer does not ignore the cost of expected harm since she will not be compensated and, as shown earlier, demand is now conditioned on the level of care chosen, so the inverse demand function is $\mathrm{p}^{\mathrm{NL}}(\mathrm{q} ; \mathrm{x})$ as derived earlier.

Therefore the firm's payoff function is:

$$
\Pi^{N L}(x, q)=\left(u^{\prime}(q)-H_{q}(x, q)\right) q-c(x) q .
$$

Again, Assumption B4 guarantees a unique (interior) optimum for the firm's decision problem in (x, q), which is characterized by the first-order conditions for the firm:

and

$$
\begin{aligned}
& \Pi_{\mathrm{x}}^{\mathrm{NL}}=\quad-\mathrm{H}_{\mathrm{xq}}(\mathrm{x}, \mathrm{q}) \mathrm{q} \quad-\mathrm{c}^{\prime}(\mathrm{x}) \mathrm{q}=0 \text {; } \\
& \Pi_{\mathrm{q}}^{\mathrm{NL}}=\mathrm{u}^{\prime}(\mathrm{q})+\mathrm{u}^{\prime \prime}(\mathrm{q}) \mathrm{q}-\mathrm{H}_{\mathrm{qq}}(\mathrm{x}, \mathrm{q}) \mathrm{q}-\mathrm{H}_{\mathrm{q}}(\mathrm{x}, \mathrm{q})-\mathrm{c}(\mathrm{x})=0 \text {. }
\end{aligned}
$$

Comparing equation (B.5) with equation (B.1) allows us to locate the firms's choice-of-care function under no liability, $x^{\mathrm{NL}}(\mathrm{q})$, relative to the socially optimal level, $\mathrm{x}^{\mathrm{W}}(\mathrm{q})$. Once again, recalling the result that $\mathrm{H}_{\mathrm{xq}}(\mathrm{x}, \mathrm{q})<\mathrm{H}_{\mathrm{x}}(\mathrm{x}, \mathrm{q}) / \mathrm{q}$ for all $(\mathrm{x}, \mathrm{q})>0$, and evaluating $\Pi_{\mathrm{x}}^{\mathrm{NL}}(\mathrm{x}, \mathrm{q})$ at $\mathrm{x}^{\mathrm{W}}(\mathrm{q})$, one finds that $\Pi_{\mathrm{x}}^{\mathrm{NL}}\left(\mathrm{x}^{\mathrm{W}}(\mathrm{q}), \mathrm{q}\right)>0$ for each value of $q$. Thus, $x^{\mathrm{NL}}(\mathrm{q})>\mathrm{x}^{\mathrm{W}}(\mathrm{q})$ for each $\mathrm{q}$ : the NL firm over-supplies (in comparison with the socially-efficient level) care when $\mathrm{q}$ is given. Note, as we will see below, this does not address the level of care provided in equilibrium, as the quantities of output may differ. Thus we know that:

$$
x^{N L}(q)>x^{W}(q)=x^{S L}(q) \text { for all } q
$$

Turning to the issue of the NL-firm's choice of output given an arbitrary level of care, $\mathrm{x}$, compare equation (B.6) with equation (B.4); we make this comparison because both the SL-firm and the NL-firm exploit their market power in choosing the level of output to produce. Evaluating $\Pi_{q}^{\mathrm{NL}}(\mathrm{x}, \mathrm{q})$ at the function that solves equation (B.4), $\mathrm{q}^{\mathrm{SL}}(\mathrm{x})$, yields $\Pi_{\mathrm{q}}^{\mathrm{NL}}\left(\mathrm{x}, \mathrm{q}^{\mathrm{SL}}(\mathrm{x})\right)=-\mathrm{H}_{\mathrm{qq}}\left(\mathrm{x}, \mathrm{q}^{\mathrm{SL}}(\mathrm{x})\right) \mathrm{q}^{\mathrm{SL}}(\mathrm{x})<0$ by Assumption B2(iii). Thus, given any level $x$, the NL-firm would reduce output from that which the SLfirm would choose; that is, $\mathrm{q}^{\mathrm{NL}}(\mathrm{x})<\mathrm{q}^{\mathrm{SL}}(\mathrm{x})$. Bringing this together with the welfare-maximization results yields: 


$$
\mathrm{q}^{\mathrm{W}}(\mathrm{x})>\mathrm{q}^{\mathrm{SL}}(\mathrm{x})>\mathrm{q}^{\mathrm{NL}}(\mathrm{x}) \text { for all } \mathrm{x} \text {. }
$$

Again, we consider how the sets of curves are related, at least at the equilibrium solutions. Differentiating $\Pi_{\mathrm{x}}^{\mathrm{NL}}(\mathrm{x}, \mathrm{q})$ yields $\Pi_{\mathrm{xq}}^{\mathrm{NL}}(\mathrm{x}, \mathrm{q})=-\mathrm{H}_{\mathrm{xq}}(\mathrm{x}, \mathrm{q})-\mathrm{H}_{\mathrm{xq}}(\mathrm{x}, \mathrm{q}) \mathrm{q}-\mathrm{c}^{\prime}(\mathrm{x})$. Substituting from $\Pi_{\mathrm{x}}^{\mathrm{NL}}(\mathrm{x}, \mathrm{q})=0$ yields $\Pi_{\mathrm{xq}}^{\mathrm{NL}}(\mathrm{x}, \mathrm{q})=-\mathrm{H}_{\mathrm{xqq}}(\mathrm{x}, \mathrm{q}) \mathrm{q}$, so employing Assumption $\mathrm{B} 2(\mathrm{v})$ means that $\Pi_{\mathrm{xq}}^{\mathrm{NL}}(\mathrm{x}, \mathrm{q})>0$ for all $(\mathrm{x}, \mathrm{q})$ along $\mathrm{x}^{\mathrm{NL}}(\mathrm{q})$. This implies that:

$$
\mathrm{dx}^{\mathrm{NL}}(\mathrm{q}) / \mathrm{dq}=\Pi_{\mathrm{xq}}^{\mathrm{NL}}(\mathrm{x}, \mathrm{q}) /\left(-\Pi_{\mathrm{xx}}^{\mathrm{NL}}(\mathrm{x}, \mathrm{q})\right)>0 .
$$

As with the other $\mathrm{q}$-functions, it is not possible to $\operatorname{sign} \Pi_{\mathrm{xq}}^{\mathrm{NL}}(\mathrm{x}, \mathrm{q})$ along $\mathrm{q}^{\mathrm{NL}}(\mathrm{x})$ except in a neighborhood of the optimal solution for the NL-firm, in which case it must be positive, yielding:

$$
\mathrm{dq}^{\mathrm{NL}}(\mathrm{x}) / \mathrm{dx}=\Pi_{\mathrm{xq}}^{\mathrm{NL}}(\mathrm{x}, \mathrm{q}) /\left(-\Pi_{\mathrm{qq}}^{\mathrm{NL}}(\mathrm{x}, \mathrm{q})\right)>0 \text { in a neighborhood of the maximum, }\left(\hat{\mathrm{x}}^{\mathrm{NL}}, \hat{\mathrm{q}}^{\mathrm{NL}}\right) .
$$

Thus, both these curves are upward-sloping near the maximum profit for the NL-firm. As earlier, when viewed in (x, q)-space we need to invert the derivatives for the x-curves, when comparing them with the q-curves, and second order conditions for the profit function under no liability guarantee that $\mathrm{x}^{\mathrm{NL}}(\mathrm{q})$ crosses $\mathrm{q}^{\mathrm{NL}}(\mathrm{x})$ from below.

Given the earlier results about the relationship between the q-curves and the result that $\mathrm{x}^{\mathrm{NL}}(\mathrm{q})$ $>\mathrm{x}^{\mathrm{W}}(\mathrm{q})$, the NL-equilibrium is not directly comparable to the SL-equilibrium, nor is it comparable to the welfare-optimum; that is; in general $\left(\hat{\mathrm{x}}^{\mathrm{NL}}, \hat{\mathrm{q}}^{\mathrm{NL}}\right) \neq\left(\hat{\mathrm{x}}^{\mathrm{W}}, \hat{\mathrm{q}}^{\mathrm{W}}\right)$. As was shown in the main text, when $\mathrm{H}(\mathrm{x}, \mathrm{q})=$ $\mathrm{h}(\mathrm{x}) \mathrm{q}^{2}$, then $\hat{\mathrm{x}}^{\mathrm{NL}}=\hat{\mathrm{x}}^{\mathrm{W}}$ (but $\hat{\mathrm{q}}^{\mathrm{NL}}<\hat{\mathrm{q}}^{\mathrm{W}}$ ). However, this result (that under no liability the firm provides the socially optimal level of care) is due to employing a specific functional form; to see this simply modify the expected harm function again. We can (in general) show that $\hat{\mathrm{q}}^{\mathrm{NL}}<\hat{\mathrm{q}}^{\mathrm{W}}$ whenever $\hat{\mathrm{x}}^{\mathrm{NL}} \leq \hat{\mathrm{x}}^{\mathrm{W}}$, simply by reference to the earlier results on $\mathrm{q}^{\mathrm{NL}}(\mathrm{x})$ versus $\mathrm{q}^{\mathrm{W}}(\mathrm{x})$. Also, evaluating $\Pi_{\mathrm{x}}^{\mathrm{NL}}(\mathrm{x}, \mathrm{q})$ at $\left(\hat{\mathrm{x}}^{\mathrm{W}}, \hat{\mathrm{q}}^{\mathrm{W}}\right)$ yields $\Pi_{\mathrm{x}}^{\mathrm{NL}}\left(\hat{\mathrm{x}}^{\mathrm{W}}, \hat{\mathrm{q}}^{\mathrm{W}}\right)>0$, so at $\mathrm{q}=\hat{\mathrm{q}}^{\mathrm{W}}$, the NL-firm would wish to expand the level of care above $\hat{\mathrm{x}}^{\mathrm{W}}$ : the NL-firm is inefficient in its choice of care if forced (or induced) to choose output at the socially-efficient level.

\section{Firm Preferences over Strict vs No Liability}

For convenience, recall that the profit function for a firm under strict liability is:

$$
\Pi^{\mathrm{SL}}(\mathrm{x}, \mathrm{q})=\mathrm{p}^{\mathrm{SL}}(\mathrm{q}) \mathrm{q}-\mathrm{H}(\mathrm{x}, \mathrm{q})-\mathrm{c}(\mathrm{x}) \mathrm{q}
$$

while that for a firm under no liability is:

$$
\Pi^{N L}(x, q)=p^{N L}(q ; x) q-c(x) q=\left(p^{S L}(q)-H_{q}(x, q)\right) q-c(x) q
$$

In a parallel manner to the main text, we now introduce a parametrized version of the profit function, $\Pi(\mathrm{x}, \mathrm{q} ; \gamma)$, where $\gamma=1$ corresponds to SL and $\gamma=2$ corresponds to NL:

$$
\Pi(\mathrm{x}, \mathrm{q} ; \gamma)=\left(\mathrm{p}^{\mathrm{SL}}(\mathrm{q})-(\gamma-1) \mathrm{H}_{\mathrm{q}}(\mathrm{x}, \mathrm{q})\right) \mathrm{q}-(2-\gamma) \mathrm{H}(\mathrm{x}, \mathrm{q})-\mathrm{c}(\mathrm{x}) \mathrm{q} \text {. }
$$

Under Assumption B4, for all $\gamma$ in the interval $[1,2]$, the first order conditions:

$$
\begin{array}{llll}
\Pi_{\mathrm{x}}(\mathrm{x}, \mathrm{q} ; \gamma) & = & -(\gamma-1) \mathrm{H}_{\mathrm{xq}}(\mathrm{x}, \mathrm{q}) \mathrm{q} & -(2-\gamma) \mathrm{H}_{\mathrm{x}}(\mathrm{x}, \mathrm{q})-\mathrm{c}^{\prime}(\mathrm{x}) \mathrm{q}=0 \\
\text { and } & \Pi_{\mathrm{q}}(\mathrm{x}, \mathrm{q} ; \gamma)=\mathrm{u}^{\prime}(\mathrm{q})+\mathrm{u}^{\prime \prime}(\mathrm{q}) \mathrm{q}-(\gamma-1)\left\{\mathrm{H}_{\mathrm{qq}}(\mathrm{x}, \mathrm{q}) \mathrm{q}+\mathrm{H}_{\mathrm{q}}(\mathrm{x}, \mathrm{q})\right\}-(2-\gamma) \mathrm{H}_{\mathrm{q}}(\mathrm{x}, \mathrm{q})-\mathrm{c}(\mathrm{x})=0
\end{array}
$$

yield the (continuous and continuously differentiable) solution functions denoted as $(\hat{\mathrm{x}}(\gamma), \hat{\mathrm{q}}(\gamma))$. Then using the envelope theorem, 


$$
\mathrm{d} \Pi(\hat{x}(\gamma), \hat{\mathrm{q}}(\gamma) ; \gamma) / \mathrm{d} \gamma=-\mathrm{H}_{\mathrm{q}}(\hat{\mathrm{x}}(\gamma), \hat{\mathrm{q}}(\gamma)) \hat{\mathrm{q}}(\gamma)+\mathrm{H}(\hat{\mathrm{x}}(\gamma), \hat{\mathrm{q}}(\gamma))
$$

From the discussion concerning the implications of the convexity of $\mathrm{H}$ earlier in this Appendix, we know that the marginal expected harm exceeds the average expected harm, so this means that the above derivative is negative: the firm prefers SL to NL, since increasing $\gamma$ lowers optimized profits.

As in the main text and Appendix A, we can totally differentiate the first order conditions for $\Pi(\mathrm{x}, \mathrm{q} ; \gamma)$ and obtain the following results for the signs of $\mathrm{d} \hat{\mathrm{x}}(\gamma) / \mathrm{d} \gamma$ and $\mathrm{d} \hat{\mathrm{q}}(\gamma) / \mathrm{d} \gamma$ :

$$
\begin{aligned}
& \operatorname{sign}(d \hat{x}(\gamma) / d \gamma)=\operatorname{sign}\left(\Pi_{q q}\left(H_{x q} q-H_{x}\right)-\Pi_{x q} H_{q q} q\right) \\
& \operatorname{sign}(d \hat{q}(\gamma) / d \gamma)=\operatorname{sign}\left(\Pi_{x q}\left(H_{x}-H_{x q} q\right)+\Pi_{x x} H_{q q} q\right) .
\end{aligned}
$$

These sign conditions are due to the negative definiteness of $\Pi^{\mathrm{SL}}$ and $\Pi^{\mathrm{NL}}$ (and thus of $\Pi(\mathrm{x}, \mathrm{q} ; \gamma)$ ) with respect to $(\mathrm{x}, \mathrm{q})$ from assumption $\mathrm{B} 4$. With the more general expected harm function employed in this Appendix, while elements of the right-hand-sides of the above equations can be signed, the entire expression cannot be signed for all possible values. However, one can show that it is not possible for $\hat{\mathrm{q}}$ to be increasing in $\gamma$ simultaneously with $\hat{x}$ decreasing in $\gamma$; such a sign pattern is mutually exclusive. In other words, in moving from SL to NL, the firm would not choose to reduce the level of care and simultaneously try to sell more output. This is because as the firm is moving from SL to NL demand is falling since consumers expect to have to cover their own expected harm, forcing a lower price; increasing output simply forces a yet further lower price. All other sign patterns are possible and we summarize the results as follows:

$$
\begin{aligned}
& \mathrm{d} \hat{\mathrm{q}}(\gamma) / \mathrm{d} \gamma>0 \text { implies } \mathrm{d} \hat{\mathrm{x}}(\gamma) / \mathrm{d} \gamma>0 \\
& \mathrm{~d} \hat{\mathrm{x}}(\gamma) / \mathrm{d} \gamma<0 \text { implies } \mathrm{d} \hat{\mathrm{q}}(\gamma) / \mathrm{d} \gamma<0 \\
& \mathrm{~d} \hat{\mathrm{x}}(\gamma) / \mathrm{d} \gamma>0 \text { and } \mathrm{d} \hat{\mathrm{q}}(\gamma) / \mathrm{d} \gamma<0 \text { can occur; } \\
& \mathrm{d} \hat{\mathrm{x}}(\gamma) / \mathrm{d} \gamma<0 \text { and } \mathrm{d} \hat{\mathrm{q}}(\gamma) / \mathrm{d} \gamma>0 \text { cannot occur. }
\end{aligned}
$$

Recall from the main text that when $\mathrm{H}(\mathrm{x}, \mathrm{q})=\mathrm{h}(\mathrm{x}) \mathrm{q}^{2}$ is a convex function, then we can show that $\mathrm{d} \hat{\mathrm{x}}(\gamma) / \mathrm{d} \gamma$ $>0$ and $\mathrm{d} \hat{\mathrm{q}}(\gamma) / \mathrm{d} \gamma<0$ for all $\gamma$ in the interval $[1,2]$ : the shift from SL to NL results in an increase in care provided but a fall in output provided to the market. In the more general expected harm model, at $\gamma=1$, $\mathrm{d} \hat{\mathrm{q}}(\gamma) / \mathrm{d} \gamma<0$ and $\mathrm{d} \hat{\mathrm{x}}(\gamma) / \mathrm{d} \gamma>0$, but the result is limited to $\gamma=1$ (i.e, is local).

\section{On the Instability of Negligence as a Policy}

Again, the implication for negligence, wherein the firm is not liable if $x \geq \hat{x}^{\mathrm{W}}$, but is otherwise fully liable, is that since the consumer can observe the chosen level of care, the firm will "signal" the consumer that the firm will be fully liable for harm by choosing $x=\hat{x}^{S L}$. This holds since if $\hat{x}^{N L} \geq \hat{x}^{\mathrm{W}}$, then if compliant with negligence, the firm meets (or more than meets) the standard, but since the firm prefers SL to NL, it will choose to violate the standard and instead produce the outcome $\left(\hat{\mathrm{x}}^{\mathrm{SL}}, \hat{\mathrm{q}}^{\mathrm{SL}}\right)$. On the other hand, should it be that $\hat{\mathrm{x}}^{\mathrm{NL}}<\hat{\mathrm{x}}^{\mathrm{W}}$, the firm will again wish to switch regimes to SL, and it again will choose $\left(\hat{\mathrm{x}}^{\mathrm{SL}}, \hat{\mathrm{q}}^{\mathrm{SL}}\right)$. Since in either possibility, upon observing $\hat{\mathrm{x}}^{\mathrm{SL}}$ the consumer knows that perfect compensation will obtain, the consumer's demand function becomes that under strict liability, $\mathrm{p}^{\mathrm{SL}}(\mathrm{q})$, which is what the firm desires to have happen. Thus, once again, negligence is unstable as a policy.

The discussion in the main text about unobservable care levels carries over to the more general expected harm function as well. Under strict liability the consumer expects to be fully compensated and so need not observe the level of care, while under no liability the consumer must conjecture about the level of care taken, which in equilibrium results in $\mathrm{x}=0$ (so as to minimize production cost). 
Welfare Preferences over Strict vs No Liability

Since $\mathrm{W}(\hat{\mathrm{x}}(\gamma), \hat{\mathrm{q}}(\gamma))=\mathrm{u}(\hat{\mathrm{x}}(\gamma), \hat{\mathrm{q}}(\gamma))-\mathrm{H}(\hat{\mathrm{x}}(\gamma), \hat{\mathrm{q}}(\gamma))-\mathrm{c}(\hat{\mathrm{x}}(\gamma)) \hat{\mathrm{q}}(\gamma)$, then:

$$
\mathrm{dW}(\hat{\mathrm{x}}(\gamma), \hat{\mathrm{q}}(\gamma)) / \mathrm{d} \gamma=\left(\mathrm{W}_{\mathrm{x}}(\hat{\mathrm{x}}(\gamma), \hat{\mathrm{q}}(\gamma))\right)(\mathrm{d} \hat{\mathrm{x}}(\gamma) / \mathrm{d} \gamma)+\left(\mathrm{W}_{\mathrm{q}}(\hat{\mathrm{x}}(\gamma), \hat{\mathrm{q}}(\gamma))\right)(\mathrm{d} \hat{\mathrm{q}}(\gamma) / \mathrm{d} \gamma)
$$

Evaluating $\Pi_{\mathrm{x}}(\mathrm{x}, \mathrm{q} ; \gamma)=0$ (equation B.7) at $(\hat{\mathrm{x}}(\gamma), \hat{\mathrm{q}}(\gamma))$ and substituting into equation (B.1) via the $\mathrm{c}^{\prime}(\mathrm{x}) \mathrm{q}$ term yields:

$$
\mathrm{W}_{\mathrm{x}}(\hat{\mathrm{x}}(\gamma), \hat{\mathrm{q}}(\gamma))=(\gamma-1)\left\{\mathrm{H}_{\mathrm{xq}}(\hat{\mathrm{x}}(\gamma), \hat{\mathrm{q}}(\gamma)) \hat{\mathrm{q}}(\gamma)-\mathrm{H}_{\mathrm{x}}(\hat{\mathrm{x}}(\gamma), \hat{\mathrm{q}}(\gamma))\right\}<0 \text { for } \gamma>1
$$

Notice that at $\gamma=1, \mathrm{~W}_{\mathrm{x}}(\hat{\mathrm{x}}(\gamma), \hat{\mathrm{q}}(\gamma))=0$ (as it should, since the SL-firm's first-order care-choice condition is the same as that for welfare maximization, equation B.1). Evaluating $\Pi_{\mathrm{q}}(\mathrm{x}, \mathrm{q} ; \gamma)=0$ (equation B.8) at $(\hat{\mathrm{x}}(\gamma), \hat{\mathrm{q}}(\gamma))$ and substituting into equation (B.2) via the term $\mathrm{c}(\mathrm{x})-\mathrm{u}^{\prime}(\mathrm{q})$, we obtain:

$$
\mathrm{W}_{\mathrm{q}}(\hat{\mathrm{x}}(\gamma), \hat{\mathrm{q}}(\gamma))=-\mathrm{u}^{\prime \prime}(\hat{\mathrm{q}}(\gamma)) \hat{\mathrm{q}}(\gamma)+(\gamma-1) \mathrm{H}_{\mathrm{qq}}(\hat{\mathrm{x}}(\gamma), \hat{\mathrm{q}}(\gamma))>0 \text { for all } \gamma
$$

Thus, there are two "simple" settings wherein the effect of shifting regime on welfare can be predicted:

1) for $\gamma=1$, since $\mathrm{W}_{\mathrm{x}}(\hat{\mathrm{x}}(\gamma), \hat{\mathrm{q}}(\gamma))=0$ and $\mathrm{d} \hat{\mathrm{q}}(\gamma) / \mathrm{d} \gamma<0$, then $\mathrm{dW}(\hat{\mathrm{x}}(\gamma), \hat{\mathrm{q}}(\gamma)) / \mathrm{d} \gamma<0$;

and 2) for $\gamma>1$, if for all $\gamma \mathrm{d} \hat{\mathrm{x}}(\gamma) / \mathrm{d} \gamma>0$ occurs jointly with $\mathrm{d} \hat{\mathrm{q}}(\gamma) / \mathrm{d} \gamma<0$, then $\mathrm{dW}(\hat{\mathrm{x}}(\gamma), \hat{\mathrm{q}}(\gamma)) / \mathrm{d} \gamma<0$.

For the two other possible combinations $(\mathrm{d} \hat{\mathrm{q}}(\gamma) / \mathrm{d} \gamma>0$, which implies $\mathrm{d} \hat{\mathrm{x}}(\gamma) / \mathrm{d} \gamma>0$, and $\mathrm{d} \hat{\mathrm{x}}(\gamma) / \mathrm{d} \gamma<0$ which implies that $\mathrm{d} \hat{\mathrm{q}}(\gamma) / \mathrm{d} \gamma<0$ for $\gamma>1)$, then the effect on welfare is determined by the relative magnitudes of the two terms in $\operatorname{dW}(\hat{\mathrm{x}}(\gamma), \hat{\mathrm{q}}(\gamma)) / \mathrm{d} \gamma$ and cannot be signed ex ante.

\section{Summary of Results from this Appendix}

Conditional on the restrictions placed on the expected harm function and the need for concavity of welfare and profit functions, many of the primary results obtained in the main text for a specific expected harm function extend to a more general version:

1) $\mathrm{x}^{\mathrm{SL}}(\mathrm{q})=\mathrm{x}^{\mathrm{W}}(\mathrm{q})<\mathrm{x}^{\mathrm{NL}}(\mathrm{q})$; all are upward sloping functions;

2) $\mathrm{q}^{\mathrm{W}}(\mathrm{x})>\mathrm{q}^{\mathrm{SL}}(\mathrm{x})>\mathrm{q}^{\mathrm{NL}}(\mathrm{x})$; all are upward sloping at the respective $\mathrm{W}$, SL, NL optima, all are cut from below by the respective $\mathrm{x}$-functions at the respective optima;

3) $\left(\hat{\mathrm{x}}^{\mathrm{SL}}, \hat{\mathrm{q}}^{\mathrm{SL}}\right)<\left(\hat{\mathrm{x}}^{\mathrm{W}}, \hat{\mathrm{q}}^{\mathrm{W}}\right) ;\left(\hat{\mathrm{x}}^{\mathrm{NL}}, \hat{\mathrm{q}}^{\mathrm{NL}}\right) \neq\left(\hat{\mathrm{x}}^{\mathrm{W}}, \hat{\mathrm{q}}^{\mathrm{W}}\right)$;

4) if the NL firm is forced to produce $\mathrm{q}=\hat{\mathrm{q}}^{\mathrm{W}}$ then $\mathrm{x}^{\mathrm{NL}}\left(\hat{\mathrm{q}}^{\mathrm{W}}\right)>\hat{\mathrm{x}}^{\mathrm{W}}$;

5) firms prefer SL to NL;

6) negligence without employing extra penalties for not employing the socially-efficient level of care is unstable: if care is observable, the firm will choose to provide $\left(\hat{\mathrm{x}}^{\mathrm{SL}}, \hat{\mathrm{q}}^{\mathrm{SL}}\right)$ instead.

7) Society's preferences are more difficult to characterize in the more general expected harm case. If $\mathrm{d} \hat{\mathrm{x}}(\gamma) / \mathrm{d} \gamma>0$ occurs jointly with $\mathrm{d} \hat{\mathrm{q}}(\gamma) / \mathrm{d} \gamma<0$, then $\mathrm{dW}(\hat{\mathrm{x}}(\gamma), \hat{\mathrm{q}}(\gamma)) / \mathrm{d} \gamma<0$ for all $\gamma$; at $\gamma=1, \mathrm{dW}(\hat{\mathrm{x}}(\gamma), \hat{\mathrm{q}}(\gamma)) / \mathrm{d} \gamma<0$, but this latter result is very local. However, once again, 
even if, from an initial position, NL was more efficient than SL, an exogenous increase in output level (e.g., due to a regulator of market performance) would increase the level of care so that the SL-outcome would eventually be more efficient than the corresponding NL-outcome.

8) SL provides a resilient policy regime in that:

a) increases in $\mathrm{q}$ will lead to increases in $\mathrm{x}$ converging in the direction of $\left(\hat{\mathrm{x}}^{\mathrm{W}}, \hat{\mathrm{q}}^{\mathrm{W}}\right)$;

b) this means that eventually SL is more efficient than NL, even if $\left(\hat{\mathrm{x}}^{\mathrm{SL}}, \hat{\mathrm{q}}^{\mathrm{SL}}\right)<\left(\hat{\mathrm{x}}^{\mathrm{W}}, \hat{\mathrm{q}}^{\mathrm{W}}\right)$, since the $\mathrm{x}^{\mathrm{NL}}(\mathrm{q})$-path does not lead to the social optimum;

c) firms will endeavor to undermine negligence;

d) unobservability of the level of care does not undermine SL while it does undermine

NL. 


\section{Appendix C: Material for Oligopoly Analysis of Quadratic Cumulative Harm Model}

In the interests of brevity, we derive only the equations necessary to characterize the symmetric equilibria. Our maintained assumptions (e.g., the convexity of expected harm in (x, q)) are sufficient to imply that the matrix of second partial derivatives is negative definite at the associated solution.

\section{Independent Cumulative Harm}

Strict Liability. Firm i's profits are given by $\Pi_{i}^{S L}\left(x_{i}, q_{i} ; n\right)=(\alpha-\beta Q) q_{i}-h\left(x_{i}\right)\left(q_{i}\right)^{2}-c\left(x_{i}\right) q_{i}$. The first-order conditions are:

$$
\begin{aligned}
& \Pi_{\mathrm{ix}}^{\mathrm{SL}}=-\mathrm{h}^{\prime}\left(\mathrm{x}_{\mathrm{i}}\right)\left(\mathrm{q}_{\mathrm{i}}\right)^{2}-\mathrm{c}^{\prime}\left(\mathrm{x}_{\mathrm{i}}\right) \mathrm{q}_{\mathrm{i}}=0 \\
& \Pi_{\mathrm{iq}}^{\mathrm{LS}}=\alpha-2 \beta \mathrm{q}_{\mathrm{i}}-\beta \mathrm{Q}_{-\mathrm{i}}-2 \mathrm{~h}\left(\mathrm{x}_{\mathrm{i}}\right) \mathrm{q}_{\mathrm{i}}-\mathrm{c}\left(\mathrm{x}_{\mathrm{i}}\right)=0,
\end{aligned}
$$

where $\mathrm{Q}_{-\mathrm{i}} \equiv \mathrm{Q}-\mathrm{q}_{\mathrm{i}}$ is the aggregate output of all other firms. At a symmetric equilibrium, all firms will choose the same output and care levels; incorporating this symmetry yields equations (9)-(10) from the text.

No Liability. Firm i's profits under no liability are given by $\Pi_{i}^{N L}\left(x_{i}, q_{i} ; n\right)=\left(\alpha-\beta Q-2 h\left(x_{i}\right) q_{i}\right) q_{i}$ $\mathrm{c}\left(\mathrm{x}_{\mathrm{i}}\right) \mathrm{q}_{\mathrm{i}}$. The first-order conditions are:

$$
\begin{aligned}
& \Pi_{\mathrm{ix}}^{\mathrm{NL}}=-2 \mathrm{~h}^{\prime}\left(\mathrm{x}_{\mathrm{i}}\right)\left(\mathrm{q}_{\mathrm{i}}\right)^{2}-\mathrm{c}^{\prime}\left(\mathrm{x}_{\mathrm{i}}\right) \mathrm{q}_{\mathrm{i}}=0 \\
& \Pi_{\mathrm{iq}}^{\mathrm{NL}}=\alpha-2 \beta \mathrm{q}_{\mathrm{i}}-\beta \mathrm{Q}_{-\mathrm{i}}-4 \mathrm{~h}\left(\mathrm{x}_{\mathrm{i}}\right) \mathrm{q}_{\mathrm{i}}-\mathrm{c}\left(\mathrm{x}_{\mathrm{i}}\right)=0 .
\end{aligned}
$$

At a symmetric equilibrium, all firms will choose the same output and care levels; incorporating this symmetry yields equations (11)-(12) from the text.

\section{Joint Cumulative Harm}

Strict Liability. Using the pure market share approach (wherein firm $\mathrm{i}$ is responsible for the share $\mu\left(\mathrm{x}_{\mathrm{i}}\right) \mathrm{q}_{\mathrm{i}} / \mathrm{M}$ of the expected harm), firm i's profits are given by $\pi_{\mathrm{i}}^{\mathrm{JSL}}\left(\mathrm{x}_{\mathrm{i}}, \mathrm{q}_{\mathrm{i}} ; \mathrm{n}\right)=(\alpha-\beta Q) \mathrm{q}_{\mathrm{i}}-\lambda \mu\left(\mathrm{x}_{\mathrm{i}}\right) \mathrm{q}_{\mathrm{i}} \mathrm{M}-$ $\mathrm{c}\left(\mathrm{x}_{\mathrm{i}}\right) \mathrm{q}_{\mathrm{i}}$. The use of the lower-case $\pi$ distinguishes this from the "adjusted" profit function that will be used in the main text. It will be convenient to define the total contribution to exposure for all firms except firm $\mathrm{i}: \mathrm{M}_{-\mathrm{i}}=\mathrm{M}-\mu\left(\mathrm{x}_{\mathrm{i}}\right) \mathrm{q}_{\mathrm{i}}$. The first-order conditions are:

$$
\begin{aligned}
& \pi_{\mathrm{ix}}^{\mathrm{JSL}}=-\lambda\left[2 \mu\left(\mathrm{x}_{\mathrm{i}}\right) \mu^{\prime}\left(\mathrm{x}_{\mathrm{i}}\right)\left(\mathrm{q}_{\mathrm{i}}\right)^{2}+\mu^{\prime}\left(\mathrm{x}_{\mathrm{i}}\right) \mathrm{q}_{\mathrm{i}} \mathrm{M}_{-\mathrm{i}}\right]-\mathrm{c}^{\prime}\left(\mathrm{x}_{\mathrm{i}}\right) \mathrm{q}_{\mathrm{i}}=0 ; \\
& \pi_{\mathrm{iq}}^{\mathrm{JSL}}=\alpha-2 \beta \mathrm{q}_{\mathrm{i}}-\beta \mathrm{Q}_{-\mathrm{i}}-\lambda\left[2\left(\mu\left(\mathrm{x}_{\mathrm{i}}\right)\right)^{2} \mathrm{q}_{\mathrm{i}}+\mu\left(\mathrm{x}_{\mathrm{i}}\right) \mathrm{M}_{-\mathrm{i}}\right]-\mathrm{c}\left(\mathrm{x}_{\mathrm{i}}\right)=0 .
\end{aligned}
$$

Using symmetry, we can find a system of equations that characterizes the symmetric equilibrium care and output levels:

$$
\begin{aligned}
& -\lambda(\mathrm{n}+1) \mu(\mathrm{x}) \mu^{\prime}(\mathrm{x}) \mathrm{q}^{2}-\mathrm{c}^{\prime}(\mathrm{x}) \mathrm{q}=0 \\
& \alpha-(\mathrm{n}+1) \beta \mathrm{q}-\lambda(\mathrm{n}+1)(\mu(\mathrm{x}))^{2} \mathrm{q}-\mathrm{c}(\mathrm{x})=0 .
\end{aligned}
$$

Notice that equations (13) and (C.1) are not the same; that is, for $n \geq 2$, noncooperative firms will provide less care than would be socially-optimal, for a given level of output, q, and number of firms, $n$.

Next, consider the "adjusted" profit function, wherein firm i's liability for harm is given by the share $(2 n /(n+1)) \mu\left(x_{i}\right) q_{i} / M$. In this case, profit is $\prod_{i}^{J S L}\left(x_{i}, q_{i} ; n\right)=(\alpha-\beta Q) q_{i}-(2 n /(n+1)) \lambda \mu\left(x_{i}\right) q_{i} M-$ $\mathrm{c}\left(\mathrm{x}_{\mathrm{i}}\right) \mathrm{q}_{\mathrm{i}}$. The first-order conditions are:

$$
\Pi_{\mathrm{ix}}^{\mathrm{JSL}}=-\lambda(2 \mathrm{n} /(\mathrm{n}+1))\left[2 \mu\left(\mathrm{x}_{\mathrm{i}}\right) \mu^{\prime}\left(\mathrm{x}_{\mathrm{i}}\right)\left(\mathrm{q}_{\mathrm{i}}\right)^{2}+\mu^{\prime}\left(\mathrm{x}_{\mathrm{i}}\right) \mathrm{q}_{\mathrm{i}} \mathrm{M}_{-\mathrm{i}}\right]-\mathrm{c}^{\prime}\left(\mathrm{x}_{\mathrm{i}}\right) \mathrm{q}_{\mathrm{i}}=0 ;
$$




$$
\Pi_{\mathrm{i}}^{\mathrm{JL}}=\alpha-2 \beta \mathrm{q}_{\mathrm{i}}-\beta \mathrm{Q}_{-\mathrm{i}}-\lambda(2 \mathrm{n} /(\mathrm{n}+1))\left[2\left(\mu\left(\mathrm{x}_{\mathrm{i}}\right)\right)^{2} \mathrm{q}_{\mathrm{i}}+\mu\left(\mathrm{x}_{\mathrm{i}}\right) \mathrm{M}_{-\mathrm{i}}\right]-\mathrm{c}\left(\mathrm{x}_{\mathrm{i}}\right)=0
$$

At a symmetric equilibrium, all firms will choose the same output and care levels; incorporating this symmetry yields equations (15)-(16) from the text.

No Liability. Firm i's profits are given by $\Pi_{i}^{\mathrm{JL}}\left(\mathrm{x}_{\mathrm{i}}, \mathrm{q}_{\mathrm{i}} ; \mathrm{n}\right)=\left(\alpha-\beta \mathrm{Q}-2 \lambda \mathrm{M} \mu\left(\mathrm{x}_{\mathrm{i}}\right)\right) \mathrm{q}_{\mathrm{i}}-\mathrm{c}\left(\mathrm{x}_{\mathrm{i}}\right) \mathrm{q}_{\mathrm{i}}$. The first-order conditions are:

$$
\begin{aligned}
& \prod_{\mathrm{ix}}^{\mathrm{JNL}}=-2 \lambda\left[2 \mu\left(\mathrm{x}_{\mathrm{i}}\right) \mu^{\prime}\left(\mathrm{x}_{\mathrm{i}}\right)\left(\mathrm{q}_{\mathrm{i}}\right)^{2}+\mu^{\prime}\left(\mathrm{x}_{\mathrm{i}}\right) \mathrm{q}_{\mathrm{i}} \mathrm{M}_{\mathrm{i}}\right]-\mathrm{c}^{\prime}\left(\mathrm{x}_{\mathrm{i}}\right) \mathrm{q}_{\mathrm{i}}=0 ; \\
& \prod_{\mathrm{i} \mathrm{q}}^{\mathrm{NL}}=\alpha-2 \beta \mathrm{q}_{\mathrm{i}}-\beta \mathrm{Q}_{-\mathrm{i}}-2 \lambda\left[2\left(\mu\left(\mathrm{x}_{\mathrm{i}}\right)\right)^{2} \mathrm{q}_{\mathrm{i}}+\mu\left(\mathrm{x}_{\mathrm{i}}\right) \mathrm{M}_{-\mathrm{i}}\right]-\mathrm{c}\left(\mathrm{x}_{\mathrm{i}}\right)=0 .
\end{aligned}
$$

At a symmetric equilibrium, all firms will choose the same output and care levels, yielding equations (17)-(18) from the text.

Remark. It was claimed in the text that under joint cumulative harm the optimal level of care and the equilibrium level of care under no liability are (1) invariant to the number of firms; and (2) equal to each other.

Proof of (1). To see that the functions $\mathrm{q}^{\mathrm{JW}}(\mathrm{x} ; \mathrm{n})$ and $\mathrm{x}^{\mathrm{JW}}(\mathrm{q} ; \mathrm{n})$ cross at the same $\mathrm{x}$ value for all $\mathrm{n}$, first solve equation (13) for $\tilde{q}^{J W}(x ; n)=c^{\prime}(x) /\left(-2 \lambda n \mu(x) \mu^{\prime}(x)\right)$ and solve equation (14) for $q^{J W}(x ; n)=(\alpha-$ $\mathrm{c}(\mathrm{x})) / \mathrm{n}\left[\beta+2 \lambda(\mu(\mathrm{x}))^{2}\right]$. Then, setting these two functions equal to each other yields an equation for $\mathrm{x}$ that is independent of $\mathrm{n}: \mathrm{c}^{\prime}(\mathrm{x}) /\left(-2 \lambda \mu(\mathrm{x}) \mu^{\prime}(\mathrm{x})\right)=(\alpha-\mathrm{c}(\mathrm{x})) /\left[\beta+2 \lambda(\mu(\mathrm{x}))^{2}\right]$.

To see that the functions $\mathrm{q}^{\mathrm{JNL}}(\mathrm{x} ; \mathrm{n})$ and $\mathrm{x}^{\mathrm{JNL}}(\mathrm{q} ; \mathrm{n})$ cross at the same value for all $\mathrm{n}$, first solve equation (17) for $\tilde{\mathrm{q}}^{\mathrm{JNL}}(\mathrm{x} ; \mathrm{n})=\mathrm{c}^{\prime}(\mathrm{x}) /\left(-2 \lambda(\mathrm{n}+1) \mu(\mathrm{x}) \mu^{\prime}(\mathrm{x})\right)$ and solve equation $(18)$ for $\mathrm{q}^{\mathrm{JW}}(\mathrm{x} ; \mathrm{n})=(\alpha-\mathrm{c}(\mathrm{x})) /(\mathrm{n}+1)[\beta+$ $\left.2 \lambda(\mu(x))^{2}\right]$. Then, setting these two functions equal to each other yields an equation for $x$ that is independent of $\mathrm{n}: \mathrm{c}^{\prime}(\mathrm{x}) /\left(-2 \lambda \mu(\mathrm{x}) \mu^{\prime}(\mathrm{x})\right)=(\alpha-\mathrm{c}(\mathrm{x})) /\left[\beta+2 \lambda(\mu(\mathrm{x}))^{2}\right]$.

Proof of (2). Simply note that the equations defining $\mathrm{x}$ are the same for case JW and for case JNL. 
References

Daughety, Andrew F. and Jennifer F. Reinganum, “Markets, Torts and Social Inefficiency,” RAND Journal of Economics 37 (2006), 300-323.

Landes, William M., and Richard A. Posner, "A Positive Economic Analysis of Products Liability," Journal of Legal Studies 14 (1985), 535-567.

Marino, Anthony M., “Monopoly, Liability and Regulation,” Southern Economic Journal 54 (1988), 913927.

Polinsky, A. Mitchell, "Strict Liability vs. Negligence in a Market Setting," American Economic Review 70 (1980), 363-367.

Polinsky, A. Mitchell, and William P. Rogerson, "Products Liability, Consumer Misperceptions, and Market Power," RAND Journal of Economics 14 (1983), 581-589.

Polinsky, A. Mitchell, and Steven Shavell. 2010. "The Uneasy Case for Product Liability," 123 Harvard Law Review 1437-1493.

Spence, A. Michael, “Monopoly, Quality, and Regulation,” Bell Journal of Economics 6 (1975), 417-429.

Shavell, Steven, “Strict Liability versus Negligence,” Journal of Legal Studies 9 (1980), 1-25.

Shavell, Steven, “Liability for Harm versus Regulation of Safety,” Journal of Legal Studies 13 (1984), 357-374.

Shavell, Steven, “A Model of the Optimal Use of Liability and Safety Regulation," RAND Journal of Economics 15 (1984), 271-280.

Sheshinski, Eytan, "Price, Quality and Quantity Regulation in Monopoly Situations," Economica (1976), 127-137.

Spence, A. Michael, “Consumer Misperceptions, Product Failure and Producer Liability,” Review of Economic Studies 44 (1977), 561-572.

Spulber, Daniel, Regulation and Markets. Cambridge, MA: The MIT Press, 1989. 


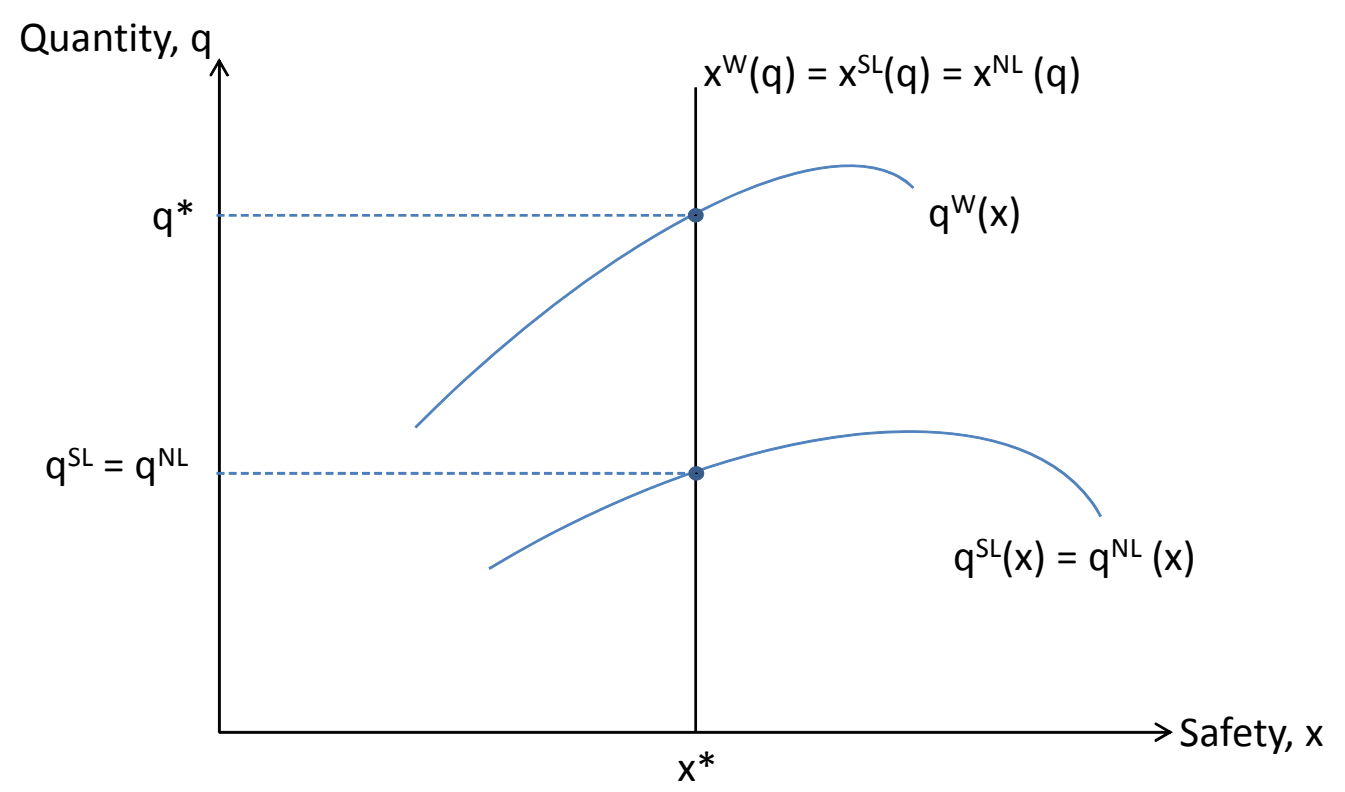

Figure 1: The Traditional (Proportional Harm) Results

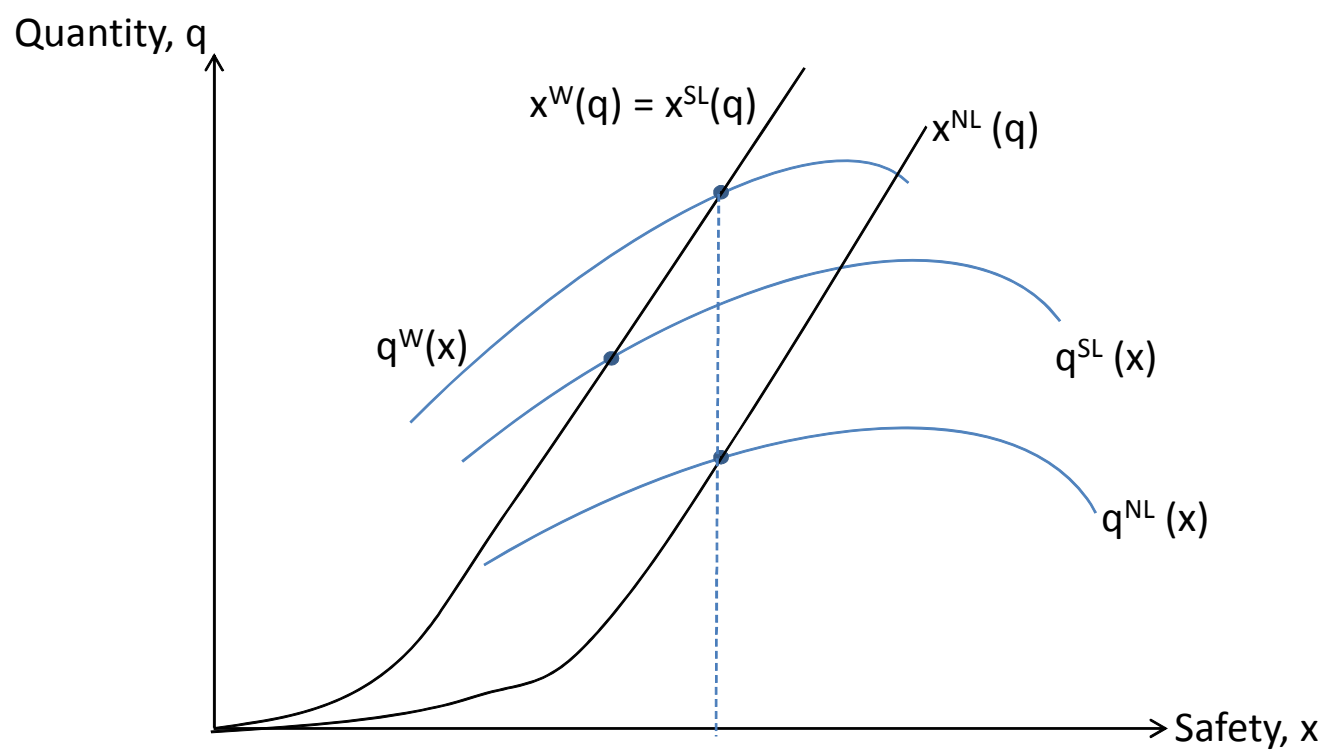

Figure 2: The Cumulative Harm Results 